University of Louisville

ThinkIR: The University of Louisville's Institutional Repository

Electronic Theses and Dissertations

$12-2010$

\title{
Cultivating our mosaic : understanding the language choices of Canadian immigrant students.
}

Julia E. Kiernan

University of Louisville

Follow this and additional works at: https://ir.library.louisville.edu/etd

\section{Recommended Citation}

Kiernan, Julia E., "Cultivating our mosaic : understanding the language choices of Canadian immigrant students." (2010). Electronic Theses and Dissertations. Paper 745.

https://doi.org/10.18297/etd/745

This Doctoral Dissertation is brought to you for free and open access by ThinkIR: The University of Louisville's Institutional Repository. It has been accepted for inclusion in Electronic Theses and Dissertations by an authorized administrator of ThinkIR: The University of Louisville's Institutional Repository. This title appears here courtesy of the author, who has retained all other copyrights. For more information, please contact thinkir@louisville.edu. 
CULTIVATING OUR MOSAIC: UNDERSTANDING THE LANGUAGE CHOICES OF CANADIAN IMMIGRANT STUDENTS

By

Julia E. Kiernan

B.A., Memorial University of Newfoundland, 2002

B.Sc., Memorial University of Newfoundland, 2003

M.A., University of Windsor, 2004

\begin{abstract}
A Dissertation
Submitted to the Faculty of the

Graduate School of the University of Louisville

in Partial Fulfilment of the Requirements

for the Degree of
\end{abstract}

Doctor of Philosophy

Department of English

University of Louisville

Louisville, Kentucky

December 2010 

CUltivating OUR Mosaic: Understanding THE LANGUAGE CHOICES OF CANADIAN IMMIGRANT STUDENTS

By

Julia E. Kiernan

B.A., Memorial University of Newfoundland, 2002

B.Sc., Memorial University of Newfoundland, 2003

M.A., University of Windsor, 2004

A Dissertation Approved on

November 18, 2010

By the following Dissertation Committee

Dissertation Director 


\title{
ABSTRACT \\ CULTIVATING OUR MOSAIC: UNDERSTANDING THE LANGUAGE CHOICES OF CANADIAN IMMIGRANT STUDENTS
}

\author{
Julia E. Kiernan
}

December, 2010

This dissertation examines the competing views of multilingualism that shape U.S. and Canadian post-secondary literacy education. Drawing on education, English studies, globalization theory, applied linguistics, translation studies, multiculturalism, and second-language studies, this project engages in a study of multilingual students from writing courses at a Canadian university. The analysis focuses on the relationships between Canadian multilingualism and current U.S. scholarship surrounding English monolingualism in terms of eradicationism, language segregation, and language interaction.

The findings challenge previous research and popular opinion, as well as Canadian government policy, all of which tend to designate Canadian classrooms and society as definitively accepting of cultural and linguistic diversity. Instead, this project positions Canadian writing classrooms as aligned with eradicationist ideologies, which is a noteworthy contrast to growing calls by composition scholars for teaching translingual composition. The data collected situates Canadian students (like U.S. students) as extremely ethno-linguistically diverse; however, in Canada, this diversity continues to be confined to home communities.

This research offers a critical assessment of how U.S. and Canadian postsecondary institutions can employ multilingualism as a resource, suggesting ways in 
which linguistic diversity can position students to excel in cultural exchange and political dialogue. Through drawing upon the ways a selection of U.S.

compositionists have been successful in their employment of student multilingualism as a pedagogical resource, this project responds to gaps in international multilingual scholarship and validates the introduction of multicultural-multilingual initiatives into Canadian writing classrooms. This work calls on composition researchers and instructors, particularly those in Canada, to redefine writing pedagogy and curricula in order to consider how institutions that boast high levels of cultural and linguistic diversity can proactively address and make use of multilingualism. 


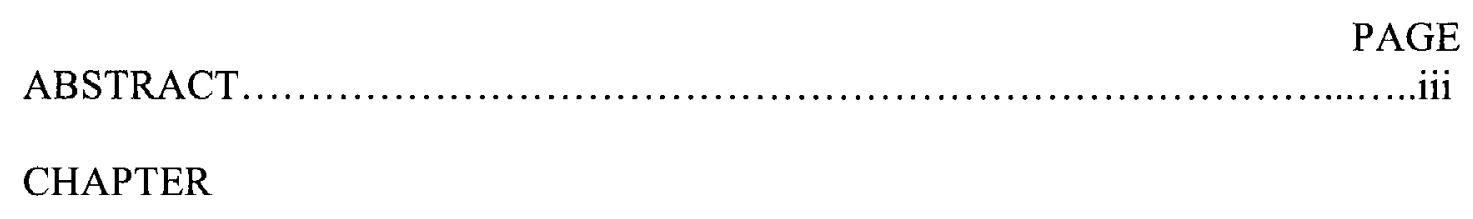

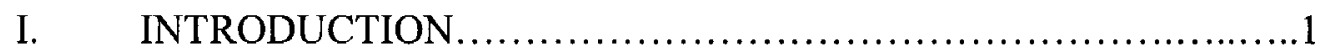

II. CANADIAN PERSPECTIVES.................................40

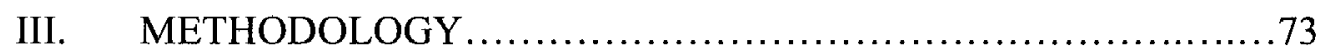

IV. QUESTIONNAIRE ANALYSIS .............................92

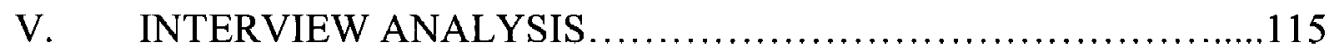

VI. CONCLUSION ..........................................

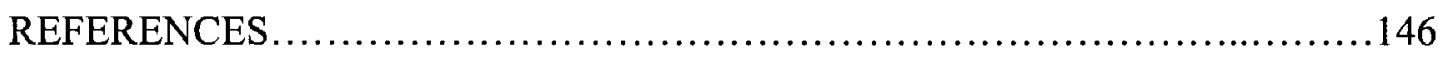

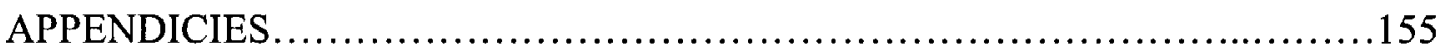

CIRRICULUM VITAE.................................................. 177 
I do not want my house to be walled in on all sides and my windows to be stuffed. I want the cultures of all the lands to be blown about my house as freely as possible.

\section{- Mahatma Gandhi}




\section{CHAPTER ONE Introduction}

We affirm the students' right to their own patterns and varieties of Languagethe dialects of their nurture or whatever dialects in which they find their own identity and style. Language scholars long ago denied that the myth of a standard American dialect has any validity. The claim that any one dialect is unacceptable amounts to an attempt of one social group to exert its dominance over another. Such a claim leads to false advice for speakers and writers, and immoral advice for humans. A nation proud of its diverse heritage and its cultural and racial variety will preserve its heritage of dialects. We affirm strongly that teachers must have the experiences and training that will enable them to respect diversity and uphold the right of students to their own language.

-Executive Committee of the Conference on College Composition and

Communication, 1972

\section{Introduction}

Mention the course "composition" to university students at post-secondary institutions across Canada and most likely blank faces will gaze back at you ${ }^{1}$. In Canada, if composition is offered within an English department it is generally an elective and not a required course. In fact, near the close of the $20^{\text {th }}$ century, at most Canadian colleges and universities, a composition course did not even count towards credits for an English major-writing existed only as an elective. In undergraduate programs across the country students are most often required to complete two writing intensive humanities courses;

${ }^{1}$ Canadian students do not recognize the term "composition" for two reasons. First, "Writing Studies" is the chosen term in Canada and composition is rarely used; second, not many institutions offer writing courses nationally. 
these courses span the disciplines and are found in departments ranging from history to philosophy to folklore. Moreover, what makes these courses "writing intensive" is simply the completion of a research essay, a task wherein students are expected to produce university-level texts without writing-based instruction from their professors. In such courses, the primary goal is to teach the discipline-specific subject matter, not writing. While the majority of Canadian post-secondary educators evaluate their students based almost exclusively on written work, there is very little to no time spent in class on any aspect of writing instruction. In these courses students are expected to be literate writers in their chosen discipline, but are not explicitly taught what literacy in that discipline specific subject consists of.

The lack of composition courses in many Canadian universities and colleges is often baffling to scholars of rhetoric and composition in the United States, as the discipline of writing has a long history in U.S. academia. To fully appreciate the Canadian model of writing instruction requires a brief survey of the rise of English Studies in British institutions, as they emerge from the same traditions. Canada as a colony of Great Britain exemplifies many of the educational choices made by her colonizer (Hubert 7). For instance, English Studies in Canada, which more often than not houses the instruction of writing, developed out of the British system. Hubert (159) explains that by the end of the nineteenth century the Anglo-Canadian curriculum in English studies,

became strongly idealistic, based on traditional British values as espoused in English literature and supported by a strong belletristic emphasis...this emphasis simply intensified the pursuit of classical models...English studies thus emphasized, to the virtual exclusion of all other literature, a canon of British authors derived from the critical stance of Matthew Arnold. All English studies programs...were transformed into curricula featuring the literature of the Mother Country...instruction in rhetoric turned largely into composition as an adjunct to the study of English literature. 
Thus, writing instruction developed in Canadian post-secondary systems as subordinate to the expansion of literature and, consequently, became an elective rather than an undergraduate prerequisite. However, although writing courses are not universally required for Canadian undergraduate students, Roger Graves (10) has documented an extended history of writing instruction,

[which] has been an integral part of Canadian university education from the foundation of the classical colleges in seventeenth-century Quebec to the present interest in student writing by the Commission of Inquiry on Canadian University Education.

To further explain how writing instruction exists very differently in Canada than in its southern neighbour I turn to Jennifer Clary-Lemon's chronology of first-year writing in Canada. In a historical overview, she describes reasons why post-secondary institutions within Canada have chosen not to implement the universal writing requirement. For instance, the head of the English department at University of Toronto-a leading educational institution in Canada, and a university that can be paralleled to those of Ivy League status in America - explained in 1954,

The function of English...is not simply to afford training in writing...it should cultivate a taste for reading as a form of intelligent recreation. In other words it has its contribution to make to the life of the student, not as an engineer, dentist (or whatever it may be), but as a civilized human being.

(Clary-Lemon 95)

In essence, such claims echo those in Crowley's summation of U.S. composition where, historically, instruction in writing was expected to act as a moral compass of sorts, borrowing from classical rhetoric in its teachings of virtue, citizenship, and good character (46). A competing narrative suggests that the need for first-year composition in the U.S. was also driven by the need for a literate, clerical workforce. As universities became professional and vocational training grounds with the onset of the post Civil War 
industrial revolution, the curriculum shifted from oral rhetoric to written composition in part to provide a literate, professional and managerial workforce. And, while English Studies in both Canada and United States evolved from rhetoric, it is only in the latter country that we have seen the development of composition as a universal requirement; in Canada the equivalent field is most often known as "Writing Studies" and is not a general education requirement. In the United States, this movement away from classical rhetoric has been renegotiated in the teaching of writing, where composition instruction is often associated with pedagogical practices that emphasize critical inquiry and reflection. On the other hand, Canadian students are regularly expected to enter the university with a degree of preparedness in writing; courses are most often discipline specific in their focus. The primary difference between the two nations is that the majority of Canadian institutions do not recognize "generic writing instruction," or a universally required composition course, as being useful to undergraduate students. Instead, writing instruction is offered through a writing-in-the-disciplines approach where students are taught to write in terms of their academic field. In recent years, this divergence has been clarified by Russ Hunt, a professor of English at St. Thomas University in New Brunswick:

The apparent rejection of the American model of composition is...the single most important fact about instruction in, and study of, writing and reading in Canadian Universities. In Canada...,it's generally, and without a great deal of reflection, been assumed that postsecondary students already know how to write, or should, and if they don't, well, it's up to them to learn.

(Clary-Lemon 95)

Ideologies that do not recognize the instruction of writing - via a course comparable to U.S. composition — as integral to post-secondary education continue to be maintained in most Canadian institutions of higher learning. Consequently, in Canada one model of 
writing instruction, which is increasingly recognized as integral to undergraduate degree programs, positions the teaching of academic writing as designed to prepare students to think critically in their field. Another model mirrors the practices of many U.S compositionists who view the composition course as a vehicle in the preparation of thoughtful citizens of the republic. And while this latter outcome is not always the case in Canada - the majority Canadian post-secondary educators work to produce literate students, with a basic or extensive knowledge of a subject area-there are programs, such as that offered at the University of Windsor, where reflexive critical inquiry is fostered ${ }^{2}$.

Nevertheless, in Canada, the dominance of English Language and Literature as a requirement, which places emphasis on literature-based curricula, is much more common than courses in composition. Henry Hubert (1), in his description of Canadian writing instruction from Confederation to the turn of the nineteenth century, explains

[a]part from their national homogeneity, Canadian English programs differed from their counterparts elsewhere, especially in the United States, by their exclusion of formal courses in applied rhetoric, both in speech and writing. Apart from programs in which speech was taught as a component of theatre, oral rhetoric was taught in no major postsecondary programs, and written rhetoric was subsumed under this study of literature. Seldom was composition specifically taught; generally, instruction in writing existed only as marginal notations in student's essays focused on literary works.

A more recent analysis of the divisions between the Canadian and U.S. models of writing instruction has been offered by Graves (36);

most Canadian English departments do not have an administrator in charge of writing programs or courses...most writing instruction in Canada is distributed among various

\footnotetext{
${ }^{2}$ The data for this project was collected at the University of Windsor. In this institution writing courses are referred to as composition courses. The calendar description is as follows:

26-100. Composition

An exploration of the fundamentals of effective writing, including attention to thetorical concepts of audience, purpose, and context; planning, logical development, and organization; and format and style. (Because of the large number of written assignments and the need for individual instruction, enrollment in 26-100 is limited.) (Not open to students majoring in English.) (Antirequisite: 26-103.)
} 
academic units outside of English departments in courses tailored to the specific needs of the academic unit sponsoring the instruction. These crucial differences thwart most attempts to find out how Canadian universities organize writing instruction while at the same time signalling the fundamental differences that separate the two countries.

As a Canadian citizen whose undergraduate and master's degrees were completed at home, I had very little experience with writing instruction and composition studies when I began a U.S. doctorate program in rhetoric and composition. What my recent academic pursuits and current research has shown me is that while composition courses are not compulsory in most undergraduate programs in Canada, when offered, students who choose to take these courses often hold the same expectations as those in the United States, which include: preparation for graduate and professional education, preparation for research, and improvement of academic writing skills. Additionally, these expectations are present in the majority of students who enrol in first-year writing courses, regardless of their cultural backgrounds.

Because Canada is recognized as an "immigrant nation" that encourages and promotes multiculturalism, it is important for educators and policy makers to fully understand how first-year writing courses, especially those based in tenets of composition, can work to serve increasingly multilingual student populations. In the United States, the response of composition research to such changes in student demographics, particularly studies concerned with language(s) and globalization, have flourished; there has not been the same concern with first-year writing and multilingualism in Canada, despite Canada's various national policies that promote and encourage multiculturalism. The current study found that Canadian students-especially multilingual students - have a tendency to enrol in composition courses when they are offered. At the University of Windsor, a central aim of these courses is to teach precepts 
of reflexive critical thinking, which often encourages students to renegotiate their patterns of thinking and reconsider their values and world views in terms of their own identities as well as those of their classmates. Therefore, it is important to understand how writing courses, which are reflexive in nature, can address student diversity - specifically, diversity related to heritage languages and culture. In the context of this research critical thinking ideologies, which are understood in terms of the development of individual identity as well as reflective practices associated with this development via writing assignments, are employed. Moreover, as this study will later position, Canadian writing courses designed within a multicultural and multilingual agenda could work to integrate ideologies of critical thinking through creating relationships between the subject matter and the students' own personal experiences with it. Thus, a central aim of this project is to employ the research of scholars of U.S. composition to evaluate the instruction of writing in Canada, especially in terms of the multilingual immigrant student. Through exploring the theoretical relationships among language, identity, and academic writing in Canada, this study aims to provide insight into how writing courses can be designed to effectively recognize and address the diverse linguistic identities of Canada's multilingual students as set out by the Canadian government's multiculturalist legislature. While this project draws from U.S. scholarship concerning multilingualism within student populations, the focus rests on the relationships between immigrant students and minority language policy in Canada. A purpose of this study is to offer an alternative model of writing instruction, in regard to multilingual student needs and realities, that emphasizes how Canadian societal approaches to multilingualism differ from those of the U.S-specifically, linguistic inclusiveness and acceptance. The data collected will serve 
to create a foundational analysis of student demographics in terms of attitudes towards and expertise surrounding language use, community affiliation, and academic writing. This information will be analyzed in terms of the Canadian Multiculturalism Act to assess the value of designing writing courses that integrate concepts of language interaction, specifically allophone-English language meshing, into English-medium texts $^{3}$. Ultimately, this research will document a series of preliminary findings concerning Canadian multilingual students and writing scholarship as well as anticipate future research in this area.

The current chapter summarizes published U.S. composition scholarship concerning language interaction and segregation. The following chapter transitions into an explicitly Canadian context, exploring Canadian post-secondary educationspecifically writing instruction - in terms of multiculturalism and multilingualism. The remaining chapters describe and interpret the data collected from a selection of students enrolled in writing courses at a university in Southwestern Ontario, drawing conclusions and offering suggestions for future research endeavours in both the Canada and the U.S. A further explication of the sections of this manuscript is found at the close of this chapter.

Before shifting this research to an expressly Canadian perspective I will offer a review of U.S. composition scholarship concerned with student multilingualism. In Canada minority language scholarship pertaining to allophone speakers is based exclusively within $\mathrm{K}$ to 12 research and post-secondary research concerned with francophone rather than allophone Canadians. Consequently, because Canadian

${ }^{3}$ The Canadian term allophone complements the anglophone and francophone labelling system. An allophone speaker is a Canadian citizen whose first language is neither English, French, nor First Nations, but an immigrant or heritage language. 
scholarship that draws upon the language choices of multilingual students in university and college education is exceedingly scarce I must draw upon the history of U.S. language research in relation to composition pedagogy in order to address how issues of language are encountered by allophone students and how identity is affected by language choices made inside and outside the classroom. Moreover, an understanding of how multilingual students are classified as well as a survey of how language scholarship operates in U.S. composition classrooms will better prepare Canadian scholars of writing to work with diverse linguistic populations.

For the purposes of this project I use the term multilingual to refer to immigrant students with allophone language backgrounds; however, in similar studies various other terms have been employed including Non-English Background Students (NEBS), multicultural speakers, Non-Native English Speakers (NNES), English as a Second Language (ESL), English as an Additional Language (EAL), Generation 1.5, L2, and so on. It seems that many scholars have coined their own terms in an attempt to find the best fit. However, the drawback to many of these terms - multilingual included — is that (a) they aren't specific enough and (b) many are moot as they have been deconstructed into sub-categories. For instance, second language students (ESL) are regularly being reclassified as ESL-international, ESL-North American born, and English as a Foreign Language (EFL). Reasons for this are varied and include scholars becoming more specific in their categorization, negative connotations that have become associated with the ESL-term, and students' avoidance of ESL-labelled sections. A further difficulty in creating categories for multilingual speakers is that there are a variety of disciplines that study populations with plural language abilities, but there is no common taxonomy. For 
instance, the research of Guadalupe Valdès, a professor of education who studies multilingual speakers, is concerned with different categories of bilingual speakers such as subtractive and circumstantial bilinguals, which deviate from traditional Canadian definitions of bilingualism. ${ }^{4}$ Additionally, scholars in different countries also have different labels for similar populations. While the allophone designation is unique to Canada, in contexts outside this nation the term has a phonetic denotation and is used in linguistics (Makkai 193). Moreover, because research concerned with language ability and acquisition is an evolving area of study there are always new groups of speakers being identified. A case in point is Canagarajah's 2007 publication "Lingua Franca English, Multilingual Communities, and Language Acquisition," which describes a population of LFE (Lingua Franca English) speakers. ${ }^{5}$ Canagarajah's LFE speakers are again a specific category of multilingual speakers; however, the author explains that the term (i.e. the categorical definition) is still under construction. To further this point, while Canagarajah uses the term LFE, other scholars have chosen to employ the term English as a Lingua Franca (ELF). And most recently, the work of Patricia Friedrich and Aya Matsuda posits that ELF is not even a variety of English, but a function of the language, which coincides with Canagarajah's assertion that Lingua Franca English is functionally dependent upon situation and speaker. I have chosen to offer a description of these terms

\footnotetext{
${ }^{4}$ Valdès's terminology for bilingualism is more specific than is commonly used in Canadian society. For instance, allophone Canadians would fall into the categories of both subtractive and circumstantial bilinguals.

${ }^{5}$ Canagarajah's Lingua Franca English is characterized by a virtual speech community, wherein speakers are global rather than local. English is used as a contact language and changes dependent upon the communicative strategies and competence of each set of speakers. As such, there is no standardized form of LFE, its form is dependent upon usage in changing situations by changing speakers.
} 
to illustrate the muddled nature of naming systems related to multilingual speakers, and to exemplify the difficulties faced when we attempt to categorize students.

Ultimately, because this study is interested in providing a general demographic of who Canadian immigrant multilingual students are, there is a limitation in using classifications like ESL, one reason being that attaching labels to students places them in boxes, implying that every student within a categorization has the same writing background, is bringing the same writing problems to the classroom, can be taught the same way, and so on. For this research, I have chosen the term "multilingual" because it includes all students who have plural language abilities, and who may be bilingual, trilingual, or polyglot. By then adding the term "immigrant" I have chosen to include students who are generation $1.5^{6}$ as well as second generation, third generation and so on. A purpose for employing such labelling practices is that this project intends to survey the larger population rather than discrete groups of multilingual immigrant students enrolled in first-year writing. Additionally, this categorization excludes anglophone Canadians who have learned French as a part of their education, or francophone Canadians who have learned English. This research is concerned with students who have an allophone or heritage language background, rather than a French-English bilingual background. A further reason for not studying those with a French-English (bilingual) mother tongue ${ }^{7}$ is that they make up less than one percent of Canada's total population (Census Canada). As such, this research is explicitly concerned with the anglophone teaching of writing to

\footnotetext{
${ }^{6}$ This term refers to students who arrive to the North America at a young age and attend North American grade schools. English is most often the only language that these students have received writing and literacy instruction in; however, often they do not define themselves as native English speakers, which is often strengthened by their placement into internationally geared ESL courses.

${ }^{7}$ Refers to the first language learnt at home in childhood, which is and still used and understood.
} 
allophone students, which takes place in Anglo-Canadian universities. There will be no in-depth examination writing instruction in regard to francophone or anglophonefrancophone bilingual student populations.

\section{Multilingualism in U.S. Composition Scholarship}

This project will explore three competing views concerning multilingualism and writing instruction that exist in U.S. composition scholarship: eradicationism, language segregation, and language interaction. The first of these perspectives holds that language which deviates from Standardized English ${ }^{8}$ is erroneous and deficient. Such language positions the writer as ignorant of and indifferent to what "correct" writing is; these writers are "treated" through eradicating the error, with the end result being the ability to compose "correctly." Simply, eradicationism perceives English as fixed, where any difference is regarded as error (Horner and Lu 145). Conversely, language segregation, which is most often referred to in composition scholarship as code-switching, advocates the use of different languages in different situations, such as Standardized English at university and one's home language at the dinner table; central to code-switching is that only one language is being used at a time, and there is no interaction between languages. Thus, in code-switching we see ideologies of eradicationism present within academic

\footnotetext{
${ }^{7}$ Please note: The term "Standardized English" is used throughout this text to umbrella similar terms, including Standardized Written English, Standard English, Canadian Standard Edited English, American Standard Edited English, British Standard Edited English, and so on. The chosen term is used in-text to describe the most formal version of the language at play. As much of this project addresses language issues from international scholars, rather than just one region on the world, the generalized use of term Standardized English is meant to describe academic language generally. While this generalization does not attempt to ignore the reality of the deviations of Standardized English that occur as one moves from one predominantly Englishspeaking country to another, because there are no examples of student writing included in this project marking the deviations between national Standardized Englishes was not deemed necessary.
} 
writing expectations; however, the recognition of languages other than Standardized English positions this perspective as more progressive. The approach to language that would appear to be most suitable for the Canadian situation would be language interaction, also known as code-meshing (Canagarajah "The Place"). This strategy enables multilingual students to integrate heritage languages with Standardized English in the writing classroom and is the method that I believe best fits Canada's policies of multiculturalism. An additional benefit code-meshing is its consideration of the many shifting meanings within languages, which work to build knowledge generally. Thus, not only students, but post-secondary institutions can benefit from the integration of diverse languages in the classroom, particularly when languages are viewed as resources, which occurs when they offer multiple representations of meaning. Yet, offered thus far are simplistic and uncontextualized definitions of these terms; in the following paragraphs I will work to unpack attitudes towards code-switching and code-meshing. However, because there are few advocates of eradicationism in composition scholarship it will not be dealt with further (Horner and $\mathrm{Lu} \mathrm{145)}$.

\section{Student's Right to Their Own Language}

Ideologies of code-switching were originally introduced under the Student's Right to Their Own Language (SRTOL) resolution in the mid-1970s by composition's main governing body, the Conference on College Composition and Communication. SRTOL calls for the realization and recognition of the many home languages students possess; however, while this movement acknowledges the variety of languages that students bring with them to the academy, it does not allow for an interaction between heritage languages 
and the accepted Standardized English of the university. The resolution, which broke from mainstream assimilative policies, concerned "students' rights to their own patterns and varieties of language" and was adopted to ensure that all individuals are able to take pride in and maintain individual identities and languages. The primary goals outlined by the resolution were to heighten consciousness of language attitudes, promote linguistic diversity, and convey facts and information about language(s) that would help instructors respond to the growing population of immigrant students enrolling in their composition classrooms. That is to say, SRTOL was created to ensure that students are supported in the maintenance and use of their home language patterns, varieties, and dialects--all of which allow them to take pride in their unique identities that are associated with the variety of English used at home. A central message of this resolution is that composition teachers must learn to recognize that there is no singular U.S. dialect, and in doing so become better prepared to cultivate writing classrooms as culturally diverse spaces. While there is no equivalent document in terms of Canadian writing instruction the Canadian Multiculturalism Act works similarly, but on a grander level—acknowledging and celebrating linguistic and cultural diversity in society. A discussion of the scholarship concerning student multilingualism and the writing classroom that comes out of the United States, in this case SRTOL, is necessary so that Canadian multilingual scholarship can build upon these findings and extend the discussion to all sectors of North America. In essence, Canadians - through the implementation of multiculturalist policy-have already accepted the tenets of SRTOL within society; in the U.S. such acceptance is only sponsored by a professional organization. Yet, the same acceptance of student home language patterns, varieties, and dialects is not present in Canadian English-medium 
writing classroom; succeeding chapters of this study will explore how Canadian multicultural policy, which is comparable to SRTOL policy concerning multilingual students, could be an asset to immigrant students enrolled in first-year writing courses. Horner critiques the resolution, claiming that the changing perceptions of and relationships among language(s), student(s), and English(es) in the United States are in constant negotiation. Composition's emphasis on the standardization of written English neglects the multiple definitions, comprehensions, and relationships with English that our multilingual students bring to our classrooms ("Cross"). In other words, the resolution fails to recognize the fluidity of languages and language varieties, pays little attention to languages other than English, and reifies Standardized English as a fixed and uniform set of notational practices. Ultimately, SRTOL treats language and language users as homogeneous populations, where dialects and varieties of language(s) do not exist in conjunction with Standardized English. The resolution encourages multilingual students to cultivate home languages only if code-switching occurs-languages cannot be meshed. Such an understanding of language fails students through its wrongful assumption that language and identity are stable and linked. While the main purpose of SRTOL appears to be the promotion of diversity, this diversity is confined within the borders of the English Only expectations of Standardized English. Consequently, in the classroom other languages are ignored, which in turn discounts the diverse language varieties of students, varieties that are central in their identity construction (Horner "Student's Right" 743).

The above summary outlines English Only teaching practices in the U.S., and while Canadian citizens and government agencies do not share this monolingual agenda - which is exemplified by policies of bilingualism, heritage language instruction, 
and multiculturalism - the majority of Canadian classrooms in anglophone universities function largely within English-medium constructs ${ }^{9}$. SRTOL as well as current Canadian teaching practices in the writing classroom employ eradicationism through their recognition of only SWE in the classroom. It is problematic that the resolution as well as Canadian society hold the belief that it is important for students to have a right to their own language, yet do not extend this right to the texts they produce in the writing classroom.

We can also consider the SRTOL model and Canadian post-secondary education as promoting "plural monolingualism," which is described by Makoni as a variant or extension of monolingualism. Plural monolingualism occurs when linguistic communities are encouraged to foster multilingual abilities, yet the result is often that speakers gain competence in only one language (Makoni 139). This illusion of multilingualism is based upon the assumption that speakers who move between languages, or code-switch, have command over the languages that they move between. Makoni argues that this is a faulty analysis of code-switching. In reality, many speakers who implement techniques of codeswitching are not meshing languages purposely; instead their linguistic patterns exist as meshed forms of languages. In other words, it is impossible to unmesh languages if regular speech is a mixture of multiple languages (143).

\section{The Language of Power}

Young (705) critiques code-switching because it tells students that "their language[s] and identities are not welcome in school." Code-switching further fails students in that it forces them to characterize themselves through unfamiliar linguistic and therefore

${ }^{9}$ Excepting Modern Languages (e.g. French, Spanish, German, etc.). 
cultural identities. This finding is applicable for Canadian students who live in or seek post-graduation employment in ethno-specific and globalized communities; yet, its ideologies do not fit well with Canadian constructs of education that position postsecondary students who come to universities and colleges to learn the knowledge and language of power. The study at hand posits that while the language of power in greater Canadian society is English, increasingly, there are also communities that demand the use of heritage languages. Thus, writing classrooms that only address anglophone concerns are ignoring the linguistic needs of the growing populations of allophone citizens as well as the changing needs of English monolinguals. Young chooses to supports pluralism rather than code-switching because it is a more democratic process wherein "all dialects and languages are equal in terms of structure, even if they are unequal in terms of prestige." Moreover, Young's attitudes align with both the SRTOL and Canadian multicultural policy, which demands citizens honour the many languages that contribute to Canada's diverse heritage.

However, strategies of pluralism position English as central, which maintain Eradicationist agendas, in their assumption that students are fixed and uniform in their desire to master Standardized English, wherein there is a "stable image of the student and his or her desires and purpose for writing" (Horner and Lu 147). Yet, when teachers encourage students to use multiple languages in the negotiation of their writing, those who successfully integrate languages obtain cultural capital through the development of multilingual competence. This negotiation is not the end goal of every writing course, as there are many in-school situations where language interaction would not be a benefit, such as in an academic biology lab report or an engineering presentation. But there are 
also out-of-school interactions wherein students are expected to move between languages, such as employment in ethno-specific marketplaces that exist in larger English-medium centres or positions in globalized firms. Thus, writing courses positioned within a multicultural framework are not for every student and the benefit of certain assignments, such as those that encourage language negotiation, will not be useful to all students. However, because there are a variety of situations wherein cultural capital is obtained via language interaction teachers of writing need to assess the need for classrooms that encourage new ways of writing. Pennycook (34) argues,

[1]anguage competence should be measured not as capacity to perform in one language in a specific domain, but rather as 'the ability to translate, transpose and critically reflect on social, cultural and historical meanings.'

This globalized view positions language in terms of code-meshing, where monolingualism is unrealistic because language is always in translation, particularly if we take into account the majority of English speakers who are non-native and not fluent in Standardized English. Suresh Canagarajah's code-meshing, which calls for the promotion of language interaction between student heritage languages and the Standardized English of the university is increasingly employed when discussing the work multilingual students do in the writing classroom. Moreover, in composition studies code-meshing rather than code-switching is central to pedagogies that support globalization because these models recognize the economic effects that globalization has on the lives of English users.

Globally, multilingual speakers have a larger speech community available to them than monolingual speakers. Consequently, there is a real need for students to develop their language abilities, particularly movement among languages, as this may be an advantage to them once they graduate. Yet, pursuing multilingualism in the classroom 
leads to more than simply commodifiable skills—-though these may seem most tangible to students. Encouraging students to negotiate between their heritage language vocabulary and that of Standardized English positions them to create texts that demonstrate rhetorical savvy in language awareness. When teachers encourage students to use multiple languages in the negotiation of their writing, those who successfully integrate languages obtain cultural capital through their development of multilingual competence; this capital is prevalent in social and economic relationships.

Two meanings of linguistic power are critical to this project. The first positions language as having a forceful capacity, wherein linguistic diversity functions within writing as a powerful resource. The second positions language as a socially assigned privilege, wherein power is most often connected to Standardized English or "the language of power." The debate over what is best suited for the composition classroom is seen playing out in the work of a variety of scholars (Canagarajah; Ball and Lardner; Bean, Cucchiara, Eddy, Elbow, Grego, Haswell, Irvine, Kennedy, Kutz, Lehner, and Matsuda; Delpit; Smitherman; Lovejoy, etc. ) and extends beyond the work set out by SRTOL. The "language of power" and "home language(s)" are two additional perspectives which further complicate scholarly research concerning language and writing instruction, the end goal of the first being student access to the classroom "language of power" (Standardized English) and the second being teacher and student understanding of the importance of "home language(s)" in both the classroom and greater society. While the latter may be more relevant to the current research seated in heritage languages and Canadian writing classrooms, the historical influences of each side are central to a rounded understanding of current arguments. Moreover, a reading of this 
debate will also illustrate the divide between U.S. and Canadian contexts of minority languages; in the United States the debate is founded upon African American English (AAE), whereas in Canada the applicable populations are First nations, francophone, and allophone speakers.

I would argue that the older of the two arguments, and that which is not as prominent in current scholarship, is the "language of power" predilection. This argument is exemplified in Delpit's “The Silenced Dialogue: Power and Pedagogy in Educating Other People's Children" which describes membership into the culture of power as contingent upon issues of power enacted in classrooms, codes for participating in power, rules of the culture of power that are reflective of the rules of those who have institutional power, membership, and recognition of this culture. Delpit believes that each cultural group should have the right to maintain their own language style; however, she also realizes that in order to succeed, students need to be able to move within the language of power. Delpit realizes both the need to respect home languages, but to teach hegemonic language practices. In Bruch and Marback's The Hope and the Legacy Smitherman stresses that composition needs to teach communicative competence, which is dependent not just on function, but on social meaning-or literacies. Smitherman is arguing for home language linguistic instruction, in the writing classroom wherein she believes that through encouraging students to better understand home languages writing teachers are strengthening the economy and making connections between language rights and economic rights. Thus, Smitherman views home languages as functioning as a resource for gaining economic power, which would lead to the attainment of linguistic power. 
Ball and Lardner's 1997 article "Dispositions toward Language: Teacher Constructs of Knowledge and the Ann Arbor Black English Case" demonstrates a conjoining of the two debates. They hold that teacher knowledge is dependent upon racially informed language attitudes and as such has effects on both teacher ability and minority students learning processes. In this sense, teacher knowledge (and consequently the choice of teaching a certain language standard) has immediate impact on the ways in which a certain language - routinely, Standardized English - is equated to hegemonic power systems. In their discussion of African American students, the authors posit that writing teachers need to become sensitive to the needs of students who utilize African American English (AAE) and, as such, create classrooms that recognize and accept linguistic difference. However, while this may be the goal, the teachers are critiqued in the article because they view $\mathrm{AAE}$ as faulty and not a possible language resource that could function to extend linguistic power. Recognizing this common failure among teachers, Ball and Lardner call for strategies to improve teacher knowledge in student linguistic diversity wherein $\mathrm{AAE}$ could be brought into the classroom and teachers can "provide a more complex more complete linguistic profile of African American linguistic behavior" (480). And while this approach to shifting the language of power in U.S. school systems and writing classrooms effects a large population of AAE speakers, the circumstances surrounding this population are too specific to easily cross over to the Canadian context of allophone students. This is primarily due to the extensive linguistic and geographic diversity of most minority language speakers in Canada, which will be discussed in the succeeding chapter. 
Consequently, I see the U.S. debate between "language of power" and "home language(s)" as leaning towards the latter perspective if it is to be applied to allophone populations in Canada. For instance, Lovejoy in "Practical Pedagogy for Composition" explains that U.S. classrooms need be more democratic and inclusive if writing teachers hope to demonstrate to students the value of language differences; that Standardized English needs to be taught within the context of other Englishes; and that if Standardized English is the only form of language required in our classrooms - and we exclude home languages - we are distorting the power and capacity of language to communicate in the written mode (to and amongst our students). The many scholars (Bean et al.) who came together in the publication of "Should We Invite Students to Write in Home Languages? Complicating the Yes/No Debate" offer further insight into the introduction of home languages into the English-medium classroom. What they agree upon is that teachers and students need to come to terms with the fact that writing takes place in social contexts, where writers are positioned in contexts that affect them, that multilingual writers are more confident when their home language is valued, and that student writers (multilingual and NES) need to belive in their own abilities and expertise, which are often based on multicultural experience.

The work of both Elbow and Canagarajah is particularly relevant to the project at hand in terms of the competing debates between language segregation and language integration. Elbow's scholarship has repeatedly defended code-switching while Canagarajah has argued for the practice of code-meshing. Elbow's "Inviting the Mother Tongue" and co-authored "Should We Invite Students to Write in Home Languages?" build upon SRTOL, offering pedagogies that serve to make the writing classroom a safer 
place for multilingual students, a place where this population of students feels comfortable (comfort and able) to write in their own dialect vernaculars and language(s). Elbow explains that we need to teach students how to utilize their home voice and their academic voice, and in doing so teachers need to realize that Standardized English is no one's mother tongue. While many argue that Elbow's pedagogies are forward thinking because he invites his students to use their vernacular dialects - home languages - in personal writing exercises, brainstorming, and all stages of the drafting process, the primary argument against him is that final papers must be composed in Standardized English. Elbow's reasoning for code-switching is that we can't create a safe space for home languages, unless we also teach the correct language (i.e., the language of power; Standardized English). Simply, Elbow is promoting plural monolingualism, treating each language as operating discretely, and as fixed. Young (703) argues against Elbow's codeswitching; his position is that by privileging one language we "simultaneously aggravate[] one problem even as it helps to solve another." Drawing upon only Standardized English in the classroom setting validates one identity (that of the student) and ignores students' out-of-school identities. Canagarajah also disagrees, arguing that our dismissal of vernacular writing in final drafts is problematic because students still want to (and will) bring their home languages into these drafts. Canagarajah ("The Place" 598) argues that we need to work with students to help them apply principles of codemeshing, not code-switching, because code-meshing is a more complex process due to its capacities for multilingualism and the demands of globalization (demands that students may not see in writing classes, but will encounter once they enter the workforce). 


\section{Additionally, in Resisting Linguistic Imperialism in English Teaching}

Canagarajah argues that multilingual students who have solid language abilities in a home language are more apt to gain and use other languages. Canagarajah identifies a level of creativity that arises out of the interaction and negotiation between languages; this argument falls in line with ideologies that linguistic diversity is a powerful resource to students. Moreover, through encouraging language negotiation, writing teachers also teach critical thinking—-students who are aware of and have to make a variety of rhetorical choices when moving back and forth between languages have no choice but to be critically reflective. Min-Zhan Lu offers insight into how code-meshing and the "creativity" of multilingual students can be used pedagogically. Instead of looking at language which varies from mainstream definitions of Standardized English as wrong, $\mathrm{Lu}$ encourages teachers of writing to enter into a process of stylistic negotiation when looking at language deviations ("Professing" 457). Similarly, instead of reading these texts as deficient, Canagarajah emphasizes that we need to view difference as resource, where students' home languages and cultures become an asset to their linguistic development. This view falls in line with Horner and Lu's (145) argument against eradicationism, which positions that language and identity are dynamic, and as such writing should be recognized as a living, changing process, rather than static. This perspective is also held by Young, whose research argues that the privileging of only Standardized English in the classroom serves to ignore and deny the interactions between the many identities and communities students are members of out-of-school.

In order to validate the many identities that students bring with them to the academy, composition classrooms need to be redesigned as spaces where students can 
experiment with their writing, drawing upon sameness and difference without inhibition. However, the attitudes of these scholars deviate from those of most writing programs across the U.S. and Canada. The more conventional - majority — approach held by teachers of writing as well as numerous other disciplines is that students enter the university to learn the language of power, Standardized English, and use this knowledge to excel in their degree program. In fact, the reality is that Canadian students do need to learn how to write in English as it is the lingua franca of most post-secondary institutions and Canadian society at large; however, the study at hand posits that when a large proportion of students are multilingual the demands on learning shift.

This is not to say that English-medium instruction should be abandoned, instead the politics of language negotiation and multilingualism should be introduced as an option. Such curricular changes would not affect all facets of university learning, I am suggesting that — when the student demographic demands it —writing courses be offered that address issues of language in Canada through critically examining multicultural policy in terms of student multilingualism. A writing course that responds to federal policies of the Canadian Multiculturalism Act would support government legislation as well as the growing allophone populations who are struggling to retain a sense of linguistic pride in a predominantly anglophone nation. The policy itself suggests that we need to support student writing that works to incorporate various home languages and identities; a fundamental way to accomplish this is to design specific classrooms where we can introduce strategies of code-meshing alongside English-medium instruction. Scholars of code-meshing argue that allowing only Standardized English in our writing classrooms is naïve because students exist (inside and outside the academy) as members 
of communities who utilize a variety of languages, where Standardized English is really only one of many English(es) and languages. Furthermore, English itself is a language that fluctuates and changes-particularly in the academy. Across the disciplines the English language is used differently in changing situations. For instance, in North American post-secondary institutions the field of philosophy is primarily English-based, yet it also incorporates the languages of French and Latin; literary theory is a kind of international jargon, based in English but not always Standardized English. For instance, much theory written in English draws heavily from terms and concepts which originated in what is recognized as other languages (e.g. the use of Derrida's distinction between "difference" and "differance," Bourdieu's concept of "the habitus," the Marxist notion of "praxis"); and, finally, while the sciences are also based in English, their use of technical idioms is often incomprehensible to a native speaker of English (Armour 22).

Canagarajah, Lu, Matsuda, Smoke, Silva, Soliday and others claim that if we are to fully understand and teach the complex linguistic ecology of students in our composition classrooms there cannot be a homogenous language because there is no homogenous student population. The sad irony in enforcing Standardized English is that by doing so we maintain the false reality that our writing classrooms and language varieties are stable and homogeneous. Studies have also shown that instructor responses to issues of style and usage are, even within the context of Standardized English, idiosyncratic. Ultimately, scholars of code-meshing are exposing that SRTOL ideologies are flawed in their failure to realize, particularly in terms of the multilingualism that has come to be associated with globalization, that English itself is a plural and fluctuating language that often intermingles with other languages. This intermingling of languages is 
especially prevalent in Canada because of the predominance of both official languages in all facets of society (e.g. the packaging of goods must be labelled in French and English). Many anglophone speakers regularly interject non-English words into everyday conversation and therefore exhibit aspects of multilingualism despite the fact they may only recognize themselves as English monolinguals.

In fact, many scholars would argue that all instances where Standardized English is used are moments of pluralization; Standardized English itself is simply a variety of English recognized by academic institutions. Nikolas Coupland offers a sociolinguistic analysis of the plurality of Standardized English in his review of Standard English: The Widening Debate, an edited collection that attempts to define the term. A major finding of Coupland's review is that the definitions used to explain Standardized English are ideological rather than descriptive, while purporting to be the latter. Moreover, in each section of the text he finds anomalies. For instance, in the first section definitions between authors are "inconsistent" and show "no general consensus" (624), while another section argues that Standardized English is a "variety of a language," "not a language," "a dialect," and "not a style" (625); and a further section describes Standardized English as having two criteria "educatedness" and "prestige" (628). The point of Coupland's argument, as well as that forwarded in this project, is that there is no legitimate answer to the question 'What is Standard English?' And instructors of writing need to realize that attempts to teach—or enforce--Standardized English are futile. In fact, I would argue that Standardized English is intangible, existing only as an ideological construction wherein hegemonic forces have positioned a particular version of the English language as the norm within the academy (and society). As such, there is an implicit belief within 
post-secondary education that English is the expected language of choice globally and students do not need to be educated in other languages in order to excel either at home or abroad.

Taking the current ideologies surrounding Standardized English and reading them both in terms of code-switching and code-meshing as well as Canadian situations allows us to garner a better appreciation of what version of composition's multilingual scholarship plays out in Canadian writing classrooms when these courses are offered. In Canada, much like in the United States, the language of the university is understood to be Standardized English. ${ }^{10}$ However, Canadian multilingual students' interaction with language in daily life is often much different than the realities that face similar populations of students in English Only America because of the acceptance of plural language ability and usage in Canadian federal policy. The same Canadian students, who speak and write in Standardized English in their university classrooms, do not necessarily speak English when communicating with friends and relatives outside the university. In fact, in common spaces within the university where instruction is not taking place, English and French are not the most frequently spoken languages and, when used, often take the form of Canagarajah's code-meshing. This phenomenon of language meshing is prevalent across North America,

On campus, I hear Spanglish everywhere on the pathways between buildings, in the union, in the library, in the parking lots, in the bathrooms, in the hallways. Students speak Spanglish on cell phones; they text-message in Spanglish; they use Spanglish on their blogs and on Facebook sites. But when they enter their English-language writing classes, they are careful to speak so-called Standard English.

(Mangelsdorf 177)

\footnotetext{
${ }^{10}$ However, there are a small number of post-secondary institutions that provide bilingual French-English education, as well as institutions within Québec and New Brunswick that are Standard Written French (SWF).
} 
What is most intriguing about Mangelsdorf's observation is that such practices--because they occur so frequently-are common, yet are held up as irregular because of the belief that Standardized English is the mainstream. Her illustration of language variety outside the classroom could very easily be my own if "Spanglish" were replaced with "mixed languages." In summation, across North America the languages spoken by our students

outside the classroom may vary, but there is a constant: the interweaving of English with a home language. In Canada, one reason why students encounter language outside their student lives through such varied and diverse constructs is primarily due to how society perceives language(s), perceptions that have been shaped nationally and internationally by the Canadian government's multicultural efforts.

\section{$\underline{\text { Linguistic Diversity in Canada }}$}

Canadian multicultural policies differ from U.S. English Only agendas in that allophone Canadians are encouraged via official and legal channels to pursue cultural free choice (Li 134), one of these choices being whether or not to maintain a heritage language in addition to one (or both) of Canada's official languages. Such multicultural initiatives shape Canadian identity in terms of diversity, and as such the concept of Canada as a cultural mosaic is generally used when explaining national identity. This concept holds that no other country in the world encompasses inhabitants from so many different backgrounds who exhibit strong loyalty towards Canada, while still preserving their cultural heritage. And because Canada is geographically situated so close to the United States, the mosaic is most often contrasted to the U.S. metaphor of a "Melting Pot," 
which is described as attempting to shape all citizens into a set mould - U.S. English Only legislation is one area of education that upholds this melting pot paradigm.

Central in Canada's promotion of itself as a cultural mosaic is the Canadian Multiculturalism Act, which was implemented as a response to radical changes in the nature of immigration to Canada during the second half of the twentieth century (Harrison 307). Passed in 1988, the Canadian Multiculturalism Act established Canada as the first country to adopt an official multiculturalist policy, reaffirming multiculturalism as a fundamental characteristic of Canadian society. Of specific interest, in terms of this project, is the policy's support of Canadian society's “acquisition, retention and use of all languages that contribute to the multicultural heritage of Canada" (Canadian Multiculturalism Act). Such federal policies support the preservation of the nation's collective and diverse heritage, reinforcing the ideology that Canadians share strong attachments to different aspects of their identity-regional, linguistic, religious, cultural and familial. The Act recognizes that language(s) is always in flux, multiple, and stratified-language acts as an element of culture. The cultural mosaic model is most often used to describe this coming together of identities. And while the image of a mosaic may suggest fixed boundaries, the implication is that within one nation all ethnic communities can co-exist, yet still maintain their distinct cultural heritage. In essence, the function of the Act is to promote not simply tolerance, but acceptance of the plurality of discrete languages and language communities that exist within Canada. However, by maintaining languages as individual and separate, the Canadian government is promoting linguistic segregation rather than pluralization, and as such maintaining the fixed boundaries visually suggested by a mosaic pattern. Makoni (139) describes similar 
'acceptance' of home languages in South Africa. In this nation, the government has granted official status to nine aboriginal languages, which allows individuals to "use the language of their choice" in public or private settings. However, Makoni argues this legislation is socially alienating and upholds "plural monolingualism," which he explains is a variant or extension of monolingualism that encourages citizens to be monolingual, but symbolically recognizes home languages. Similarly, Canadian critics of multiculturalist policy argue that the federal government's acknowledgment of language diversity is no more than a token of symbolic pluralism, wherein only moderate financial assistance and political demands are placed upon key cultural and education institutions (Li 135). Consequently, a central aim of this project is to assess whether or not the Canadian Multiculturalism Act is being used within the academy and, if not, how should it be applied in response to multilingual students' needs in the writing classroom?

In addition to the Canadian Multiculturalism Act and the mosaic analogy of national identity, Canada further differs from the United States in that it exists as a country with two official languages, namely French and English. Yet-while encouraged — citizens are not forced to be competent and fluent in both (unless they hold Federal government employment). As a result, citizens of French-speaking towns, cities, and provinces are expected by citizens of English-speaking regions to use English in dayto-day encounters when visiting English-speaking localities and vice-versa. The obvious result of such encounters would be code-switching; using English when those you are conversing with are English and using French when those in your company are French. Yet, in Canada because of the plurality of official languages there is an acceptance of 
code-meshing in daily communications. It is typical for a person with knowledge in both official languages to use them interchangeably within sentences, particularly in speech.

Language mixing (e.g. code-meshing) is a part of daily encounters between English- and French- speaking Canadians. Such mixing takes different forms including borrowings, blendings, and meshings, all of which are prevalent in Québécois French. For instance, we see borrowings in phrases such as francophones' incorporation of le week-end [the weekend] or le hot dog [the hot dog] into their standard dialect and anglophones usage of toque [wool hat]. Blending can occur when an English word is used in French and then conjugated using French Je dois me parker [I am parking], or in English When are we mangering? [When are we eating?]. Meshing arises when both French and English words are used separately (without blending) within the same sentence, where one language serves as the foundation. Bilingualism in Canada has made citizens more aware that when we encounter errors in the conversation of those with a different home language these "mistakes" are most often conscious negotiations.

The employment of multiple languages emphasizes the conflicts that arise when moving between two discourse communities; in such instances these deviations, which may be considered as error in an English-medium writing environment, can be understood in terms of cultural rhetorical choice (Canagarajah "Multilingual" 34). Moreover, because language meshing is so frequent there is less stigma placed on immigrants who use the same strategies when moving between English (or French) and their home language(s) in Canadian society when compared to other countries who do not promote multilingualism and cultural pluralism. For this reason, if you visit any location where a large intersection of society gathers (e.g. public transport, shopping centres, etc.) 
you hear a variety of languages being used. Similarly, on campus, outside of the classroom you again encounter a cacophony of languages. However, move this conversation into the walls of a first-year writing classroom and Standardized English is the language of choice. What is important to this study is how such segregations of language affect the cultivation of immigrant student language choices and ability to maintain home language in first-year writing classrooms.

As noted, Canadian and U.S. universities' use of Standardized English in the writing classroom is quite similar; divergent is the cultivation of immigrant languages outside the classroom, and the practice of code-meshing in these situations. This project examines data gathered from a cross-section of first-year writing students at a Canadian university in the context of Canada's official and unofficial attitudes toward language variation. A primary objective of this analysis is to provide a demographic analysis of a sample of Canadian students, as well as assess how their language choices play out both inside and outside the academy.

The existence of a policy such as the Canadian Multiculturalism Act would suggest that language meshing is a facet of all areas of Canadian society; however, as I have outlined, students who attend postsecondary institutions in Canada are expected to practice monolingualism, or language segregation -if they speak Hindi, or a combination of English and Hindi, outside of the university, they are expected to use the postsecondary lingua franca of English once they are seated in their classrooms. However, as Pennycook (34) demonstrates, a central problem in such an expectation is its perception of language as a monolingual enterprise, especially in official situations like the classroom. Yet, in reality, both inside and outside the academy, language is always a fluid 
enterprise. There are no true speakers of Standardized English because it is a construct abstracted from actual language practice. Thus, the predominance of language segregation in the classroom appears at odds with the Canadian Multiculturalism Act and, consequently, is an essential theme of this research. Of central importance is the juxtaposition between government legislature that, seemingly, promotes language negotiation within society and post-secondary education's maintenance of standardized and segregated language expectations.

Guillaume Gentil's study of student biliteracy in an English-medium university in francophone Québec reinforces the current project's conjecture that scholars in composition and writing have rarely attended to the struggles of multilingual university students who attempt to write in more than one language. Gentil (425) affirms that "much research on academic literacies in university settings remains focused on the struggles of monolingual or multilingual writers to attain English-medium literacy," rather than investigating the ways in which multilingual literacies exist in post-secondary education. Gentil concludes that social forces should be taken into account if we are committed to empowering multilingual students to invest in their heritage/allophone languages. $\mathrm{He}$ suggests the creation of social conditions that allow for multilingual sustainability, as well as engendering student awareness of said social conditions in terms of the consequences of students' own multilingual writing. The current project responds to these suggestions, presuming that social conditions are already in place, namely Canada's multicultural policies, and positions the classroom as an ideal site for engendering student awareness and encouraging multilingual dialogue. Consequently, this research is especially interested in students" perceptions of how they need to write in order to "fit" 
into the monolingual and monocultural expectations maintained in current academic language communities. In compiling this research, attention was paid to the perceptions of multilingual students towards heritage language acceptance in the writing classroom and academic textual production..

\section{Conclusion}

The silencing of the multilingual voice of students via Standardized English has been met by a call to action in current U.S. and international composition scholarship; increasingly, teachers are being challenged to realize the need to be trained and prepared to work with the multilingual resources our students have to offer and, consequently, to accommodate intersections of race, culture, and ethnicity (Chiang and Schmida; Matsuda and Silva; Matsuda). And, even though English Only ideologies remain implicit in most U.S. (and Canadian) post-secondary writing classrooms the chances of entering a homogeneous, monolingual classroom are few. This reality is not going to change; however, many teachers of first-year writing have not been trained to understand the compositional moves multilingual students make. It is not an easy task to realize the variety of moves between languages that students are making, especially if one considers that in a twentyperson class there may be heritage backgrounds/languages of Polish, Lebanese, Greek, Chinese, Croatian, and more. However, this study will demonstrate that those who teach first-year writing in both the U.S. and Canada need to consider how writing classrooms can work to make use of language diversity. If we consider our students and their experiences to be our largest resource, curricula must capitalize on their knowledge in order to encourage meaning-making. One way of doing this is to assign work that 
engages students in the exploration of how their heritage culture(s) and language(s) work in the construction of identity. Valdès and others stress that mandatory training in areas of second language acquisition should be compulsory for all teachers of first-year writing, as all teachers are going to have to face the challenges of teaching combinations of multilingual and monolingual students. Additionally, teacher training and graduate programs in rhetoric and composition need to include core course requirements that prepare incoming instructors for encounters with multilingual students, be these students G1.5, ESL, EFL, etc. If choosing language is, as Canagarajah argues, a process that is becoming more and more utilized by multilingual students then we, as teachers of firstyear writing, need to understand how students manoeuvre, choose, and reinvent language in the classroom.

The remainder of this project explores the language choices made by Canadian students through the lens of the Canadian government's language policies. An analysis of data collected from a selection of students will provide a detailed narrative of who these students are and how they encounter language in their first-year writing classes. A crosssectional view into the classroom practices of this population of multilingual students will allow for a discussion of potential pedagogical and curricular changes that will improve how we teach writing to diverse student populations.

Chapter two of this manuscript will offer a historical survey of Canadian language histories, policies, and practices (inside/outside university). This section will address the historical circumstances causing Canada to emerge as an officially bilingual country, and the conflicts surrounding French-English bilingualism that have arisen in terms of multiculturalism and multilingualism. A discussion of the implementation of the 
Canadian Multiculturalism Act and its mandates in terms of multilingualism will follow, with attention to how this policy addresses education. In this examination, I will offer a summary and critique of government legislation regarding education and the history of language(s) in Canadian education, including distinctions in practices and legislation among the various provinces and territories. Finally, I will offer a critique of linguistic traditions in Canadian education, paying attention to the monolingual practices that serve to favour the English speaking population.

The third chapter of this project will be methodological. Here, I will describe details of the research project, outline the data gathering methods, and explain why specific choices were made. The fourth and fifth sections of this project offer analyses of the data collected, with chapter four analysing a series of mass-distributed questionnaires and chapter five offering case studies of two student subjects. In evaluating the questionnaire data, attention will be paid to student demographics in terms of language ability as well as a discussion of the obstacles these students face in the writing classroom. Moreover, I will elucidate the ways in which students use language inside and outside the academy, and how such language choices are made. In the case-study portion I will establish specific challenges faced by the students interviewed.

The final chapter of this project will offer instructors of first-year writing strategies to better serve multilingual student populations through a critique of language inclusive pedagogies. In terms of the Canadian Multiculturalism Act, I will discuss how the Act, if it is to truly operate as a tool for encouraging cultural diversity, must be reassessed in terms of post-secondary education and writing curricula. Furthermore, I will illustrate how my findings offer example and insight into how teachers can approach and 
realize the conflicts and struggles that multilingual students face, which will respond to gaps in current global, U.S., and Canadian multilingual research. Outlining how issues of language and cultural experience affect this population's classroom writing processes and identity formation will position my research as a tool to inform and potentially change current post-secondary teaching practices, highlighting the importance of understanding this category of students, providing instructors, researchers, and policy makers with potential informed changes that need to be made in Canada's current post-secondary educational programs.

Studies carried out by composition scholars in Australia, the United Kingdom, the United States, and other regions of the world have closely investigated the relationships between language and the writing classroom, language and pedagogy, language and cultural identity, and language and globalization; however, these topics, specifically in regard to first-year writing, have rarely been explored in relation to post-secondary education in Canada - a noteworthy gap in Canadian educational research especially in light of the Canadian Multiculturalism Act, Canada's longstanding official policy of bilingualism, and our country's encouragement of First Nation language retention. Building upon discussions surrounding multilingual post-secondary students in the United States will expand Canadian perceptions of how immigrant students exist within our classrooms, how their academic identities are formed, and how these identities influence this population's understanding of what it means to be Canadian. Gesturing to Horner and Trimbur, Matsuda articulates that behind our pedagogies lie assumptions about who our students are and what they want and need from their education to succeed in life; these assumptions primarily label our students as constituting a stable and 
linguistically uniform population —a population that (due to globalization and centuries of immigration) does not exist. In line with these monolinguistic pedagogies, our writing classrooms continue to exist as sites of linguistic containment, from which those who are different (multilingual) are segregated. First-year writing courses must be reassessed so that they no longer segregate students with diverse language capabilities and thusly maintain the propagation of monolingual pedagogies; such unidirectional practices limit the use of the linguistic resources our students bring to our classrooms. 


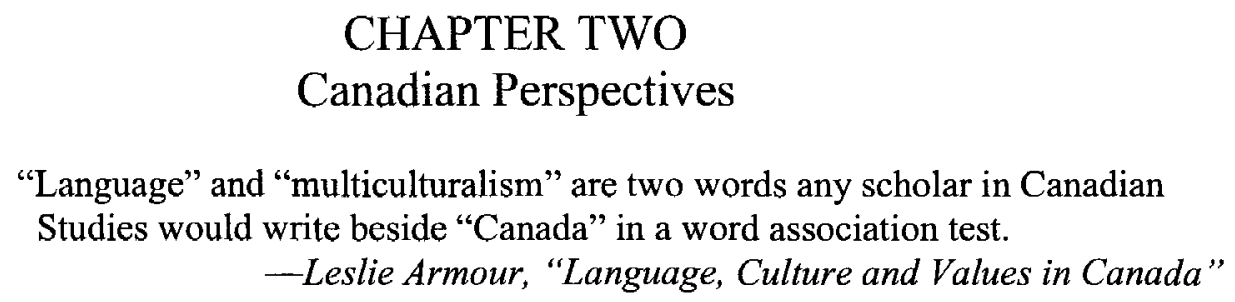

The survey of Canadian language histories, policies, and practices outlined in this chapter is seated in multiculturalism. This narrative of Canadian identity politics will use multiculturalism to describe population demographics in terms of language and language practices. Twentieth-century cultural initiatives based in immigration, which developed into multiculturalist policy and legislature, will be used to investigate how the experiences of different language groups in Canada - anglophone, francophone, First Nations, and allophone- - have come to be treated in the federal and provincial government's educational initiatives. An analysis of government legislation regarding minority language education, including distinctions in practices among the various provinces and territories, will draw attention to the unique treatment of language in Canada.

Throughout Canadian history, language issues have remained central to national identity and, consequently, dominant in public policy. Canadian multiculturalist legislature accepts that citizens have strong relationships with the country's two founding cultures-English and French-as well as various vibrant non-founding cultures 
(Bumsted 649). An essential aim of multiculturalism is to avoid assimilation or integration with the mainstream and, instead, work to change the definition of what is mainstream (Williams 161). Simply, these ideologies work to support cultural pluralism, a model wherein citizens are encouraged, by government agencies, to maintain heritage languages - be they anglophone, francophone, First Nations, or allophone-as well as the two official languages of English and French. The current model of pluralism maintains that cultural lines and linguistic policies must exist as dynamic so as to preserve the nation's cultural mosaic, which is often described as uniquely Canadian. Moreover,

The history and development of this country is very much the story of successive immigrations and the interaction of these groups with the existing society. How they adapted their way of life to Canadian conditions and influenced Canadian patterns has been and will continue to be one of the determining forces in establishing a Canadian identity and nation. (Munro 12)

As such,

Canadians have prove[n] that while the exercise of rights requires some conformity to community norms it does not necessitate the end of group or individual differences and heritages. (Bleasdale 35)

Canadian acceptance of cultural pluralism is most often exemplified by the mosaic model, which boasts that no other country in the world encompasses inhabitants from so many different backgrounds who exhibit strong loyalty towards Canada while still maintaining their immigrant cultural heritage.

However, this official policy, which is committed to pluralism and as such represents a kind of multilingualism, maintains diversity by situating languages as separate and discrete. Pluralist tendencies concerning language were first felt in Canada in the mid-1960s when the federal government moved to recognize anglophonefrancophone biculturalism and bilingualism as fundamental to the national agenda. At 
this time, the Pearson government introduced the principle of "equal partnership" in language, in efforts to appease a francophone population who threatened separation (Bumsted 415). The Royal Commission on Bilingualism and Biculturalism was established and offered recommendations concerning the development of Pearson's "equal partnership" between languages and evaluated contributions made by the other ethnic groups to the cultural enrichment of Canada. The Commission advised that the federal government adopt a trichotomy to characterize multilingualism in Canada, wherein Canadians could identity as francophone, anglophone, or as a member of the "Third Force"11_immigrants with a linguistic background not based in British or French ancestry ( $\operatorname{Li} 125)$.

In response to Pearson's Commission, the primary political platform of succeeding Prime Minister Pierre Elliott Trudeau became the development of language policy. The Trudeau government initially extended affordances to the francophone population, through the Official Languages Act, and later included allophones via the Canadian Multiculturalism Act. The Official Languages Act legislated bilingual EnglishFrench language policy and was entered into parliament in 1969, receiving Royal assent in 1988. The fundamental goals of the Act are the modernization, improvement, and advancement of French and English languages in Canadian government and all facets of Canadian society (Minister 32). Two years later in 1971, the Trudeau government announced multiculturalism as integral to government policy, establishing the Canadian Consultative Council on Multiculturalism in 1973 and the Canadian Multiculturalism Act

${ }^{11}$ Also known as allophone. 
in 1988, as well as introducing multiculturalist policy into the Constitution Act in 1982 and the Charter of Rights and Freedoms in 1988 (Williams 157).

Primary in all of the government legislation outlined here is the superficial facilitation of belonging. The legislature is "superficial" because, while diverse languages are recognized as central to Canadian identity, the government has not worked sufficiently to endorse programs that enable linguistic belonging among allophone populations. While the current federal government maintains that no ethnic group or race is more desirable than another-emphasizing that all cultural groups are essential elements in Canadian identity constructs (Cullen 24) - there are no government programs in place to develop or even maintain this sense of belonging, particularly with postsecondary education. Critics of the government's pluralist agendas argue that multiculturalism is simply a weak attempt at the regulation of diversity, providing only a symbolic framework to interpret and incorporate difference. Critics have further emphasized that the outlined legislation places little political demand on key cultural, educational, or political institutions, maintaining the government's linguistic policies as a token, or symbol, of Canadian pluralism (Li 135). While the legislation itself is progressive, the lack of practical attention to these multicultural linguistic policies fails to foster pride in and maintenance of heritage languages within multilingual and, particularly, allophone speakers. Most research to date has explored the failure of multicultural advancement, cultivation, and functionality within society; however, this study explores how a subsection of society, post-secondary education-specifically the writing classroom — can function as a space wherein multicultural and multilingual learning can be fostered and encouraged. How linguistic diversity functions within 
university and college education is a critical point of inquiry when exploring public policy because the federal government argues that in order for multiculturalism to flourish all levels of government, including public educational institutions, must work together. Thus, the study at hand offers practical curricular initiatives, based within current student demographic data, which serve to take a proactive stance in the establishment of post-secondary multicultural and multilingual education.

While critics focus on the failures of Canadian multiculturalism, Colin $\mathrm{H}$. Williams (158) suggests these policies are much more than a "symbolic gesture," arguing that they work to unite the nation, providing a sense of purpose to its citizens. Further, if cultivated and encouraged, multiculturalism has the capacity to create a highly developed society, due to the flexibility of its policies. The government itself emphasizes the need for action within multiculturalist policy, articulating that multiculturalism is simply a springboard that promotes acceptance and action rather than a set of rules that will lead to cultural pluralism (Munro 14). The government takes the position that multiculturalism is a living policy that is only achieved through the steps that citizens take to make it real. Yet, while the language polices outlined earlier have been in place for several decades, they do not show any particular signs that they have changed the day-to-day activities of Canadian citizens. This project, with its focus on post-secondary writing classrooms, aims to explore the ways of extending Canadian linguistic pluralism within a small sector of society and in doing so, will analyze the tensions that arise when diversity is encouraged only superficially. In other words, as this study will show, linguistic diversity amongst the participants was quite high; however, there is no tangible celebration or 
move to cultivate this diversity, or diversalité, in post-secondary classrooms, which serves to limit its function within greater society.

In the context of this study the distinction between diversity and diversalite is borrowed from scholars of Creolité (Bernabé, Chamoiseau, and Confiant; Chamoiseau; Confiant; Grenier and Guilbault; Szwed). The term diversity assumes cultures and languages as discrete and static - to be celebrated, but not necessarily allowing for dynamic interaction. Conversely, diversalité presumes that cultures and languages are connected through interplay. Chamoiseau's work explores the ways in which Creolité aims to extend past the local into the global, wherein the goal of Creolité "is neither to create their own classics, nor to replace the world's classics in an act of totalitarian universality, but to reach toward 'diversalité"' (Szwed). While the ideologies of diversalité, in relation to Creolité, come out of the work of Chamoiseau other scholars have offered interpretations which are more accessible in terms of this study. For instance, Grenier and Guilbault (211) explain diversalité as an aesthetic approach characterized by a particular way of apprehending the diverse, the complex and the heterogeneous; that is, a rapport au mond (relation to the world) based on the conscious harmonization of preserved diversities.

Raphaël Confiant, a French writer committed to Creole literature, further clarifies,

The Créole message is that of "diversalité," the need for all peoples, all nations, all individuals to come out of themselves to discover within them, even if the process is difficult or even painful, the other, the stranger in them.

Central to this study are the concepts of harmonization and self-discovery described as building block to reaching a society, or classroom, which embraces diversalité-a coming together and acceptance of diverse culture and identity. A recognition of Canadian diversalite in the classroom simply calls for the intermingling of the intricacies 
of diversity through recognizing, celebrating, and cultivating the unique characteristics of each immigrant language in terms of culture and identity - an expectation already present in multicultural policy. Thus, one goal of this research is to offer linguistic data that demonstrates the diversalité of Canadian linguistic cultures present among a cross-section of students enrolled in first-year writing.

Linguistic tension within Canada is spread across its ten provinces and three territories, which are traditionally grouped in terms of socio-political region. The five regions are Atlantic Canada, Central Canada, Prairies, Pacific Coast, and Territories. However, while the Canadian Territories-Yukon Territory, Northwest Territories, and Nunavut—encompass more than one third of Canada's total land and freshwater area, less than one percent of the country's total population is located here. Furthermore, First Nations language legislation differs from the rest of the country in terms of education and government, consequently their linguistic practices are not readily applicable to this discussion of immigrant multilingualism and multiculturalism. Scott Lyons (88) argues that multicultural inclusion is not an objective of indigenous nationalism because the very essence of a nation implies sovereignty, or separation. As such, because this research is concerned with ideologies of rhetorical hybridity—specifically, strategies of language mixing, or code-meshing - in multilingual immigrant students' writing, the linguistic practices of First Nations peoples, which seek homogeneity rather than heterogeneity, are of limited relevance. Therefore, we are left with ten provinces that span four regions, but only four of these provinces-New Brunswick, Québec, Ontario, and British Columbiaare home to substantial populations of non-anglophone speakers, each of which will be 
described below. Ultimately, language use and ownership are specific to province rather than region.

In Canada there are three primary language groups: anglophones, francophones, and allophones. Table One illustrates the national population demographics of these languages in terms of mother tongue, or the first language learnt (at home) in childhood

\section{Table One: National Language Populations}

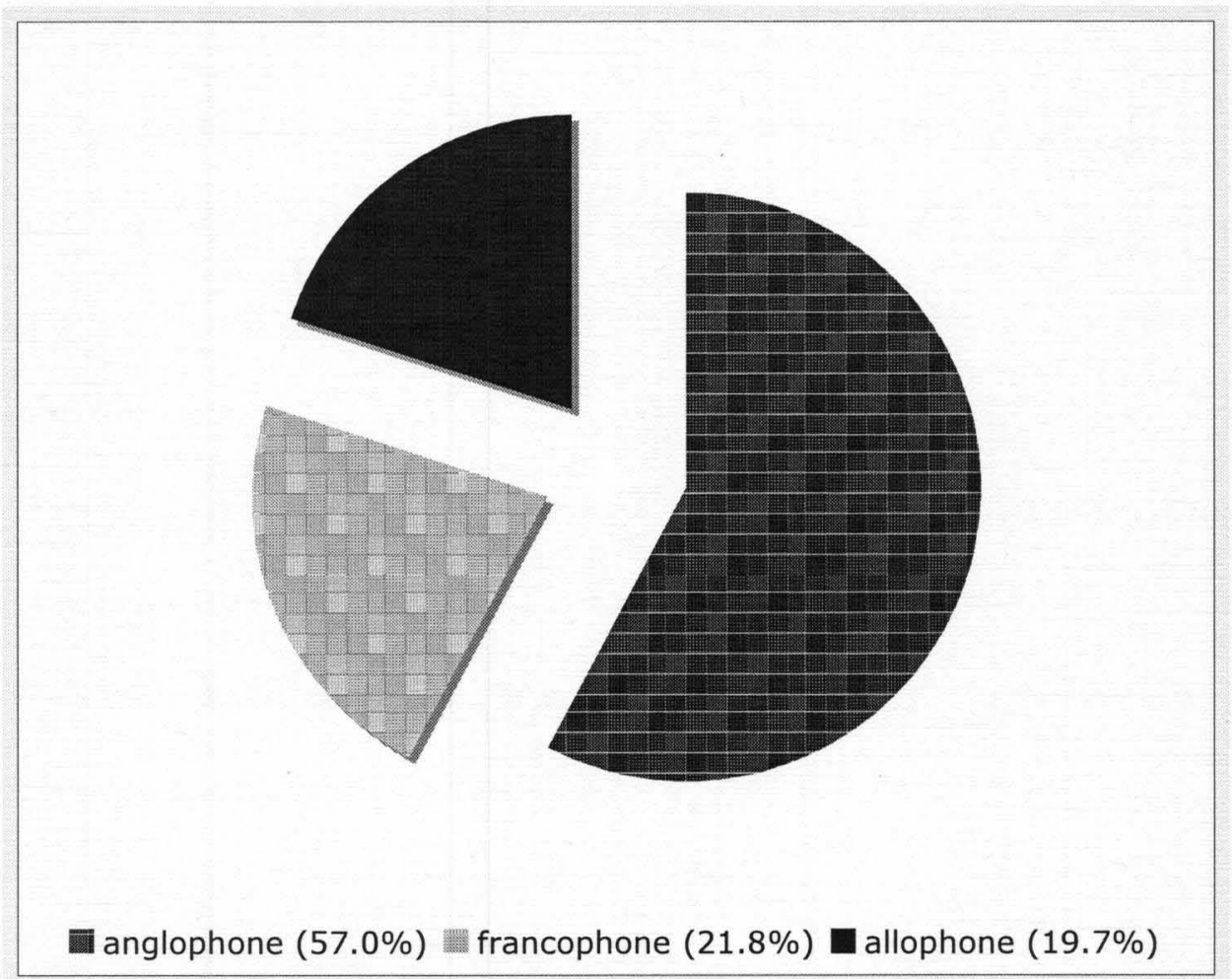

and still used. ${ }^{12}$ Moreover, as Table Two indicates, anglophone populations are dominant in three of four regions of Canada —Pacific Coast, Prairies, and Atlantic Canada.

The majority of Canadian provinces identify as anglophone-Alberta, Saskatchewan, Manitoba, Nova Scotia, Prince Edward Island, and Newfoundland \&

${ }^{12}$ One's mother tongue is often synonymous with one's heritage language. 
Labrador - while only one province-Québec —identifies as francophone. However,

Québec's linguistic population, while unique, is comparable to that of New Brunswick,

Table Two: Regional Language Populations

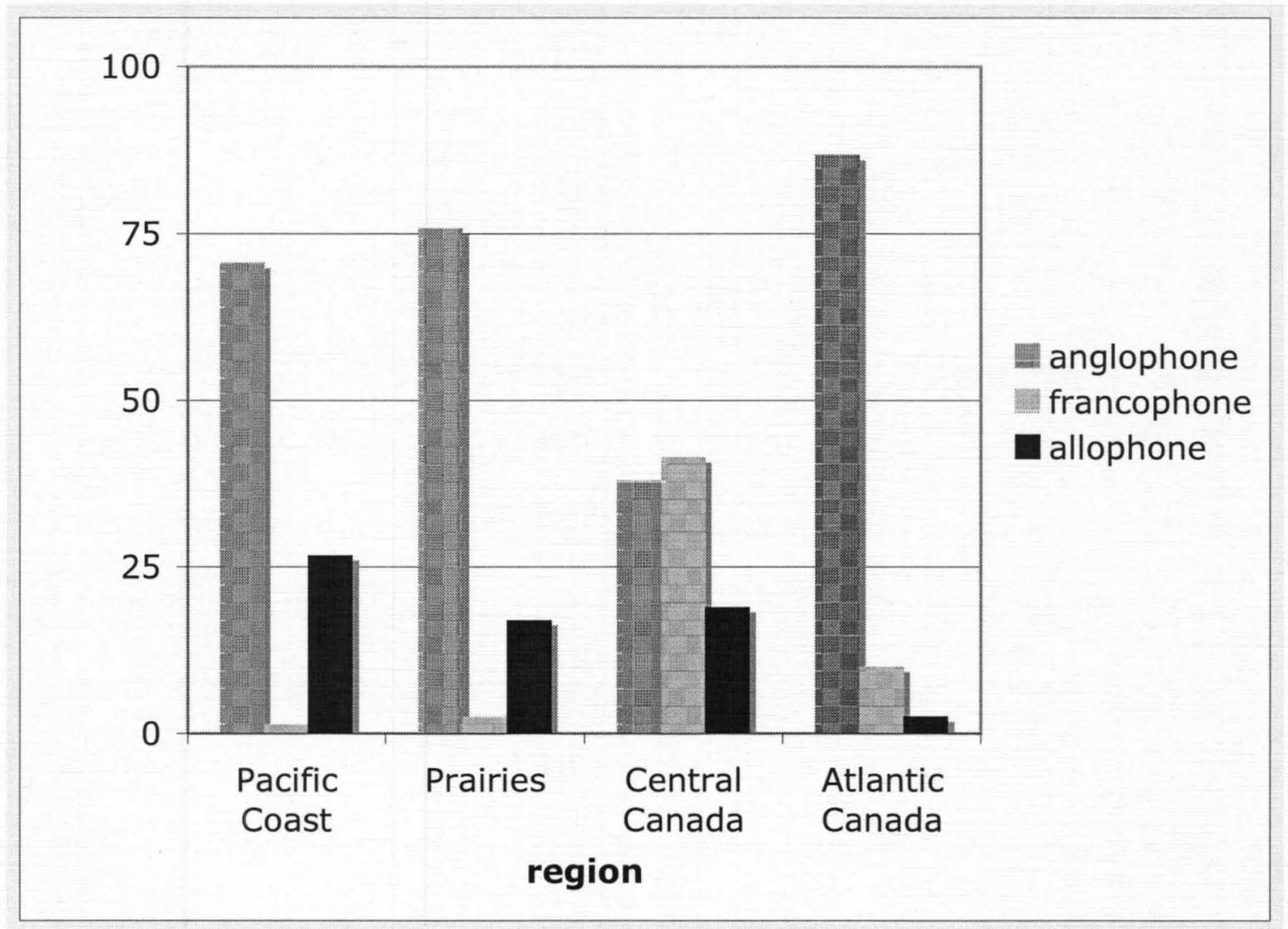

which is recognized as Canada's only bilingual province. ${ }^{13}$ This leaves Ontario and

British Columbia, two provinces with allophone speakers who comprise more than one

quarter of the total provincial population. Moreover, it is really only in Central Canada

\footnotetext{
${ }^{13}$ While New Brunswick is identified as Canada's sole bilingual province, Census Canada's linguistic analysis of this province, and all other regions, recognizes language spoken in terms of first language learnt at home, which in New Brunswick is predominantly anglophone (64.4\%) followed by francophone (32.4\%). And while a large population of citizens from this province learn to communicate in both official languages, less than one percent identified as bilingual, in terms of first language spoken at home. Moreover, in each province Canadians who identify as English-French bilingual comprise less than one percent of the population, with the total national bilingual population standing at $.3 \%$.
} 
that the nation's linguistic diversity - in terms of the three language communities-is evident. In the remaining regions anglophone Canadians are the majority, with allophone, and then francophone populations following. Only in Atlantic Canada is there a pronounced francophone population, which is due to the inclusion of bilingual New Brunswick, rather than a high proportion of French-speakers in the four provinces. Tables Two and Three illustrate that in the majority of regions allophones make up a large minority, often outnumbering the francophones.

Table Three: Provincial Language Populations

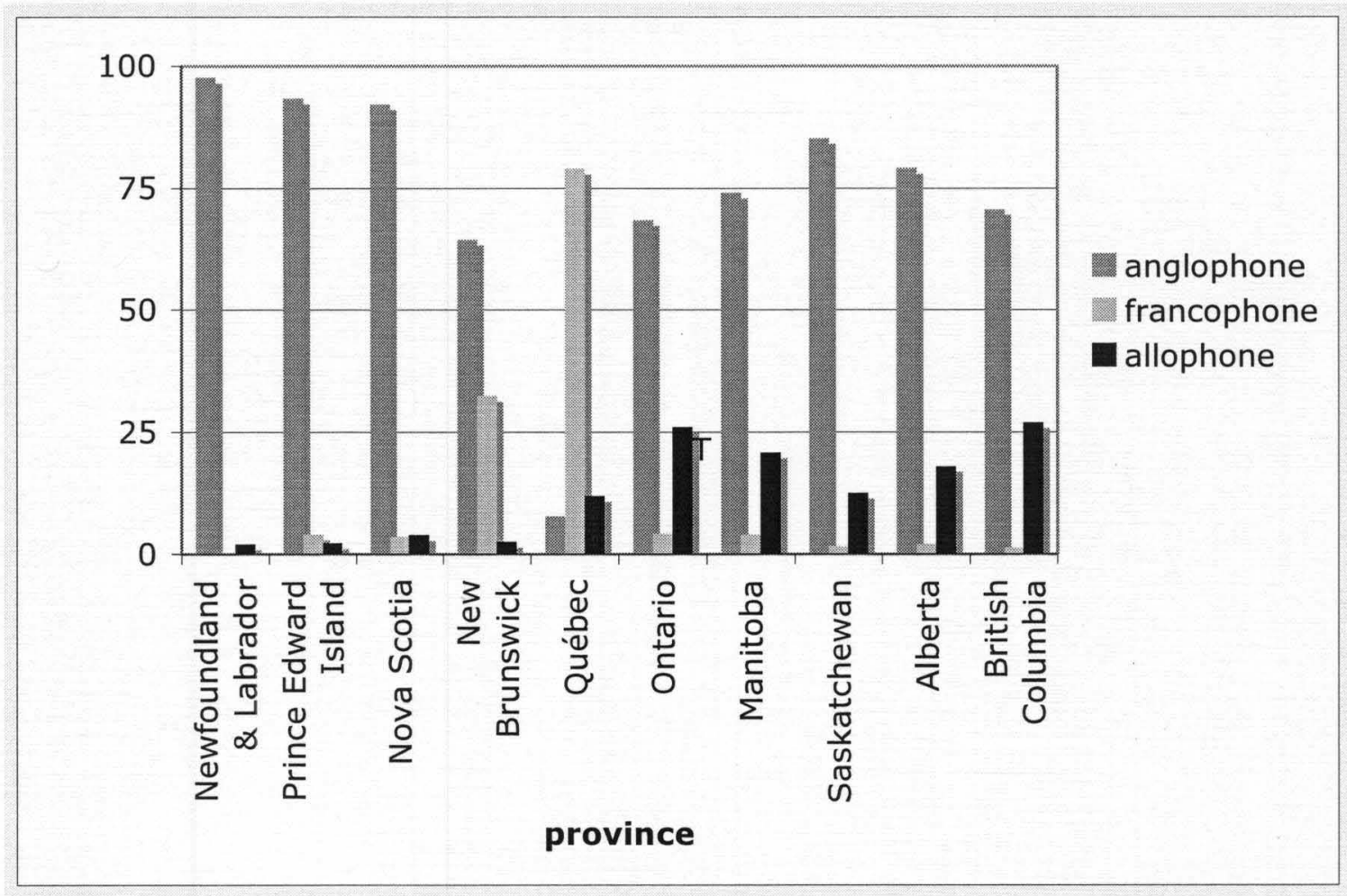

Table Three highlights that only Québec and New Brunswick have French language communities with large populations of speakers; moreover, in five of the ten provinces allophone populations are proportionally larger than those of the francophones. Ultimately, the data confirm that anglophones are the largest population, followed by 
francophones, and then allophones; however, the percentage differences between francophone and allophone populations are minimal. Yet, Canada protects the language rights of francophone Canadians in the Official Languages Act, but does not offer similar legislation in the Canadian Multiculturalism Act to protect allophone languages. A primary reason why the French language is protected extends beyond total population numbers - although these do play a role—and into government finance and national economics. As previously mentioned, the principle of "equal partnership" in language as well as the Royal Commission on Bilingualism and Biculturalism were established to appease a growing separatist French movement in Québec, which also led to French becoming an official national language. In terms of economics the government concluded that the cost of introducing and maintaining French as an official language would be offset by the cost of preserving national unity as well as the rich industrial and agricultural resources of the Québec province; however, protecting the rights of French as an official language is a costly endeavour. The Federal Government spends hundreds of millions of dollars annually in the upkeep of bilingualism in Canada. In regard to the protection of allophone language rights, the data concerning the cost of bilingualism make it obvious that it would be financially unfeasible to protect the many heritage languages of Canadians in the same way that the official languages are protected, which is a central reason why multicultural policy is often viewed as only a "symbolic gesture" towards equality. In other words, it would be an enormous task to protect the language rights of all allophone language communities because of the diversity of use, location, population, etc. However, creating spaces outside of home, heritage, or immigrant communities that value allophone languages is necessary to validate these languages in 
the larger community and would be less costly than developing linguistic protection comparable to that given to francophone Canadians.

The tensions as well as limitations present within federal multiculturalist policies of linguistic and cultural pluralism are accentuated by the degree of independence granted to provincial and territorial governments. Because provinces and territories function as independent socio-economic regions rather than as a cooperative many anomalies arise between regions concerning language and educational practices. These tensions exist because not all regions of Canada are inherently diverse and multicultural- two characteristics that the federal government capitalizes upon; the country's large size has worked to maintain populations that are also homogeneous. ${ }^{14}$ Each province and territory has been significantly shaped by regional history, immigration, and population dynamics, which has resulted in diverse linguistic communities in each region. The long history of this diversity can be traced back to the British North American Act (BNA), wherein the founding provinces of Canada obtained regional control over their educational systems. Consequently, Canada's geographic and linguistic boundaries are further emphasized by school systems that teach regionally specific curricula. The benefit of regionalized educational systems is that students primarily learn languages that are usable in their daily lives. Students in anglophone provinces learn English almost exclusively, unless parents choose to enrol them in French-immersion-the reverse, though unlikely, could also occur in francophone regions. Moreover, in areas where immigrant languages are high, such as Ukrainian in Saskatchewan and Chinese in British Columbia, there is also a level of language schooling available to primary and secondary school allophone

\footnotetext{
${ }^{14}$ Newfoundland \& Labrador, Prince Edward Island, and Nova Scotia all have anglophone populations greater than $90 \%$.
} 
students. However, the drawback to this method of linguistic education is that Canada's multicultural and multilingual heritage remains regionalized and not recognized nationally. The regionalization of education serves to limit the influences of federal multicultural policy in its lack of a national multicultural standard in education. Canada's regionalized education systems are province-specific; consequently, provinces with low levels of cultural and linguistic diversity can choose to ignore curricula that address issues of multiculturalism—despite national trends—-because these issues are not as socially and economically relevant in provinces with low ethnic diversity. An outcome of regionalized education is to focus on the population at hand and ignore the larger national population, which limits students' understanding of Canada's multicultural and multilingual heritage.

Specifically, in Canada, linguistic education is primarily controlled by provincial and territorial governments, although the 1969 Official Languages Act, which maintains language rights for English and French Canadians, also plays a role in the educational initiatives of every region. Thus, we see linguistic education as falling into two jurisdictions: provincial and federal. This duality has led to several provinces enacting their own language legislation. An example is Québec's Bill 101 (Loi 101), which requires all immigrant school-age children to enrol in French-speaking schools; in other provinces there is no requirement that students receive anglophone- or francophonespecific education. ${ }^{15}$ However, the only stalwart obligation set out by the federal government is that all school-age children are to receive some level of education in both the country's official languages. Moreover, the lack of federal influence on language

\footnotetext{
${ }^{15}$ A school-age child in anglophone Prince Edward Island may be enrolled in a Frenchimmersion school. The reverse is possible in francophone Québec, but extremely unlikely because of the strong cultural and linguistic heritage maintained in this region.
} 
policies in education, particularly in the case of allophone languages, has created a "hodgepodge of competing principles regarding language policy at the federal and provincial levels" (MacMillian 3). In certain regions provincial governments have made efforts to address linguistic diversity, but in others these issues have been overlooked. Examples of provinces that have addressed cultural and linguistic diversity include New Brunswick and Saskatchewan. New Brunswick has been home to Chinese immigrants since the 1890s; in the mid-nineteen-seventies this group formed the Chinese Cultural Association and with federal government assistance opened schools with oral and written instruction in Cantonese and Mandarin (Leavitt 378). In Saskatchewan the allophone population isn't particularly high; however, there is a long tradition of Ukrainian ancestry and as such Ukrainian is offered as a core language program in primary and secondary education. There is one Ukrainian bilingual (with English) school in the province, and until 1990 the federal government funded after-school and weekend language classes in Ukrainian (Denis 439). Yet, despite the fact that multiculturalism and multilingualism as well as biculturalism and bilingualism are central to how the federal government defines the nation of Canada, there remain regional divisions in terms of language, education, and citizens' rights to these-the most striking being the lack of multicultural curricula in a number of provinces. Additionally, because education is in the hands of provincial and territorial governments, the federal government's mandates of cultural pluralism play a small role in deciding what language and educational policies and practices to adopt, serving to further emphasize the country's multilingual tensions.

In accordance with grade-school educational programs, policies of pluralism are not overtly present within Canadian post-secondary schooling; again, multiculturalism is 
a federal policy whereas education is under the purview of the provinces and territories. For instance, Williams (159) posits that the failure of the federal government to integrate multiculturalism into educational curriculum does not reflect its policy, which is problematic because curriculum development is a chief agency for building mutually tolerant society through socialization effects. And while Canada has contributed financially to heritage language education (MacMillian 200) these programs are disappearing. Moreover, allophone families who take advantage of such programs must send their children to special language classes after the regular school day or on the weekends (Ashworth 84). However, Section 23 of the Canadian Charter of Rights and Freedoms, "Minority Language Educational Rights," which developed out of the 1964 Royal Commission on Biculturalism and Bilingualism, posits that the provinces and territories must work to expand curricula to include both official minority language communities at the primary, secondary, and post-secondary levels (Minister 17). And while the minority education referred to in Section 23 pertains to official language education, its obligations are applicable to multiculturalism particularly in regions with high linguistic diversity. However, as outlined above, the relevance of government mandates concerning multiculturalism differs province by province due to divergences in immigrant populations; as a result multicultural and multilingual ideologies are not consistent nationally. Many of the findings of this study that are directly linked to immigrant linguistic diversity will only be useful to a selection of provinces-those with substantial allophone populations. Moreover, within provinces there are also regional linguistic boundaries, some cities and towns may be predominantly anglophone while others may be francophone or allophone. For example, in Ontario- one of two provinces 
with markedly high allophone populations - a variety of ethno-linguistic specific pockets exist both inside Toronto and the Greater Toronto Area (GTA); in these areas multicultural initiatives by the government would be received much differently than in the city of St. John's, Newfoundland where the anglophone population exceeds $97 \%$. In respect to education, I would argue that high levels of linguistic diversity among citizens pushes federal policy into action. For instance, in Ontario the teaching of heritage languages throughout the public school system began in 1977, and now more than 60 languages are taught to more than 120000 students; this language instruction takes its place as part of the regular school day (King 409). Moreover, since 1988 heritage language instruction takes place if twenty-five or more parents in one school board request it (MacMillian 200). Thus, in Canada the inclusion of minority allophone education appears to be more of a bottom up rather than top down scenario, where the mandates of the federal government may come into play, but only when they are requested.

However, in the case of post-secondary education students often do not request the same minority language privileges that their parents may have expected and demanded during their grade-school education. In terms of this project, the central outcome is still bottom up - this is really only the work of one researcher realizing a need to integrate multilingual initiatives into the writing classroom and advancing her findings through a suggested curricular design-however, the advancement of the multilingual ideologies suggested in this project are intrinsically dependent on the federal government's multicultural polices, mandates, and legislature. For instance, the Charter provides that educational institutions should teach students tenets of effective 
communication, ensuring the continuation of a group's identity through the provision of a socially and culturally stimulating environment (Martel 16). In post-secondary education "effective communication" is primarily defined as academic discourse; the ability to communicate and succeed in a scholarly environment. In these situations, academic institutions are concerned with students' ability to communicate within the academic community rather than larger society. Moreover, because this study is dealing with multilingual linguistic populations, the ability to communicate outside the classroomnegotiating between languages when necessary--is paramount to the success of allophone students who live in ethnically diverse communities, particularly when these communities expect the use of both English and one's heritage language for differing situations. For example, individuals who work in ethno-specific jobs, such as those related to the food industry (e.g. groceries, restaurants, etc.), are often expected to be able to communicate to the specific ethno-linguistic group the store caters to as well as the larger anglophone or francophone population. Thus, for the purposes of this research, "effective communication" is concerned with students' abilities to negotiate between or within languages in specific cultural situations. Ultimately, it would benefit multilingual students to be able to draw upon their diverse language backgrounds in their efforts to develop tenets of effective communication within their writing. A writing classroom based in multiculturalism would promote effective communication through drawing upon federal policies in the encouragement of students' consideration of their linguistic and cultural heritage. Allophone students would have the opportunity to incorporate elements (e.g., words or phrases) of their heritage language in their writing, anglophone students would be invited to bring French or any other heritage language with which they might 
have knowledge, and francophone students English or another language Simply, students would be provided with a place to develop strategies of academic code-meshing. Yet, provincial and territorial governments often fail to recognize the merits of developing a multilingual agenda within curricula and feel no real pressure from the federal government to modify existing programs. I deem this a major educational oversight. This project differs from mainstream educational culture in its claim that a central flaw within Canadian education, in terms of linguistic pluralism, is that there is no real call to action in federal legislation to incorporate multicultural and multilingual perspectives within post-secondary systems. Moreover, as long as there is no pressure to consider the national agenda of linguistic and cultural pluralism within the classroom, multiculturalist policy will remain symbolic rather than tangible and usable. Advocates of multiculturalism need to work in partnership with the federal government, because this is the regulatory branch of multicultural policy, as well as with post-secondary teachers and administrators, particularly those in culturally rich regions, in order to incorporate pluralist agendas into the classroom. One way to accomplish this task is through the adoption of writing curricula that explore Canada's multicultural and multilingual heritage, through exploring the histories of students.

Martel (9) describes cultural pluralism as central to notions of difference between groups in terms of attachments, customs, values, and languages, concluding: "culture is therefore central to notions of instruction and school management." Moreover, because populations of English and French speakers as well as First Nations and immigrants vary significantly by province, and because "each province has its own school system formed by history, immigration, the size of its territory, the demands of different groups, laws 
and political affinity" (Martel 8), it is plausible that there is little to no attention paid to multicultural and multilingual issues within regular curricula--especially in regions with homogeneous linguistic populations. Accordingly, a central aim of this project is to better understand how linguistic culture exists within post-secondary writing classrooms. Incorporating federal ideologies of Canadian multiculturalism into post-secondary education would allow teachers, administrators, and policy makers to positively utilize aspects of linguistic pluralism in writing classrooms, particularly in terms of effective communication via code-meshing, future students will be provided a service that the federal government has requested, but current provincial and territorial governments have overlooked. Further, if the federal government, in partnership with post-secondary educators positioned pluralist agendas as pedagogically useful, provincial and territorial governments may be more apt to fully consider the benefits of integrating these policies within regional curricula.

Making connections between Canadian bilingualism and multilingualism is a necessary step in promoting the latter cause. While Canadian multicultural policies support the "acquisition, retention and use of all languages that contribute to the multicultural heritage of Canada" (Canadian Multiculturalism Act), these policies do not carry the same weight as bilingualist policy; bilinguals have been granted language rights whereas allophones have only been conferred privileges. In other words, allophone languages are recognized as integral to Canadian society and heritage, yet there is not the same level of protection paid to them as Canada's official languages within legal and educational institutions. As such, allophone languages are assigned to spaces outside the 
legal and educational. A consequence of this is the possible disappearance of allophone languages and culture over time.

The remainder of this chapter analyzes the policies and practices that affect each language group's population both provincially and nationally — paying special attention to allophone populations. The five factors that will be used to discuss policy and practice include a numerical assessment of language groups, the degree to which language exists as an identity marker, the value of language as commodity, a consideration of Canadian linguistic ideologies, as well as a survey of linguistic pluralism in post-secondary education.

Regardless of provincial and federal policies and initiatives that support either biculturalism or multiculturalism, the reality faced by linguistic communities is that the greater the number of a language's speakers the more power, rights, and privileges the language and its speakers enjoy. The data from Tables One, Two, and Three (pages 7, 8) demonstrate that anglophones in Canada are the linguistic majority by nearly two thirds. Canada has been and continues to be anglophone in terms of ancestral origin and linguistic ability. At Confederation, the population was British (60.5\%), French (31.1\%), other European (6.9\%), First Nations (0.7\%), and other (0.8\%) (Minister 6); the statistics collected by the 2006 Census provide a relatively unchanged linguistic composition, with English (57.0\%), French (21.8\%), allophone languages (19.7\%), and First Nations $(0.7 \%)$. Of note, however, is the increase in "other European" or "allophone language" groups; this growth positively correlates with increased immigration to Canada, which has been recorded as steadily rising since the mid-nineteenth century. Thus, while both French and English speakers had settled in regions of Canada prior to Confederation, 
since 1867 there has been and continues to be a significant influx of immigrant, allophone Canadians into the country. Nevertheless, due to the more recent establishment of allophone speakers as Canadian citizens, in relation to anglophone and francophone Canadians who had settled before Confederation, as well as the huge diversity of allophone languages in Canada that exist in comparatively small populations across the country, immigrant languages remain marginalized in Canadian society.

Due to their larger population, English-speaking Canadians enjoy significantly more language rights and privileges than the other four groups. Throughout Canada English is the dominant linguistic force in industry, politics, economy, tourism, etc. Problematic in anglophone predominance are Canada's attempts to create a nation based not within monolingual ideologies, but a culture of bilingualism as well as multilingualism - a goal which this project seeks to address in terms of post-secondary writing classrooms. The following paragraphs will further address the minority language issues that continue to define francophone, First Nations, and allophone speakers in terms of the anglophone majority. The first step in helping students identify with and take pride in their heritage languages in the university setting is through creating a space where students can critique and question language barriers that face all Canadians.

For instance, across the globe Canada is recognized as being an anglophonefrancophone bilingual country; however, most citizens (and students) do not rely on both languages in their daily lives. The skills of spoken and written bilingualism are really only evident in the provinces of Québec and New Brunswick. Nevertheless, because French is an official Canadian language francophone Canadians hold many rights that First Nations and allophone citizens still struggle towards, including access to speakers of 
their languages within all levels of government. What is unique about francophoneanglophone bilingualism in Canada is that both languages, though one is primary and the other secondary, maintain linguistic rights and institutional language obligations - other minority language groups do not have a collective right to language (Li 134). This reality is primarily due to the extraordinary economic costs of recognizing all citizens' languages. It would be financially infeasible to grant allophone languages the same level institutionalization as is held by French and English. Nevertheless, despite bilingual legislation, francophone Canadians have remained in the minority-particularly in terms of population size - and as such continue to fight for the equality of the French language. English Canadians do not have the same pressure to conform as do French Canadians because two thirds of the country speaks English (Table One, page 7). Due to this, some argue that the government's support of bilingualism remains superficial because many citizens choose to remain monolingual anglophone. This "superficial" support of bilingualism is an interesting point of discussion in terms of multilingualism because of the divergence in the two policies. Francophone Canadians have linguistic rights and freedoms that have not been granted to allophones; yet, the fact that francophones exist as a minority and continue to struggle for linguistic equality tells a different narrative of linguistic pluralism—a narrative that the federal government's policies of linguistic biculturalism and multiculturalism work to dismiss. Moreover, this battle for minority language rights against the anglophone majority is fought by each minority language group.

The smallest group of minority speakers in Canada are the First Nations peoples, who maintain the argument that their home languages, rather than French and English, 
are the country's founding languages and as such should be given the same treatment as Canada's two official languages (MacMillian 181). This claim for linguistic equality is regularly challenged by the argument that official languages must reflect the size of linguistic communities. French and English are official languages because, respectively, one quarter and two-thirds of the population use these languages in daily interactions, whereas less than one percent of Canada's total population speaks First Nations languages. There is also a lack of value associated with First Nations languages and global commerce. Ultimately, First Nations peoples do not possess the same language rights and privileges as do francophones because there are so few of them, the implication being that it would not be worthwhile to grant minority language status to First Nations peoples because of their small total population proportion. Additionally, there are a large number-fifty-three-First Nations languages, which would create further problems if each were to be granted official status. In terms of francophone official status, all written and spoken government agencies must provide services in French and English; however, providing these services in an additional fifty-three languages, particularly when the population is limited, would be extremely costly. Nevertheless, for First Nations peoples language is more than a communicative tool; it is central to cultural membership. As such, the retention of traditional languages functions as cultural capital within First Nations communities and the national expectation that this population should be versed in English or French, rather than their home language, is not in keeping with the Canadian government's commitment to cultural retention. Moreover, this retention focuses upon immigrant culture, which some may argue serves to erase First Nations people from the mosaic. 
Many of the issues surrounding language retention in First Nations groups are comparable to those of allophone Canadians (e.g. diversity of home languages; cultural membership); the primary difference is that the number of allophone speakers is much larger. The allophone population in Canada is roughly equivalent to that of francophones; moreover, allophone populations are also consistently larger than francophones in the Pacific Coast and Prairie provinces (Table Two, page 7). Nevertheless, despite the substantial population of allophones across Canada and the multicultural policies that promote linguistic retention, few immigrant languages have L1 survival rates of fifty percent or better; moreover, first and second generation immigrants show marked differences in their ability to retain heritage languages-as generations increase language ability decreases significantly (Li 135, Laponce 82 ). Unlike biculturalist and bilingualist federal legislation, which is grounded in preserving the francophone minority's language rights, initiatives that encourage multiculturalism and multilingualism do not protect immigrant heritage language rights (MacMillian 194) or language retention programs (Comeau 40). This is especially problematic in light of the fact that Canada continues to pride itself on the pluralist agenda of the cultural mosaic. Li (140) suggests,

There is a danger that Canada could lose its linguistic diversity because of insufficient institutional and social support to preserve non-official languages beyond the first generation of immigrants.

Thus a central aim of this research is to establish who our students are, and in turn better meet their needs as multilinguals - needs that are acknowledged but not necessarily supported by government policies of multilingualism and multiculturalism. Allophones, as an extensively large population in Canada, exist as a minority language group; nevertheless, their numbers are significant. Bringing allophone languages into the writing classroom as a point of discussion and inquiry would not only be in keeping with 
Canada's multiculturalist agenda, but it would also create a place for students to consider their own linguistic identity and diversity in the context of others, which is an ideal task in critical thinking.

Although the situations surrounding minority language groups are quite different for francophones, First Nations, and allophones, the fate of each population's cultural structure is dependent on language retention. This retention often occurs in the home and in home communities, but is not always a component of public schooling, particularly post-secondary education. The creation of spaces in universities and colleges where heritage languages can be learned and used by students is not only in keeping with federal legislation, but is also incredibly important to language retention in terms of the many identity challenges placed upon students who enter post-secondary education; at this stage in their lives many students have moved away from home and, consequently, are removed from their home language(s). Working under the auspices of the federal government writing classrooms could be designed as ideal spaces to respect and maintain heritage languages, promoting cultural pluralism as well as acceptance. In the case of allophone Canadians, the presence of bilingual initiatives - and absence of multicultural ones-within the sphere of education essentially works against the preservation of their linguistic identities, pushing these students toward anglophone and francophone assimilation, which leads to allophone language loss. This phenomenon is comparable to "bilingual" education in the U.S., which mandates assimilation to English and suppresses the use of immigrant languages. In many countries there is no room to question such assimilative forces; however, in Canada, a nation that welcomes and encourages diversity, we must question why multiculturalism is not working - or only functioning 
symbolically - for minority language populations and explore ways in which multiculturalist policy can be used to tangibly benefit these populations.

For minority language speakers language functions as more than a communicative tool, it is an identity marker and maker. We have looked at how language is central to cultural identity in First Nations, francophone, and allophone groups, but language in Canada also works as a regional identity marker and maker. Language spoken has strong associations to province or territory of residence. Because Canadians have extremely strong ties to their home province or territory language and dialect are integral in maintaining community ties, even when members of that community have relocated to other regions of the country. While regional dialects are multiple within provinces and territories and are used by insiders and outsiders to categorize speakers, it is the clustering of minority language communities within specific regions that is especially intriguing, particularly because Canada's self-representation as a bilingual and multicultural country alludes to nationwide linguistic diversity. Of Canada's thirteen regional districts it is only the Territories, New Brunswick, Québec, Ontario, and British Columbia that have large populations of minority language groups.

In the Territories reside the largest populations of First Nations peoples, though there are smaller populations of aboriginal speakers in a number of provinces. In these communities those fluent in aboriginal languages are mostly middle aged or older, consequently First Nations peoples continue to worry about the fate of their cultural structure. The prospect of total language extinction looms, and with such a fate would also come a loss of cultural identity (MacMillian 186). Yet, without First Nations' languages being validated by the Canadian government there remains the possibility of 
language extinction as more and more speakers are raised in environments where the understanding of English or French is necessary for inclusion in Canadian society. MacMillian (183, italics original) argues,

Where languages are central to the daily life of established communities in a country, it is readily arguable that a concern for the equal consideration of interests requires state recognition of certain languages. Where languages are used in the daily lives of people, they reflect their essential interests.

One of these "essential interests" is the construction of not only culturally-specific identity, but pride in one's identity. Because heritage language use and knowledge is essential to identity construction in minority language groups, there is an urgency to elevate the status of First Nations languages before home cultures disappear. Scott Lyons (98) recognizes the same urgency existing on reservations across the United States, tribal languages are precious heritages and the best indication of a national difference from other nations...so much traditional knowledge is kept secure in heritage languages, and when the latter goes, so does the former.

First Nations language rights will remain a point of contention because they are so intimately tied to culture, history, and daily life. Moreover, in the Canadian context, this linguistic group's struggle will remain separated from other minority language groups because of the possibility of language extinction and, thus, cultural extinction.

Francophone Canadians have been successful in acquiring language rights because they argue that the French language is central to their francophone identity, and hence losing language would equate to the loss of French-Canadian history and culture. However, what this group of speakers and First Nations speakers share is a commitment to home languages, which they view to be fundamental to cultural retention. Because Québec is overwhelmingly francophone, their language rights are rarely challenged, especially within provincial borders. Additionally, in Québec there is a low tolerance of 
English, except in districts of Montréal. Conversely, francophones in New BrunswickCanada's only bilingual province — reside in a province where anglophones retain majority status (64.4\%) and francophones constitute only a large minority (32.4\%). The distinctive identity marker between francophones in Québec and New Brunswick is that the latter is home to a unique population of French-speakers: Acadian francophones, who are descendants of seventeenth-century French colonists. And while francophones in Québec have easy access to their linguistic history and identity, francophones in New Brunswick often feel like foreigners despite four centuries of presence (Comeau 39). It is most likely for this reason that Acadians have worked to maintain their distinctive francophone identity and not assimilated to the larger populations in Québec. However, despite the inclusion of French as an official language Acadians still struggle to maintain their cultural heritage and identity because Acadian French has been designated as a variety distinct from Québécois French. In turn, due to the duality of official languages and unique form of French in this province, there is a culture of linguistic acceptance that is maintained in provincial policies. For instance,

New Brunswick's official policy on multiculturalism 'recognizes the great value of cultural diversity set in the context of the province's official bilingual status'. It 'strives for a unity which does not deny or eradicate diversity, but which recognizes and transcends it'.

(Leavitt 374)

New Brunswick is unique in that so many of its citizens maintain knowledge and use of both official languages, but also because its linguistic polices insist upon the recognition of diverse cultural identities. It can further be argued that because home language affiliation is so divided in this province there is more of a tolerance for diversity and cultural preservations through linguistic cultivation. 
In Ontario and British Columbia, provinces with the highest allophone populations, the role of language as an identity marker is somewhat different than other minority language groups because within these populations of speakers exist a variety of languages. The difference between the two provinces is that in British Columbia the allophone population is dominated by Chinese immigrants, whereas in Ontario the linguistic communities are much more diverse. Consequently, how language functions as an identity marker and maker in the two regions is quite different as British Columbia has a larger and more unified allophone community. Ontario is home to more than half of the immigrants who come to Canada, with the majority settling in the Greater Toronto Area (GTA) where one in three speakers has an allophone mother tongue- - the GTA has been described as the most multicultural region in the world. In regard to language as an identity marker, maintaining community ties through language is easier for most allophone speakers in this region because of high rates of linguistic diversity and a general societal acceptance of this diversity. Moreover, because of the number of diverse populations, there are palpable and discrete linguistic and cultural communities that are dependent upon the maintenance of allophone home languages. Thus, in Ontario, more than any other province, language as an identity marker is most obvious and accepted. In Ontario, particularly the GTA, the value of language as a commodity is also most evident. In this region language is intimately tied to community and culture, which serves to drive a variety of market enterprises including restaurants, groceries, fashion retailers, bookstores, etc. And, while common to the GTA, ethno-specific immigrant malls and concentrated ethnic business areas are found in all urbanized areas of Canada (Li 139). Thus, on the most basic level, language--particularly allophone languages-work to 
drive ethno-specific trade through reinforcing community affiliations of language and culture. As such, in British Columbia and Ontario, as well as other areas in the country where large homogeneous populations of immigrants have settled, there exist higher levels of accommodation of certain regionally-specific allophone languages.

However, the commodity of language has evolved from segregated shopping districts (e.g. little-Italy, china-town, etc) into a position of centrality in Canadian identity building. The linguistic and social diversity of Canadians has become a form of human capital used by the government to promote the development of Canada as a veritable leader in global relations ( $\mathrm{Li}$ 142). In efforts to promote multiculturalism, rather than anglophone or francophone assimilation, the government has taken the stance that "multiculturalism creates a greater appreciation of the value of culture and language which works to the benefit of all Canadians in all parts of the country" (Munro 13). Thus we see the government as central in the push towards maintaining a multiculturalist national character within trade relations. Multicultural policy positions linguistic pluralism as a provider of "multiple literacies" that function in Canada's pursuit of "global economics" in regard to trade, employment, science and technology, globalization, as well as peace and security.

Multiculturalism has become one of Canada's most sought after renewable resources where diversity functions to bridge world marketplaces, positioning Canadians to excel in areas of global commerce, cultural exchange, and political dialogue (Williams 164). Consequently, in recognizing and explicitly including anglophone, francophone, and allophone experiences in the classroom, would be teaching critical reflection, through the acknowledgement and assignment of "multiple literacies," providing students 
with a "global" way of thinking that would allow them to communicate with diverse audiences - two outcomes that are conceivably crucial aims for many writing courses. Creating a space for intercultural dialogue to play out will prepare students to use the skills they learn from writing classrooms in real world situations such as paid work places and community spaces.

Canada has been described, most simply, as "an immigrant country" (Li vii), a country where diversity dominates, a space for all ethnicities to come together and coexist via intercultural dialogue; however, the distinction between whether these interactions are discrete and coexisting or, interacting and thus, mutually transforming is not always clear. Pluralist language ideologies are a prominent motif in all areas of federal governing, introduced and maintained as an instrument which enables immigrants to come to terms with their new environments and combat racism, thereby promoting civil liberty and social justice (Williams 160). Governing agencies hold the view that the maintenance of dynamic cultural lines and linguistic policies serves to preserve the nation's cultural mosaic. Because Canada is shaped by the discrete interaction of diverse and self-defined groups of peoples, varied and changing notions of identity, community and nation exist so as to enable belonging (Schaub et al xi). While regional linguistic markers are often what citizens most easily associate with; it is plurality (of languages and cultures) that is quintessentially Canadian.

However, the exclusion of allophone language education in higher learning is problematic on a number of levels, but for minority language students this exclusion is emphasized in their movement away from home to attend universities and colleges, a consequence being the loss of home language culture as well as language. Thus, there is a 
sacrifice to membership in immigrant heritage culture, gained through the maintenance and usage of heritage language and culture, when post-secondary institutions only legitimize English and French. In Critical Academic Writing and Multilingual Students Canagarajah explores how the linguistic differences multilingual students bring to the classroom can be embraced by instructors and viewed as a resource. Arguing against the long held ideology that students with diverse linguistic backgrounds have strong tendencies to create deficient texts, Canagarajah juxtaposes two methods that are often used in the writing classroom. He offers the conversion approach and the negotiation approach. The first is comparable to code-switching, and the second to code-meshing. The conversion approach calls for home languages to be used in home environments and academic languages to be used in school, Canagarajah suggests that this method creates either/or binaries and is not inclusive; he, instead, presents the negotiation approach, which allows a meshing of languages and identities. In the negotiation approach home languages are brought into school, interacting with each other in student writing. In order to establish multicultural curricula a negotiation approach should be adopted, which allows a meshing of multiple worldviews; home languages would be brought into the school and school languages into the home. Laponce (84) suggests that languages need to be given social recognition outside the immigrant community in order to be maintained. Establishing multiculturalism as central to Canadian writing instruction will connect culture to the classroom, thereby recognizing the importance of the outside community as well as providing federally sanctioned multicultural learning programs.

Bumsted (652) articulated, "by the end of the twentieth century, most Canadians appeared to have accepted the principles of multiculturalism." This may be true in terms 
of the larger Canadian society, but the "principles of multiculturalism" have not been as accepted in educational policies and initiatives. This project aims to better understand how writing classrooms can adapt multicultural policy to serve the needs of allophone student populations, in terms of language and the writing classroom, language and pedagogy, language and cultural identity, as well as language and globalization. To date, most educational research in Canada concerned with linguistic communities and learning explores anglophone and francophone relationships in colleges and universities; however, this chapter indicates that because a large group of minority speakers in Canada are allophones this population of students deserves further attention. Thus, the remainder of this project will work to connect the dialogue surrounding Canada's Multiculturalism Act with allophone student populations in terms of post-secondary writing instruction. 


\section{CHAPTER THREE \\ Methodology}

You know my method. It is founded upon the observance of trifles.

- Sir Arthur Conan Doyle

\section{$\underline{\text { Introduction }}$}

This project emerged out of personal inquiry into the pedagogical experiences and struggles I encountered as a writing instructor who relocated to a new region of Canada. Moving from the province of Newfoundland and Labrador to Ontario was overwhelming, particularly in terms of my experience communicating and working with diverse linguistic communities. In Newfoundland and Labrador, the anglophone population stands at $97.6 \%$, while in Ontario it is $68.4 \%$. The linguistic uncertainty I experienced when working with students in Southern Ontario, as well as my subsequent education in areas of multilingualism and composition scholarship in the U.S. has forced me-for the first time in my life - to seriously consider how language(s) exists within Canada. Not only did I come to see that, in various circumstances, anglophone speakers are members of a linguistic minority, but during this period I also encountered multilingual allophone students for the first time.

By employing methods of ethnographic research, this study garners a better understanding of how allophone students function within the academy and how issues of language and cultural experience affect this population's writing processes. The 
descriptive practitioner research I have chosen to conduct relies on observation and analysis rather than a conscious restructuring of the classroom environment. This project's primary purpose was to obtain data concerning student language demographics, to allow/enable a more comprehensive understanding of how multilingual students see their language knowledge function in the writing classroom, their writing, and their feelings towards writing. A further aim of this project is to determine how successful multilingual students are in appropriating "academic" discourse in their post-secondary writing, by identifying the strategies they use to manoeuvre among languages and language communities.

This study took place in Windsor, Ontario, located in the southernmost area of the country. The city population is just under a quarter of a million. The language breakdown of the area is $67 \%$ anglophone, $28 \%$ allophone, and $4 \%$ francophone. Of the allophone population, half use their mother tongue as first language at home. Moreover, of the city's total population, $28 \%$ are immigrants, with $91 \%$ of all residents holding Canadian citizenship. University of Windsor, the post-secondary institution where this research took place, is mid-sized, with approximately 16,000 students. The university is selfdescribed as internationally oriented, with broad student diversity. Further, this institution prides itself in its "awareness and appreciation of difference-difference in ethnic backgrounds, difference in cultures" (University of Windsor).

Data was collected from students enrolled in composition, a first-year writing course offered through the English department. At University of Windsor, ten to twelve sections of composition, English 26-100, are offered in the Fall and Winter semesters (see appendix for syllabus). This writing program is somewhat anomalous in character to 
the discipline of Canadian "Writing Studies" in its similarity to U.S. composition programs and courses, particularly its focus on personal inquiry through critical reflection, rather than discipline-specific writing. As outlined in the syllabus, 26-100 is designed to help [students] gain greater fluency, confidence, and control as writers through an exploration of [their] own lives, communities, and cultural experiences. [Students] will use writing as a way to learn and to critically examine the world.

And, like many composition courses in the U.S. enrolment is capped, at the University of Windsor no more than twenty students can register per section. Thus, a very small number of the total student population enrols in this course. Students can take this course at any stage in their university career, though it is encouraged as a first-year course.

Oftentimes students who are further in their academic careers choose to take this course because instructors have commented upon their poor writing abilities. The content of the course (e.g. readings, assignment topics) varies with instructor, though each follows a pre-designed syllabus. Central to the course are the development of a final portfolio that requires a selection of genre-based writing (e.g. narrative, expository, descriptive, ethnographic, research, multi-modal, etc.) as well as attention to the stages of the writing process (e.g. invention, drafting, peer-review, etc.).

The data collected from students enrolled in this course pay special attention to multilingual students' perceptions of their heritage languages in terms of the monolingual and monocultural expectations maintained in current academic discourse communities. In doing so, this study contributes to the growing research on multilingual student populations globally (Bhabha; Blommaert et al.; Canagarajah, Critical Academic; Canagarajah, "Multilingual Writers"; Canagarajah, “The Place”; Canagarajah, "Toward”; Canagarajah "Lingua"; Horner and Trimbur; Leung et al.; Rassool), as well as expanding work in this area of Canadian research (Hayday; Heller; Taylor) which most often 
focuses on anglophone-francophone communities and limits the object of study to French and English. Consequently, this project extends the Canadian discussion to allophone post-secondary students who maintain their immigrant languages outside the university.

\section{Review of Problem}

In recent years, there has been an increase in research studying academic writing contexts and the social practices of students and teachers. The social practices studied herein are associated with linguistic communities, specifically the language practices of allophone students. This project is ethnographic in nature due to its focus on real-world contexts, with no experimental conditions; it attempts to understand community events from information provided by participants; data collection from a number of sources; as well as analysis of data in terms of the meaning and function of participant actions. In this study, participants were asked to talk about texts, where data were collected via questionnaire, face-to-face interview, and email. Lillis explains that using ethnography as methodology creates opportunities for contextualizing research on academic writing. Central to this methodology is the literacy history interview (eliciting autobiographical accounts of language and academic literacy learning in order to understand current situations) and cyclical dialogue around texts (focused talk wherein topics develop from the literacy history interview). Both of these data collection techniques-the literacy history interview and cyclical dialogue around texts-were central to collecting the data for this study. A series of general surveys were distributed, followed by later interviews with focus students. This strategy of implementing three or more systems of data collection ensured triangulation, that is to confirm validity and generate a "thick description" (Lillis 363). 
The data collected for this study offer insight into the various ways student multilingualism operates within Canadian post-secondary writing classrooms at one midsized university in Southwestern Ontario. The data concerns multilingual students who have an allophone or heritage language background; to enable efforts to better understand this populations of students this study focused on the following primary issues: the Canadian contextualization of the U.S. definitions of multilingualism within composition scholarship $^{16}$; a comprehensive definition of one population of Canadian multilingual students; an application of past research in terms of language exploration and cultural identity; and an analysis of the function of the Canadian Multiculturalism Act within Canadian post-secondary education systems. In order to provide sufficient analysis of the situation, the concerns outlined above are represented in the following research questions: Of the definitions of multilingualism defined/understood in US composition scholarship, which one best fits the context in Canadian Writing Studies?; What are the defining characteristics of the multilingual students under study?; Why is it important to explore language in terms of cultural identity?; and, To what extend does the Canadian Multiculturalism Act play a role in education within the academy in Canada?

In composition and writing studies scholarship, descriptive research is perhaps the most widely used because it focuses on observation and analysis of situations/environments, with little to no restructuring of said environment. In line with standard research practices in the field, the current project was designed around existing sections of first-year writing and altered the classroom environment minimally ${ }^{17}$. This approach was used because this study is concerned with creating a preliminary analysis

\footnotetext{
${ }^{16}$ Eradicationism, code-switching, and code-meshing. See Chapter One.

${ }^{17}$ The researcher was only present in the absence of the instructor and was present only to distribute questionnaires.
} 
of student demographics in terms of language use, community affiliation, and academic writing ability. As such, this project offers situated interpretations of the issues concerning Canadian multilingual students and writing scholarship rather than exhaustive conclusions. This study anticipates future research in this area that will move towards the application of test environments.

Consequently, a major drawback of this research, in terms of ethnographic methodology, is that the study took place over only one semester (12 weeks), rather than a longer period of time where the researcher would become a member of the community. This problem was exacerbated by my presence only during questionnaire distribution and student interviews ${ }^{18}$; no participatory tie was created between me and the participants. However, my distance from the classroom environment and the collection of multiple data sources (questionnaire and student interview) did allow me to remain consistently situated and collect data systematically. Moreover, the series of focus-student interviews offer a case-study approach, providing a depth of observation that was not achievable via questionnaire. Additionally, the decision to implement case-study techniques enabled the collection of sufficient data to observe variation between subjects. Future studies would aim to create a more intimate connection between the research and student experiences with writing, wherein the researcher may also take on the role of instructor.

\section{Description of Data Collection}

Data were collected in the fall of 2009 from students enrolled in first-year composition. Undergraduate participants engaged in the study by completing three anonymous language questionnaires that were distributed at the beginning, middle, and end of the

\footnotetext{
${ }^{18}$ University of Windsor's Research Ethics Board (REB) would not approve a study that required the researcher to regularly sit-in and observe classes.
} 
semester ${ }^{19}$ (see appendix). Of this core group of students a selection were invited to participate in video-taped case-study interviews; however, only two students took part (one female and one male) ${ }^{20}$.

Data were gathered from five sections of English Composition via anonymous questionnaire. Language questionnaires were distributed to students in an effort gain a broad understanding of how participants use language inside and outside the writing classroom. Questionnaires were administered at the end of the class period, in the absence of the course instructor, and took no longer than ten minutes to complete. The questionnaires were anonymous; however, students generated anonymous codes so their responses throughout the semester could be tracked. Participants were also provided with a contact sheet that they completed if interested in taking part in follow-up interviews.

The first questionnaire, distributed during the third week of classes, was broken into two sections: My Background and How I Use Language. The first section asked yes or no questions concerning gender, year of education, birth country, and first language(s) learned to speak, write, and read. This section also provided a list of categories scholars most regularly use to refer to multilingual speakers and asked students to select whichever they identified with. The second section was concerned with language use among students and their families. Students were asked to identify which languages they are familiar with-excluding languages studied only in school - and scale their use in terms of comprehension as well as speaking, reading, and writing. Participants were then asked to scale the same questions in regard to their parents and grandparents. Students were also given a variety of situations (e.g. talking to parents; writing to friends) and

\footnotetext{
${ }^{19}$ During weeks three, seven, and eleven.

${ }^{20}$ All students were invited to participate in the interview process; however, only students with multilingual capabilities were contacted to participate.
} 
asked to rank these situations in terms of English language use. Finally, participants were required to identify their best language(s) and the language(s) they feel most comfortable using.

The second questionnaire, distributed during the seventh week of classes, included the sections: How I Use Language in My Daily Life and How I Use Language at the University. The first section was concerned with how participants mesh languages in day-to-day activities; asking students if they ever choose to mesh languages, in what situations language meshing occurs, and when meshing happens (e.g. during speech and/or written communication). The latter section looked at how students mesh languages at the university and provided questions that dealt with both written and cognitive activities. Participants were also presented with a variety of classroom situations and asked to consider these situations in terms of language and language-meshing expectations.

The final questionnaire, distributed during the twelfth week of classes, dealt explicitly with the current class section and included three sections: Why I Chose This Class, How I Use Language in This Class, and How I Use Language in My Final Portfolio. As first-year writing is not a required course the first section of the final questionnaire sought to better understand why students are enrolling in first-year writing as well as who these students are in terms of academic background. Questions in this portion concerned students' majors and academic expectations. The second section was concerned with the writing process. Questions explored the use of English or the meshing of languages at different stages of writing including planning, invention, drafting, peer review, and revision. The concluding section was concerned with final portfolios, and 
asked participants to provide topic information in relation to cultural identity and consequent language choices.

A small portion $(n=2)$ of the total students $(n=90)$ who participated in the questionnaires agreed to follow-up interviews. These focus students were both selfselected-choosing to take part in the interview process - and researcher-selectedfitting into the criteria of Canadian-born or Generation 1.5 students who speak multiple languages. The selection of interview participants occurred within the first four weeks of class, and was based on the answers provided in the initial questionnaire. The interviews that took place were approximately thirty minutes long and occurred within two weeks of the distribution of the initial and final questionnaires. The interviews were open-ended and videotaped. Open-ended questions were employed in order to encourage participants to provide full, meaningful answers. Additionally, open-ended questions tend to be more objective and less leading than close-ended questions. The questions posed were based upon questionnaire responses and, thus, while the general direction of the questions between the two participants was similar, there were anomalies. The primary reason for this was because one interviewee was Canadian-born and the other was Generation 1.5. Therefore, follow-up interview questions were personalized in terms of the interviewees' experiences. The interviews were videotaped to capture student diversity, which is often left unrepresented in transcripts. Video allows additional nuances of communication to be captured through voice, gesture, and facial expression. Often when researchers discuss students with multilingual backgrounds, a common response for readers/audience is to imagine or place students into categories, or stereotypes. By offering the images and the voices of the participants—rather than written description — this study aims to visually 
and orally illustrate how multilingual students are a diverse population and, as such, must not be recognized categorically (i.e. L2, ESL, bilingual, immigrant, etc), but recognized as distinct individuals who have individual experiences and needs.

There were limits and benefits to each of the data collection methods implemented. Limitations to questionnaire distribution included participant absence on researcher visits, participants who dropped/added the class, and participants who did not follow directions properly when completing the questionnaires. Other limitations included illegibility of written responses and participant incomprehension. Some of these problems, particularly absence, may have been rectified if the questionnaire had been distributed digitally; however, this method would not guarantee completion of responses as my physical presence often did. Benefits to questionnaire distribution were that responses were gathered in a standardized and objective fashion, collection of data occurred immediately, and information was able to be collected from a large group. A primary limitation of the undergraduate participants' interviews was that while initially more than twenty students agreed to take part in these sessions, only two students actually participated in the interview process. A second limitation of the interviews was that the small number of participants did not provide the same diversity of response and background suggested in the questionnaire data. In other words, although the interviews potentially promised more detailed and varied responses, the participants interviewed had similar rather than varied experiences with language. However, a major advantage to this data collection method was the ability to probe student questionnaire and interview responses, gathering needed explanatory data. Additionally, videotaping the interviews 
proved successful in capturing student diversity, despite the small number of students who participated.

\section{Justification of Methodology}

Perhaps the most noteworthy reason why methodologies based in descriptive research are relevant to this study is due to the current project's design, which set out to create a descriptive and foundational analysis of student demographics in terms of language use, community affiliation, and academic writing ability.

Due to the importance of participants' multilingual capabilities, the responses of those students with only monolingual capabilities are of minimal importance to the analysis of this study. Of the total number of participants initially surveyed three quarters were multilingual and one quarter monolingual; accordingly, because this project is interested in students who are members of diverse and multiple linguistic communities the initial sample size of the participants $(n=90)$ was reduced. A major drawback of the reduction of total sample size (to $n=68$ ) is that a smaller sample size is not as reliable as a larger one. Nevertheless, as the research at hand is concerned with multilingual student populations it would be disadvantageous to focus on monolingual participants.

Regardless of language ability, all research that involves human participants must be carried out in an ethical manner. Newkirk's "Seduction and Betrayal" emphasizes that researchers need to do more than recognize their own partialities when conducting and analyzing research; they must also be fully aware of the vulnerability of research participants. One attempt that this research has made to recognize ethics concerns is its approval through both the IRB (Internal Review Board) approval at the University of Louisville and the REB (Research Ethics Board) approval at the University of Windsor. 
Both review boards work with the objective of formally approving, monitoring, and reviewing behavioural research involving humans, where the primary aim is to protect research subjects from researcher misuse and abuse. However, Newkirk argues that ethics approval in itself is not sufficient to be conducting research in an ethical manner. For example ethics boards work, in most institutions, on a medical model of research and legal definitions of harm and safeguards that provides a fairly rigid and limited conception of ethics and the rights and concerns of participants, especially in regard to research taking place in the Humanities and Social Sciences. This study was not concerned with physical harm to participants; however, it did realize the potential emotional risks that some questions may trigger. Participants were given the opportunity to opt out, which was emphasized throughout this study. Participants were reminded at the time of each questionnaire that they had the ability to choose whether or not to take part in this study. Moreover, participants were also given the opportunity to withdraw up to one month upon course completion as well as refuse to answer questions during both the questionnaire and interview process. This information was outlined in the consent forms (see appendix) for the questionnaires and the interviews and was also explained verbally.

However, Newkirk also argues that we need a broader and more sustained set of ethical concerns and approaches, including our consideration of what we do, as researchers, with the data collected. Too often researchers position informed consent as the end point of ethical considerations. Researchers' approaches and perspectives within their writing must also be recognized as an ethical concern. In regard to this project, a central ethical concern which arose throughout the writing process was attention to 
student representation. In order to portray participants in an ethical manner, students were provided the opportunity to read analysis of the interviews as well as respond to this analysis. This gesture may seem insignificant; however, such moves give participants a degree of power and position them as active subjects rather than passive objects.

Participatory-action research is another strategy which promotes the ethical treatment of subjects. Cushman's "Rhetorician as Agent of Social Change" posits that in the conduct of research it should not only be the researcher benefiting, the participant/s should also have some level of gain. It is unethical for researchers to only take research away without considering the ramifications of their injection into an environment. Instead researchers need to show respect to subjects, environment, society, and so on through providing services to the community they are working within. In regard to this project, my services were offered in terms of contributing my knowledge to graduate instructors in the form of informal meetings and provision of advice; however, I was not able to offer hands on benefits to the students, as REB required me to only have anonymous contact with them (save the interview subjects).

Finally, central to the ethics of this study was that participants clearly understood my role-as researcher - in their lives as students. It was repeatedly stressed that as a researcher I had no connection to the course, students, or instructors of the courses. Further, consent forms described how and when data would be collected, destroyed, and used as well as how the data may affect participants. In describing this information efforts were made to explain the project as self-reflexive, through acknowledging in the consent forms that

The possible benefits of this study include a better understanding of how you use language in the university classroom, which could offer you insight into how your language choices may impede or facilitate your larger academic career. However, the 
information collected may not benefit you directly. The information learned in this study may be helpful to others.

Thus, participants were made aware that answering the questions posed to them may help them garner a better understanding of themselves as multilingual writers; however, it was also explained that most likely the findings would not affect the participants directly. Thus, while the current study did not "give back to the community" of participants studied, it did maintain a goal of developing a descriptive and foundational analysis of multilingual student demographics, which will both aid future multilingual students and the teachers of these students.

\section{$\underline{\text { Research Subject Position }}$}

Most problematic in my subject position as writer of this text is that I am not a multilingual immigrant, though I am a first generation immigrant, my parents both being born outside of Canada. Nevertheless, my parents are of Anglo-Saxon descent and, like myself, only speak English. Unlike the students represented in this research, my background is that of a privileged, white, English-speaking Canadian and differs drastically from the participants of this study. Thus, my experiences with multilingualism come from the outside and are only observations.

Consequently, although my research seeks to attain a level of linguistic equality for Canadians of all language backgrounds, I may never fully be aware of the challenges multilingual Canadians face. This reality was made apparent throughout the research process. For instance, although I am quite interested in and sympathetic to the challenges of multilingual students, I was unable to offer any level of camaraderie during the interview process, which was evident when I was asking questions concerning language 
practices and cultural celebrations. During these questions, one participant asked for further clarification of my questions and I had trouble doing this because I had no personal experiences to draw upon. If I had a more relatable background I may have been able to make my interviewees more comfortable and, thereby, collected more nuanced examples.

In respect to the writing process and my representation of data, I attempted to present my findings honestly. For instance, while I may be working to change the way multilingualism is received in the academy, I have striven to provide contextualized quotations of participants and, consequently, a rounded perspective of the issues.

\section{$\underline{\text { Variables }}$}

While I made various attempts to avoid inconsistencies within this project, certain variables that may have an impact on the outcome of the research were encountered. The variables that arose throughout the project can be categorized in terms of individual participants, sample size, and questions posed.

As touched upon, student attendance (or lack there of) may have worked to somewhat skew the final results. Specifically, students who participated in the first questionnaire may have been absent from class for later questionnaires, which would impact the analysis of the data. As well, due to a final drop date of mid-November, which is ten weeks following the first day of classes, it is possible that some students may have completed one or two of the questionnaires, but not the third. Although data contamination due to participant absence was kept in check through requiring students to 
provide the same anonymous code at the beginning of each questionnaire ${ }^{21}$, the act of generating this code proved problematic. Participants, despite reminders, often left this portion of the questionnaire blank, or explained that they had difficulty remembering what they wrote previously (despite the fact that the directions remained unchanged). Additionally, a large quantity of students did not have a middle name, which created some problems when generating the code. Consequently, while the majority of the three questionnaires can be linked by anonymous code, this was not the case across the board. Additionally, there were a small number $(n=7)$ of international students who participated in the study who identified as multilingual; thus, the sample size is reduced further $(\mathrm{n}=$ $61)$.

Finally, a frequent variable that occurred both during the distributing of the questionnaires and conducting the interviews was clarifying the meaning of terminology in the questions. Due to my high level of knowledge of the subject matter some jargon was included in questionnaires that needed to be explained. As a result, clarification was often not made until a participant asked a question, which usually occurred during the process of distributing the questionnaires to the first or second section ${ }^{22}$. Clarifications were made at the onset of questionnaire distribution in later sections. The drawback to this practice would be that the first section of participants who received the questionnaire may not have had the same understanding as later sections, which may have impacted their comprehension of certain questions. Additionally, it was found that conducting the

\footnotetext{
${ }^{21}$ Please generate a unique, anonymous code. Include, the first two letters of your middle name, the last two digits of your student number, and the first two letters of your mother's maiden name. For instance my code would be: EI43LO. My middle name is EILEEN, my student number is $98151 \underline{43}$, and my mother's maiden name is LOCKYER.

${ }^{22}$ This confusion with terminology remains a topic of considerable debate among language scholars.
} 
first interview was less relaxed and often ran into minor complications, such as explanation of a term or question. Consequently, the interviews, while relying upon much the same questions, are somewhat inconsistent in that they were affected by my own comfort levels, which influenced the relationship between the interviewer and interviewee and the interview process in general.

\section{$\underline{\text { Analysis }}$}

Data for this project were collected and analyzed manually. Basic statistics, spreadsheet tabulation (MS Excel), and observational narrative were used. Central to data analysis is the recognition of patterns within questionnaire responses. Simple statistics will be implemented to illustrate positive correlations that arise in questionnaire responses. The inclusion of charts and graphs will illustrate the compiled questionnaire findings, by visually representing response patterns among the multilingual students surveyed. Observational narrative will be used for interview analysis.

Because researchers must always weigh the reliability and validity of their work, this project is based on triangulation to ensure validity. Upon analysis, consistent outcomes from each data source worked to establish that the findings are concrete and sound. The primary themes that have arisen during data collection are concerned with student language capabilities (e.g. number of languages used in oral and written communication), language meshing, and inside/outside language use. Thus, when analyzing data that is relevant to these issues parallels were also drawn between previously published research as related to the current project. Moreover, while the 
consistencies within student answers will be significant to the process of analyzing the data, those that contradict previous research will also be noteworthy.

\section{$\underline{\text { Conclusion }}$}

This project builds upon current research concerning multilingual students, through offering an analysis of Canadian allophone students. In describing Canadian students in terms of multilingual language politics, this research draws upon the work of a variety of scholars globally (Bhabha; Blommaert et al.; Canagarajah, Critical Academic; Canagarajah, "Multilingual Writers"; Canagarajah, "The Place"; Canagarajah, "Toward"; Canagarajah "Lingua"; Horner and Trimbur; Leung et al.; Rassool), who have argued that if we are to fully understand and teach the complex linguistic ecology of the students in our classrooms we must better understand who our students are. In terms of Canadian scholarship, the data collected pays special attention to multilingual students' perceptions of the usefulness of their heritage languages in terms of the monolingual and monocultural expectations maintained in current academic discourse communities (e.g. how the participants feel about those who use heritage languages, those who don't, and those who don't know how) building upon Canadian research (Hayday; Heller; Taylor) which is primarily concerned with anglophone-francophone communities. Consequently, this project extends the Canadian discussion to multilingual immigrant post-secondary students who maintain their heritage languages outside the university. 
CHAPTER FOUR

Questionnaire Analysis 
I am my language. Until I can take pride in my language I can not take pride in myself...until I am free to write bilingually and to switch codes without having to translate...my tongue will be illegitimate.

- Gloria Anzaldúa, How to Tame A Wild Tongue

The academy's language ideologies often limit the study of multilingual writing, in their implicit maintenance of monolinguistic assumptions that favour Standardized English. As such, academic discourse often mirrors Bakhtin's understanding of hegemonic language, where "common unitary language is a system of linguistic norms" (270). In terms of the writing classroom, this tells us that the language used in the academy is often perceived as fixed, which is problematic if - as this study has found - the languages our students encounter outside classrooms are in constant flux. Further, even if we do acknowledge the individualities of language(s) within our students, and their rights to these languages outside the classroom, Soliday ("Towards" 62) challenges that this "does not mean that teachers still don't expect them to accommodate to the dominant uses of written language within the university." This research will illustrate that in Canada, despite bilingual and multilingual initiatives, multilingual students who chose to enrol in post-secondary institutions must practice code-switching-English in the classroom and meshed or other languages outside the classroom. The current, as well as succeeding chapters, will discuss how the students surveyed and interviewed experience and understand language, particularly languages other than English, in the writing classroom and greater university. The two chapters will respond to the four themes addressed in the previous chapter's research questions: namely, a Canadian contextualization of multilingual students; a survey and analysis of the academic and linguistic backgrounds of Canadian multilingual students; a discussion of previous research concerned with cultural identity and language; 
as well as the significance of the Canadian Multiculturalism Act's mandates within the writing classroom. The current chapter will discuss the outlined research topics in terms of the undergraduate students' questionnaire responses; the following chapter will offer an analysis of the two focus students' interviews.

To offer a comprehensive interpretation of the data collected, this discussion will respond to issues introduced in the first chapter. To begin, I will describe the students surveyed, paying special attention to their academic and linguistic backgrounds. Drawing upon the responses of the multilingual student participants will demonstrate their linguistic expectations in regard to the class, which will serve to build a model of how to best serve their needs in the future. My description of these students will develop perceptions concerning multilingual categorization as well as the limitations of these categories, with the end purpose being the provision of a foundational interpretation of who Canadian multilingual students are, specifically in the region of Southern Ontario. The discussion will then move into how students encounter language, be it eradicationism, language segregation, or language interaction. Emphasis will be placed upon the latter two models in respect to a comparison between U.S. and Canadian classrooms. To close this chapter, I will expose which languages are in play in Canadian writing classrooms and comparatively analyze this finding in terms of my earlier discussion concerning the nation's multiculturalist policies.

As explained in the previous chapter, undergraduate students across five sections of first year writing were provided with questionnaires throughout the fall semester, which required them to reflect and comment upon topics relating to their private, academic, and linguistic backgrounds. Of the potential one hundred student participants 
(twenty students per section) ninety students contributed. However, not all participants responded to all questions in each questionnaire; thus, the total number of participants per question does not always correspond to ninety. Of the participants, forty-six were female and forty-four were male. Sixty percent of those surveyed were first-year students, seventeen percent were second-year, eleven percent were third-year, six percent were fourth-year, and six percent were other. ${ }^{23}$

Academically, students enrolled in these sections of first-year writing came from diverse academic and degree backgrounds, which are comparable to those of students enrolled in composition at post-secondary institutions in the United States. However, while composition is typically a general education requirement for all undergraduate students in the United States, in Canada writing courses are-as a rule-electives. Further, at the institution where this study took place there is only one first-year writing course available to students, not a two-course series as found in a number of U.S. institutions. Of the students surveyed, educational backgrounds ranged from accounting to drama to labour studies, and of the assorted academic majors represented, only fiveor, roughly twenty percent - required students enrolled in that degree program to complete first-year writing. ${ }^{24}$ Table One shows a breakdown of how many students were enrolled in which major programs. What is interesting about these data is that academic degrees that required students to complete first-year writing were all Science disciplines; moreover, two thirds of respondents were Science students.

\section{Table One: Academic Majors of Students}

\footnotetext{
${ }^{23}$ The Canadian post-secondary system does not use the freshman, sophomore, etc. nomenclature that is exercised in the United States.

${ }^{24}$ These programs are: accounting, biology, medicine, and pharmacy. Additionally, one of the participants who was required to take this course was a graduate student; often students who have weak writing skills may be requested to take a writing course to complete their graduate degree.
} 


\begin{tabular}{|c|c|c|c|}
\hline Major & Students & Major & Students \\
\hline Accounting ${ }^{\text {req }}$ & 1 & General Science & 5 \\
\hline Biochemistry & 7 & Graduate school ${ }^{\text {req }}$ & 1 \\
\hline Biology req & 16 & History & 1 \\
\hline Business & 5 & Kinesiology & 1 \\
\hline Chemistry & 4 & Labour Studies & 1 \\
\hline Communications & 2 & Liberal Studies & 1 \\
\hline Computer Science & 2 & Math & 1 \\
\hline Criminology & 4 & Medicine ${ }^{\text {req }}$ & 1 \\
\hline Drama & 1 & Music & 1 \\
\hline Economics & 1 & Pharmacy ${ }^{\text {req }}$ & 1 \\
\hline Education & 2 & Psychology & 8 \\
\hline English & 1 & Sociology & 1 \\
\hline Finance & 1 & Undeclared & 1 \\
\hline
\end{tabular}

Ten percent of respondents were Arts students and twenty-six percent were from the Social Sciences. Thus, the vast majority of students enrolled in first year writing are coming to the class with a Science background; this relatively large percentage corresponds with recent publications (Lerner; Blakeslee; Bridgeman and Carlson; Lutz and Fuller; Juzwik, Curcic, Wolbers, Moxley, Dimling, and Shankland) which suggest that competence in written communication is a requirement of employment in science, business, and other technical fields. Moreover, a number of respondents described their expectations for the course as relating not only to improvement in writing, but also to subsequent education, professional programs, and future research endeavours (Table $\mathrm{X}$, see appendix). As the vast majority of students who registered for first-year writing were not required to do so, it is important to understand the motivations for enrolment; the most common reasons students chose this course, after it being a prerequisite, were: advised academically (16\%), advised by family or friends (15\%), and to improve writing skills (15\%). For a complete list of reasons for enrolment please see Table Y, appendix. Because the majority of degree programs do not require students to enrol in first-year- 
writing, gathering information that explains why students chose this course, in conjunction with linguistic data, will better prepare educators to design courses that will take into account student diversity as well as engage students in terms of personal academic goals. For instance, the data collected suggest that students are seeking practical training in writing for both the job market and future education. This tells us that courses (designed to cater to Canada's multilingual populations) should consider discussions of the globalized marketplace in terms of the national and international opportunities available to students and employees who can communicate in multiple languages. Moreover, programs that incorporate writing instruction in multiple languages could effectively prepare all Canadian students for international opportunities that would become available to them with such training. As advanced in Chapter Two, recognizing and explicitly including multilingual experiences in the classroom serves to acknowledge multiple literacies, providing students with a global way of thinking that will prepare them to communicate with diverse audiences.

Of the total number of participants surveyed, seventy percent were born in Canada. Of the thirty percent born elsewhere, eight percent were international students. Of Canadian born students, all but three are originally from Ontario-these students being born in Nova Scotia, Québec, and Alberta. The majority of student participants were born and raised in Ontario and spent the majority of their lives in this province. However, this is not to say that the majority of students are English Only speakers; as the data show, a large percentage of students are fluent in a variety of allophone languages.

More than half of the immigrants who come to Canada settle in Ontario; high levels of urbanization and industrialization in this region continue to attract new 
Canadians to this province, making it the most multicultural in the country.

Correspondingly, the majority of students in the public school system speak English as a second language (King 1998). The data collected herein support King's finding of intensified immigration in this region. Approximately one quarter (22\%) of the total students surveyed were born outside of Canada and could be categorized as Generation 1.5 , three quarters (77\%) identify as first, second, third, or fourth generation immigrant, and the remaining students' $(<1 \%)$ families have been living in Canada for at least the last five generations. Thus, in regard to categorization, the chosen term "immigrant" is a good fit to describe the total population of students surveyed; moreover, because the total population of participants have strong immigrant backgrounds, one could project that all students enrolled in first year writing at the University of Windsor self-identify or have family members who self-identify as immigrant Canadian. In other words, these students would be categorized as immigrant both in terms of familial entrance into Canada as well as their identification as Canadian citizens, wherein Canada is characterized as a multicultural nation overwhelmingly comprised of immigrant citizens.

If we look specifically at Generation 1.5 students, Table Two indicates that students have emigrated from a variety of countries; there are no startling trends in Table Two: Birth countries of Generation 1.5 Students

\begin{tabular}{ll}
\hline Birth Country & Students \\
\hline Bangladesh & 1 \\
Bulgaria & 1 \\
China & 2 \\
Congo & 1 \\
India & 5 \\
Jamaica & 2 \\
Kenya & 1 \\
Lebanon & 2 \\
Nigeria & 2 \\
Russia & 1 \\
\hline
\end{tabular}




\begin{tabular}{ll}
\hline Saudi Arabia & 1 \\
Taiwan & 1 \\
Thailand & 1 \\
Yugoslavia & 1 \\
\hline
\end{tabular}

emigration background. Ultimately, in this region of Southwestern Ontario, and in this specific post-secondary institution, immigrant students literally come from all over the world, with no specific region boasting majority numbers. Additionally, the age of Generation 1.5 student entry into Canada also varied, with no definite trends (Table Three). English is most often the only language that these students have received writing and literacy instruction in prior to entrance into Canada. Of student participants who were

Table Three: Age When Generation 1.5 Students Immigrated

\begin{tabular}{ll}
\hline Age & Students \\
\hline$<5$ & 5 \\
$6-12$ & 7 \\
$13-17$ & 2 \\
$>18$ & 10 \\
\hline
\end{tabular}

born in Canada, forty-two percent identify as first generation Canadians, twenty percent second generation, six percent third generation, and nine percent fourth generation. Additionally, students exhibit more than a strong immigrant heritage, a markedly large number $(73 \%)$ also maintain multilingual capabilities. This staggering diversity not only aligns with King's research, but also suggests that a writing curriculum based within a multicultural and multilingual framework would accommodate both government policies and the needs of this diverse base of students. For instance, the Canadian Charter of Rights and Freedoms provides that educational institutions should teach students tenets of effective communication, ensuring the continuation of a group's identity through the 
provision of a socially and culturally stimulating environment (Martel 16). Effective communication is already a central goal of first-year writing courses. However, if we pay attention to the language issues at play within multiculturalism when assigning this work and designing writing prompts we can also create a "socially and culturally stimulating environment." Curricula wherein assignments have a foundation in multiculturalism will work to engage students, under the aegis of interpersonal relationships between classmates, family, and other organizations outside the academy. Ideally, a narrative or descriptive essay that draws upon multiculturalism as a resource should create an animated classroom environment, rich in discussion and critical reflection.

While the first language learnt by many multilingual students is not English, the lingua franca of the Canadian school system is. Consequently, all Canadian-born students surveyed had knowledge of English for most of their lives. Despite this, I was interested in how students classified themselves linguistically and asked them to qualify themselves in terms of their language use. Students were provided with a list of categories scholars most regularly use to refer to multilingual speakers and asked to select whichever they identified with. The categories were: Native English Speaker (NES), Non-native English Speaker (NNES), Native French Speaker (NFS), French-English Bilingual, bilingual in languages other than French and English, English as a Second Language (ESL), and English as a Foreign Language (EFL). Included in Table Four are the categories that students selected at least ten percent of the time. The majority of students (72\%) selected the NES category. However, almost half also recognized themselves as bilingual in a language other than French. Additionally, 20\% self-identified as NNES, $17 \%$ as bilingual French-English, $14 \%$ as ESL, and $10 \%$ as EFL. As Ontario is primarily an anglophone 
province it is hardly surprising that the majority of students associated their linguistic capabilities as NES. However, it is of interest that despite Canada's duality of official languages (French and English) significantly fewer students categorized themselves as officially bilingual when compared to allophone bilingual. In other words, in the selection of students studied those who identify with an allophone language rather than the official Table Four: Students' Linguistic Self-Identification

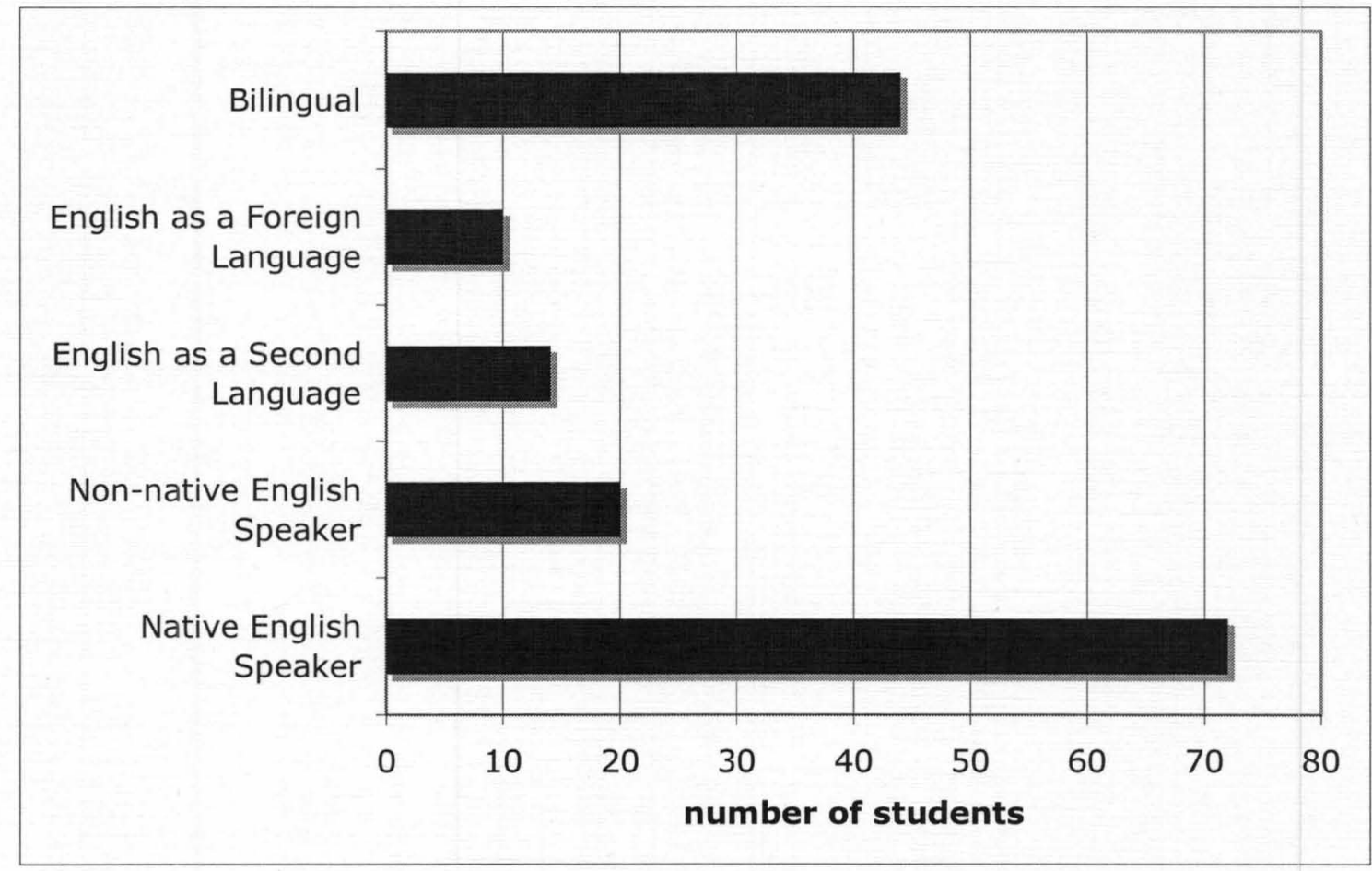

language of French as their second language is higher than anticipated. Due to the connotations associated with the term "official language," one may expect French and English to trump heritage languages; however, as Table Four indicates, the number of students bilingual in English and a heritage mother tongue is more than double the number of students bilingual in Canada's official languages. Students who self-identified as multilingual made up three quarters of the total pool, leaving just one quarter of the students surveyed as having English Only capabilities. Moreover, the range of languages 
used by these multilingual students was truly incredible. Students provided 42

combinations of languages used, ranging from two known languages, which was the majority trend, to one student with linguistic skills in five languages (see Table Five). In regard to linguistic categorization, this data illustrates two realities, or common denominators, concerning labelling practices: the vast majority of students are multilingual and all of these students have immigrant backgrounds. Thus, my decision in Chapter One to refer to these students as "multilingual immigrants" is functionally applicable as well as a valid appellation. Moreover, the finding that the bulk of students with multilingual capabilities also self-identify as NES suggests that segregating students into categories-like bilingual, ESL, or NNES-may insinuate discrete linguistic capabilities for administrators, but student responses show that they are more apt to identity with a number of categories (half of students selected between two and five categories). As such, writing courses designed specifically for minority language students may be problematic because, for instance, a variety of students self-identify as both allophone bilingual and NES. Ultimately, creating courses where students are segregated

Table Five: Combinations of Languages Used by Students

\begin{tabular}{|c|c|c|c|}
\hline $\begin{array}{l}\text { Language } \\
\text { Combinations }\end{array}$ & Students & $\begin{array}{l}\text { Language } \\
\text { Combinations }\end{array}$ & Students \\
\hline English, Punjabi & 1 & English, Dutch & 1 \\
\hline English, Serbian & 2 & $\begin{array}{l}\text { English, French, } \\
\text { Spanish }\end{array}$ & 1 \\
\hline English, Hindi & 2 & English, Polish & 1 \\
\hline English, French (INT) & 4 & English, Chinese & 2 \\
\hline $\begin{array}{l}\text { English, Marathi, } \\
\text { Hindi }\end{array}$ & 1 & $\begin{array}{l}\text { English, Vietnamese, } \\
\text { Chinese, Spanish }\end{array}$ & 1 \\
\hline English, Cambodian & 1 & $\begin{array}{l}\text { English, French, } \\
\text { Italian }\end{array}$ & 1 \\
\hline $\begin{array}{l}\text { English, French, } \\
\text { Arabic }\end{array}$ & 4 & English, Portuguese & 1 \\
\hline
\end{tabular}




\begin{tabular}{|c|c|c|c|}
\hline English, Vietnamese & 2 & English, Italian & 1 \\
\hline $\begin{array}{l}\text { English, Bangla, } \\
\text { Arabic, Hindi, French }\end{array}$ & 1 & English, Macedonian & 1 \\
\hline $\begin{array}{l}\text { English, Gujarati, } \\
\text { Hindi }\end{array}$ & 2 & English, Arabic & 1 \\
\hline $\begin{array}{l}\text { English, French } \\
\text { (CAD) }\end{array}$ & 12 & English, French, Urdu & 1 \\
\hline $\begin{array}{l}\text { English, French, } \\
\text { Polish, Serbian }\end{array}$ & 1 & $\begin{array}{l}\text { English, French, } \\
\text { Moroccan }\end{array}$ & 1 \\
\hline English & 24 & $\begin{array}{l}\text { English, Spanish, } \\
\text { Urdu, Russian }\end{array}$ & 1 \\
\hline $\begin{array}{l}\text { English, Lebanese, } \\
\text { Japanese }\end{array}$ & 1 & English, Urdu, Hindi & 1 \\
\hline $\begin{array}{l}\text { English, French, } \\
\text { Portuguese }\end{array}$ & 2 & English, Urdu & 1 \\
\hline $\begin{array}{l}\text { English, Swahili, } \\
\text { French }\end{array}$ & 1 & $\begin{array}{l}\text { English, Chinese, } \\
\text { Taiwanese }\end{array}$ & 1 \\
\hline English, Patois & 1 & English, Bulgarian & 1 \\
\hline $\begin{array}{l}\text { English, French, } \\
\text { Greek }\end{array}$ & 1 & $\begin{array}{l}\text { English, Hindi, } \\
\text { Telugu }\end{array}$ & 1 \\
\hline $\begin{array}{l}\text { English, French, } \\
\text { Lebanese }\end{array}$ & 1 & English, Spanish & 2 \\
\hline English, Hebrew & 1 & English, Bini & 1 \\
\hline $\begin{array}{l}\text { English, Chinese, } \\
\text { Cantonese }\end{array}$ & 1 & $\begin{array}{l}\text { English, Hindi, } \\
\text { Punjabi }\end{array}$ & 2 \\
\hline
\end{tabular}

in terms of language would not be suitable for this institution because of the immense range of linguistic capabilities. Moreover, as the number of students across sections fit into a variety of categories already (see Table Five), it would be more suitable to create curricula similar to that suggested by Matsuda and Silva in their essay "Cross-Cultural Composition." In this course, monolingual and multilingual students came together to critically reflect upon cross-cultural topics. The difference between this course's demographic and that found at the University of Windsor is that in Matsuda and Silva's situation placement procedures were put in place to secure equal numbers of monolingual and multilingual students; however, at the current institution there is already a definite division between these groups in each section. 
While the variety of language combinations held by the students surveyed work to illustrate a reality of Pratt's contact zones they also suggest a large linguistic range of knowledge and comprehension. Participant responses in respect to allophone language learning and ability indicate that the levels of immigrant language usage correspond to previous studies which report that with succeeding immigrant generations comes loss of heritage language. Specifically, Laponce (82) concludes that in Canada few immigrant languages have survival rates of fifty percent or better, and that retaining heritage languages over two generations is unlikely. Thus, despite the fact that almost one hundred percent of the participants have a strong immigrant background most will lose their allophone language capabilities within succeeding generations. This is a dismal reality in terms of Canada's linguistic diversity. Moreover, because the federal government's multicultural polices do not effectively promote multilingualism as a pedagogical tool there is no in-class support for the maintenance of these students' linguistic heritage. However, if writing courses were designed within a multiculturalmultilingual framework, students would be expected to draw upon their unique cultural heritage as a linguistic resource, especially those with fluency in heritage languages-be their ancestry sixth generation British, second generation Croatian, first generation Chinese, or fourth generation Ukrainian — which would unequivocally support the Canadian Multiculturalism Act's mandate of retention in respect to the "use of all languages that contribute to the multicultural heritage of Canada." One way to accomplish this is through providing students with an academic platform to explore aspects of their cultural and linguistic identity. 
For allophone Canadians, particularly those in Ontario, language functions as an identity marker and maker; ethno-immigrant populations' cultural and linguistic heritage is dependent upon the retention and maintenance of their home languages. The prevalence of ethno-immigrant communities within this region, which are marked by ethno-specific shopping districts, cultural centres (clubs, halls, temples, etc), as well as pockets of towns and cities wherein residents rely exclusively on immigrant language and culture, illustrate that within this region of the country many immigrant citizens have come to accept language as intrinsic to identity. In this way heritage languages provide users with a sense of who they are and who they want to be, affecting how they are identified or want to be identified by others. As such, heritage languages function as both identity markers and makers. The data collected illustrates that this acceptance is most evident outside the university, not within. In the academy students primarily communicate in English; the majority of research participants with allophone language backgrounds acquired English as their first spoken, written, and read language as children (see Table Six). However, what is of interest is that the number of students who

Table Six: First Language Acquired by Multilingual Students as Infants 


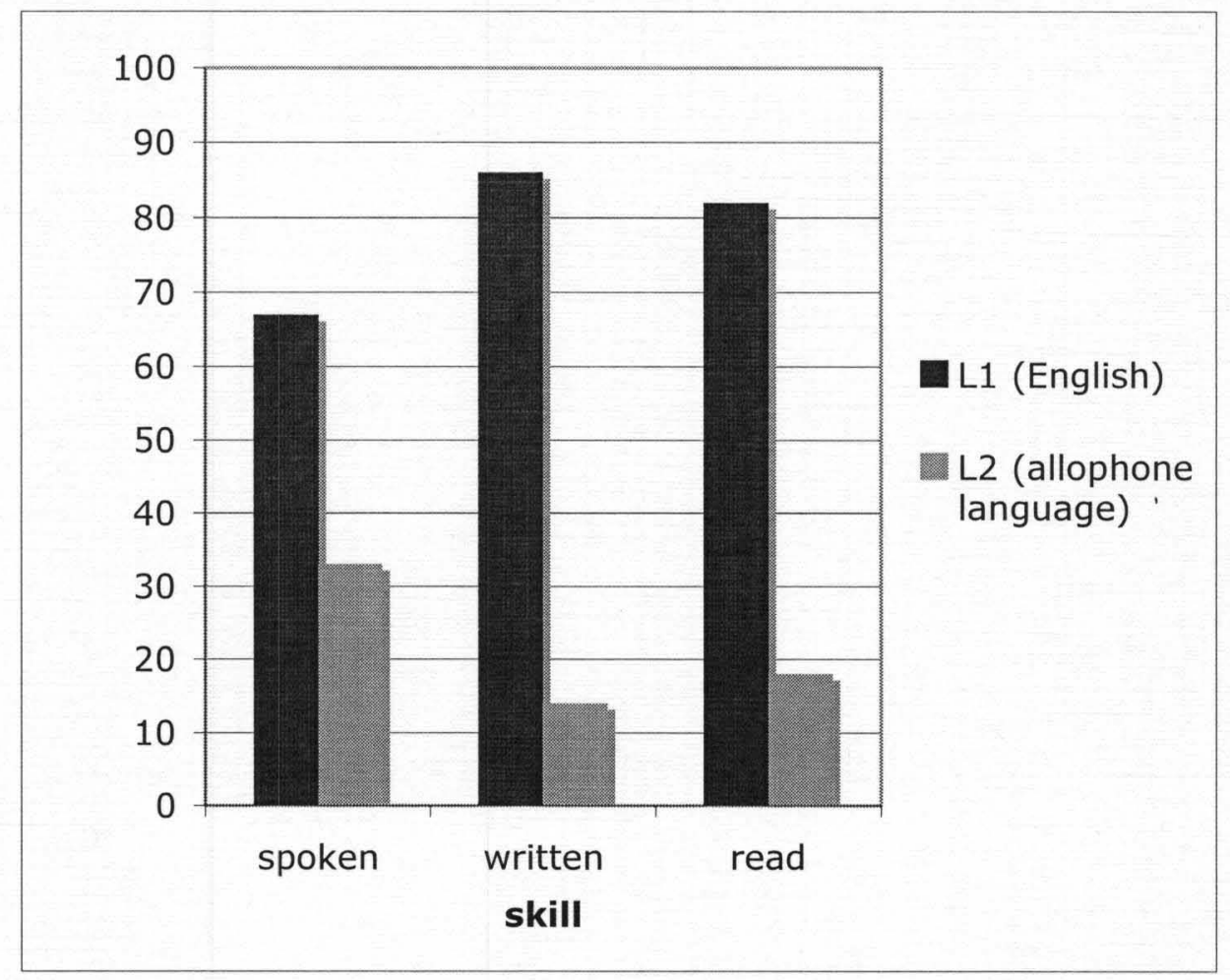

were taught to speak in immigrant languages (33\%) is significantly higher than those who were taught to read and write in these same languages $(14 \% ; 18 \%)$. Of the Generation 1.5 students, roughly three quarters were taught to speak their home language before English; however, only half of this population of students were taught to read and write in their home language before learning English. Of immigrant students, ranging from first to fourth generation, a very small percentage (12\%) were taught their heritage language as their first spoken tongue; however, all of these students were first generation Canadians. This finding, which suggests that language retention and learning is most prominent in early generations of immigrants, corresponds to those of Laponce and $\mathrm{Li}$; it also suggests that researchers should ask subjects to consider their personal connections to heritage languages in terms of learning and usage. 
Table Seven: Level of Allophone Linguistic Skill \& Comprehension

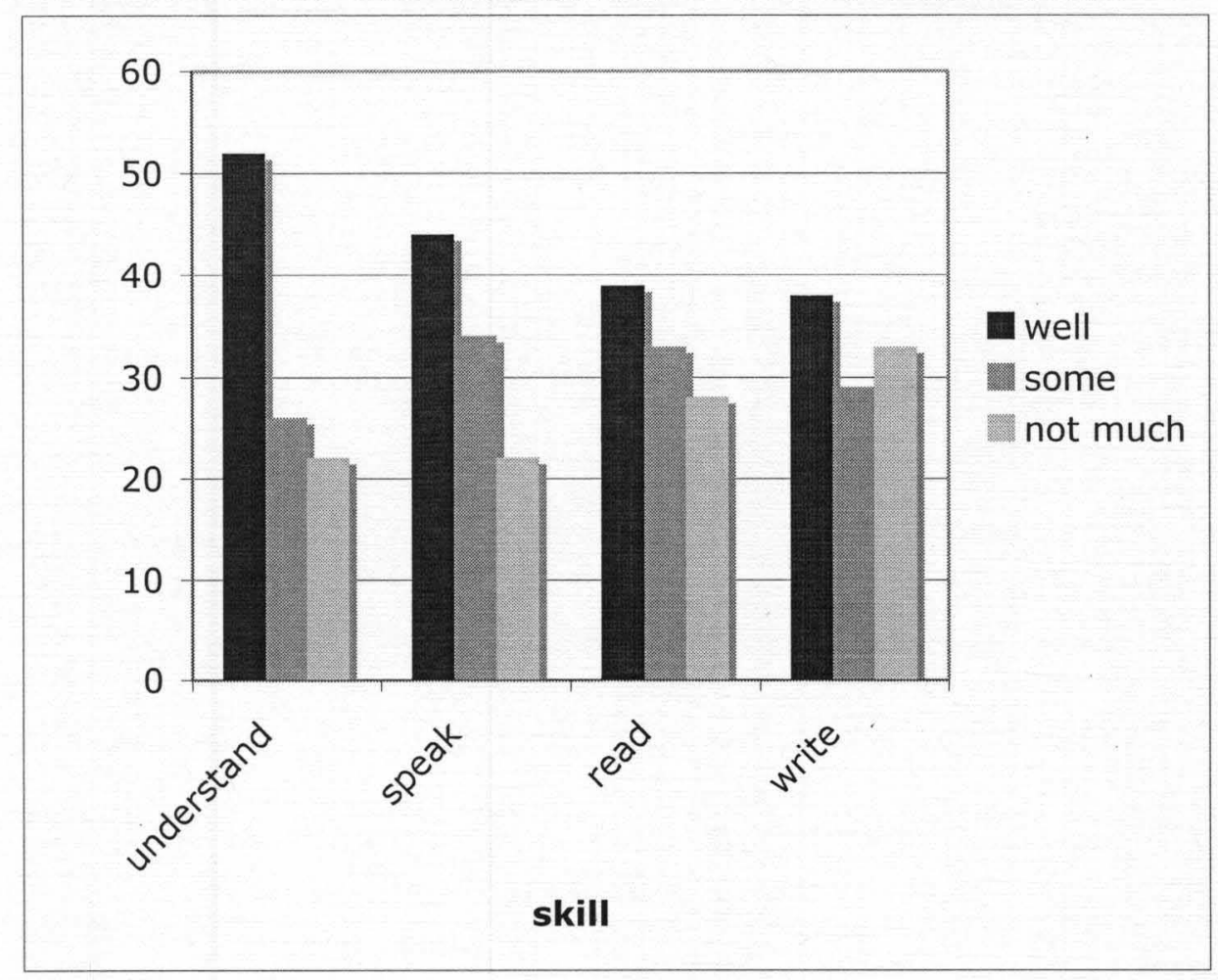

Because a large number of the multilingual student participants acquired their allophone language as an L2 language, one might assume that these students would not have maintained usage of these languages. However, as Table Seven demonstrates, most students self-reported some level of L2 competence. Furthermore, students are better able to speak their allophone language than read or write it. The primary reason for this speaking facility would be that many of the multilingual students surveyed ( $80 \%)$ attended grade school in English, where the skills of reading and writing are taught. Most likely these students only use heritage languages in the home or in their home communities. Ultimately, what these Canadian multilingual students practice, which is also the case for similar populations of students in the United States, is code-switching.

As students have been socialized to use different languages in different situations, it is not surprising that within the classroom students code-switch, where one language is 
used at a time and no interaction occurs between languages. Many students reported that they use English as their language of choice outside the classroom; as Canada is primarily an English-speaking nation it is not an unexpected finding that most students have chosen to communicate in the country's most dominant language. What is noteworthy about the information provided in Table Eight is that students most often choose English when speaking to peers (siblings and friends), but choose English less often when speaking to elder family members: parents, grandparents, and other relatives. One reason for this may be, particularly in the case of communication with grandparents, that English is not a viable option. Another possibility may be due to language expectations among older Table Eight: Use of English Outside of School

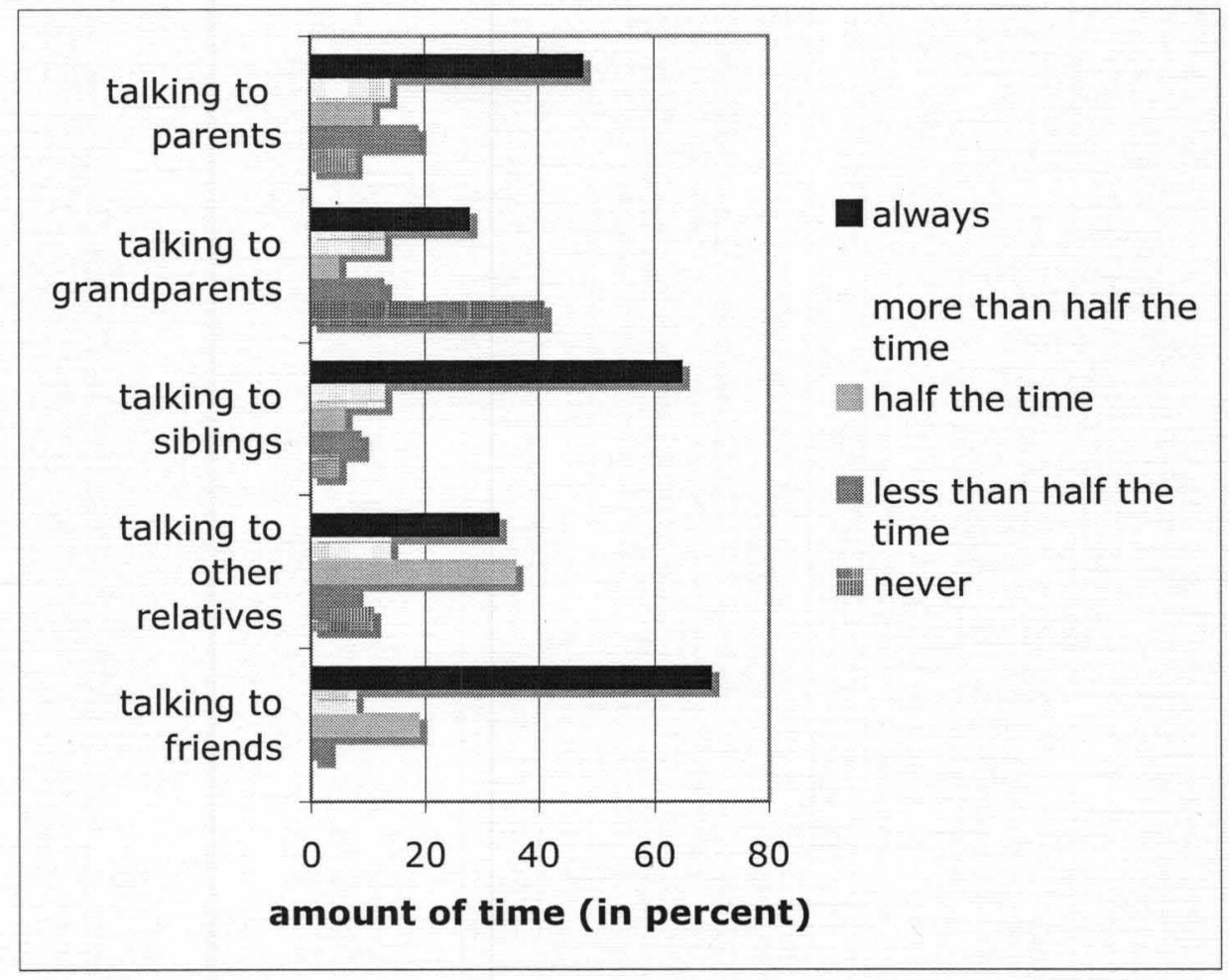

members of ethnic communities, or country of residence (students were not asked if these relatives were Canadian citizens). The cause could also be due to findings that few immigrant languages have survival rates of fifty percent or better in later generations, the 
reality that students may not have the allophone vocabulary necessary to engage in certain topics, as well as the possibility that participants do not view their ability to speak allophone languages as central to their understanding of who they are.

Yet, code-meshing is also a phenomenon that occurs among the students surveyed; thus, introducing the merits of code-meshing (partnered with code-switching) would rhetorically prepare students for the variety of communicative situations they will encounter upon leaving the university. This research indicates that $68 \%$ of allophone students mesh languages when they communicate, and across the board, students with multilingual language capabilities mesh languages $20 \%$ of the time, regardless of whom they are communicating with in out-of-school situations. It is of note that students mesh languages in out-of-school communication quite consistently among all relativessiblings included (see Table Nine). Again, students use English most often in communication with friends, a possible reason being that friends are not members of their immigrant communities. Still, they mesh languages more often with grandparents than with friends, which corresponds to the above analysis of Table Eight. Most simply, English use correlates to the age of members in a linguistic community; English use increases as age decreases. These findings suggest the students surveyed regularly employ strategies of language meshing, such as regular movement between allophone languages and English in home and community conversation. Moreover, Tables Eight and Nine indicate that the same Canadian students who speak and write in Standardized English in their university classrooms do not necessarily use English when communicating with friends and relatives outside the university. 
Table Nine: Meshing of Languages Outside of School

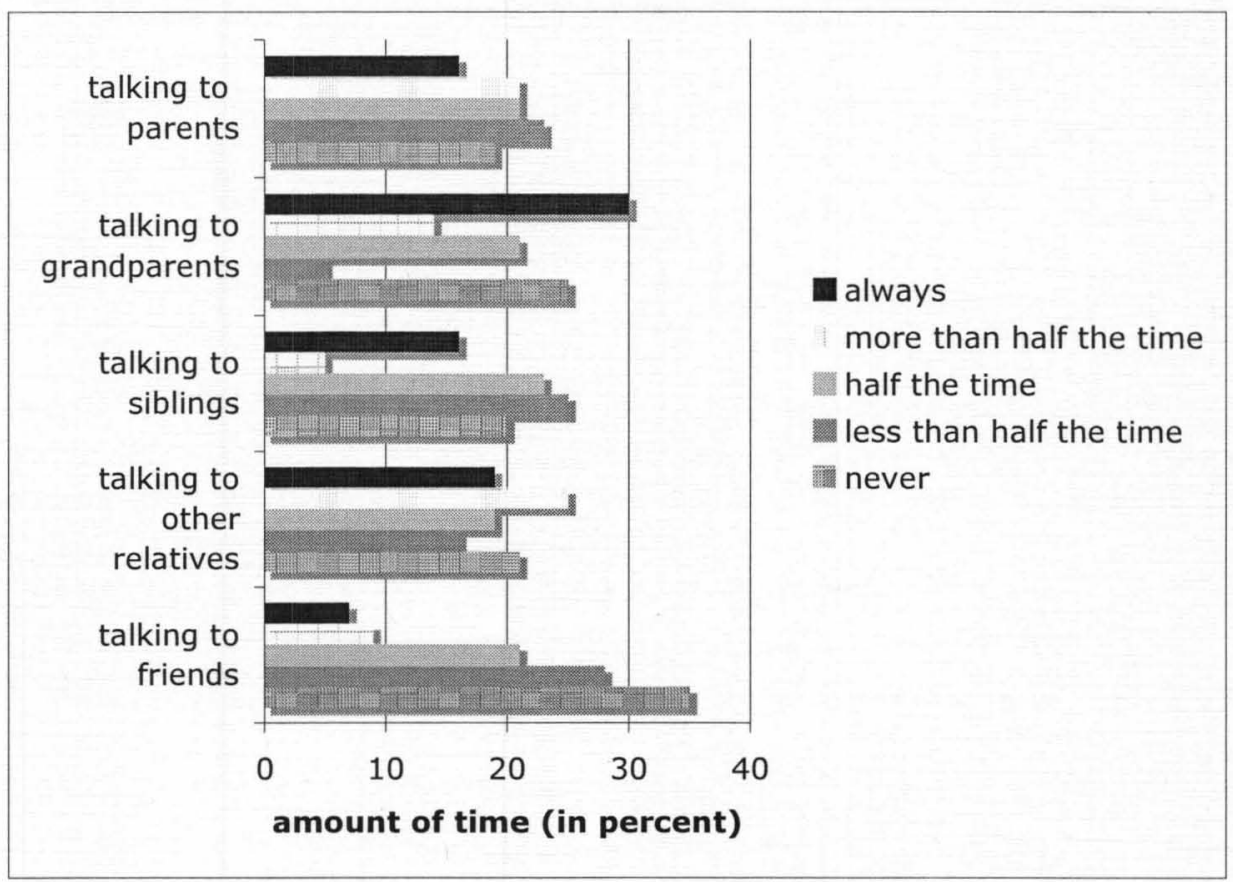

Moreover, when students were asked to distinguish between language meshing and types of communication $75 \%$ of students reported meshing languages in speech, but only $43 \%$ in writing. In formal writing situations, which took place inside of school, less than $12 \%$ of respondents used a language other than English. To better understand how language meshing occurs in written text, students were asked to rank their levels of language meshing in terms of activity. The activities provided to the students included note-taking, drafting, brainstorming, and writing a paper. The vast majority of students only used English in these situations; however, when questioned about cognitive activities, meshing of languages occurred more often, specifically when thinking about a difficult subject (34\%), when considering an essay topic $(22 \%)$, or when trying to remember the appropriate word (59\%). This information tells us that students understand the subject matter and are attempting to create texts in Standardized English, despite the fact that the English words they choose may not be the best fit. As mentioned, the multitude of 
languages being used by the students surveyed indicates that within the classroom English is the lingua franca. In "Lingua Franca English, Multilingual Communities, and Language Acquisition," Canagarajah has argued that uniformity is not a constraint of LFE students; participants bring their own immigrant language to the table when writing in English. As such these students should be encouraged to negotiate their heritage language vocabulary and that of Standardized English—particularly if this negotiation creates texts that demonstrate the students' rhetorical savvy in language awareness. In this sense, students should be encouraged to fully utilize all aspects of their language resources, allophone as well as French and English. As one student put it, "As long as you explain what the word means, it would add richness to your writing." According to Canagarajah, this negotiation is a strategy that enables multilingual students to integrate home languages with Standardized English ("The Place"); moreover, the data collected suggests that this strategy would also enhance the richness of students' thoughts and, consequently, the content of their writing.

Furthermore, when asked to comment on their writing process, participants overwhelming reported that they use only English when planning, free-writing, inventing, peer reviewing, revising, and drafting. To gain a sense of why students have chosen to employ English throughout the writing process, participants were asked to select from a series of reasons why they "use only English," including: English is the only language I know (how to write in), writing using only English is easier, I think the teacher's first language is English, I have never used another language when drafting, I am expected to use English, and I never considered using a language other than English. Additional factors which could be considered, but were not posed to students, concern the privilege 
and linguistic capital associated with English literacy in Canadian society (Gentil 429430) As Table Ten illustrates, the primary reason why students draft in English is because they feel it is an expectation of post-secondary education. The second highest response was that using English is "easier," and the remainder of the responses are distributed fairly equally. The fact that English is "easier" and "expected" is not surprising, after all once these students reach university and college they have been educated primarily in English for at least thirteen years. English is also considered "easier" because thinking in familiar patterns (e.g. English), rather than trying new and different ways of thinking (e.g. moving between languages), is uncomplicated. These patterns are also "easier" because

\section{Table Ten: Why Students Choose English in Academic Writing}

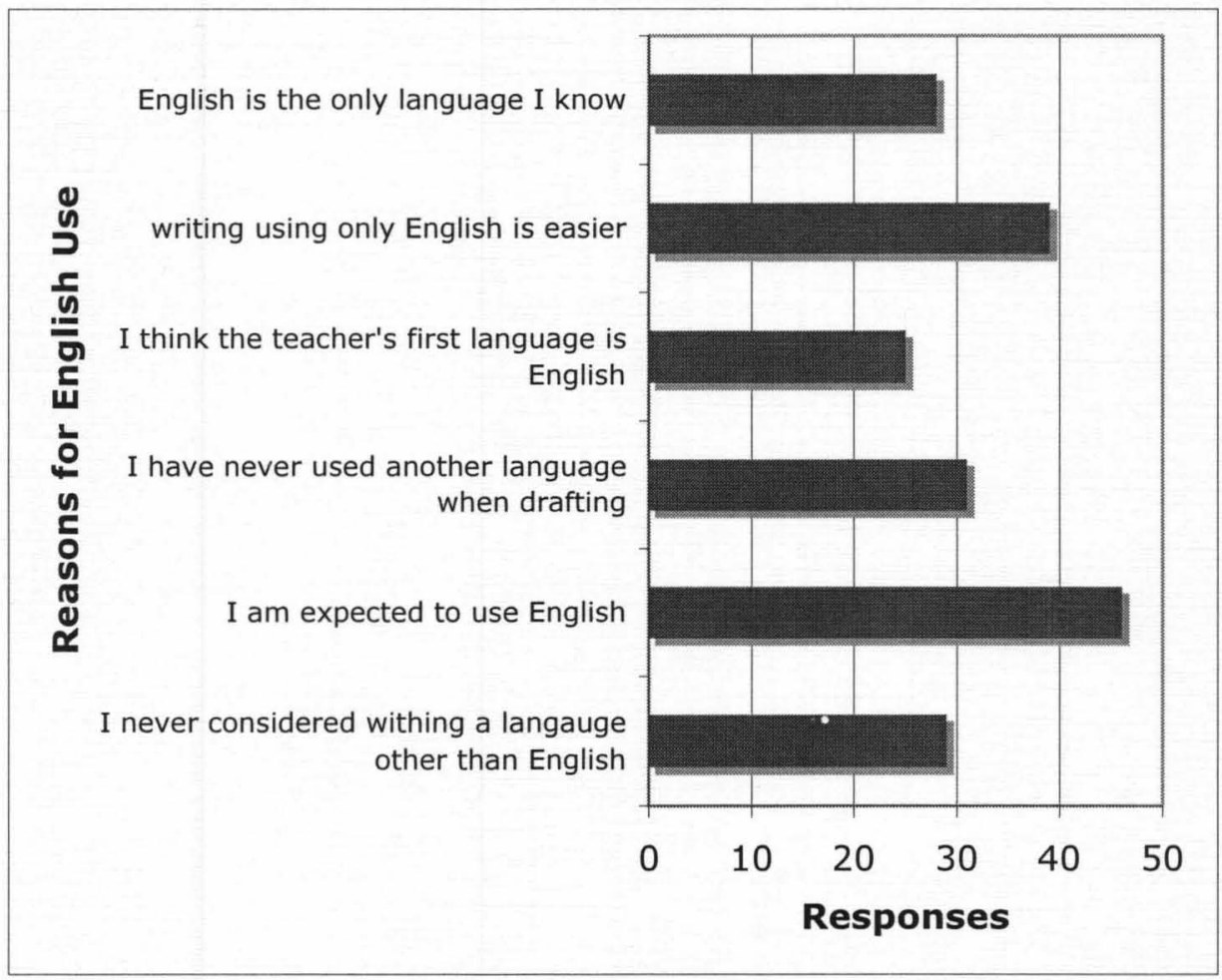

they are rewarded within the academy. Yet, because students choose to utilize a combination of languages outside the university (Table Eight and Nine), as well as think 
in languages other than English when drafting, one may assume that they will continue to do this upon completion of their English Only education. The respondents' choice to code-mesh in certain circumstances exhibits a language competence that is hardly an effortless endeavour. Such rhetorical choices demonstrate communication that is dynamic, situated, and use driven (Larsen-Freeman et al. 160). Consequently, if writing classrooms are working to prepare students for effective communication there is a need to better understand how students are communicating inside and outside the university and how this communication can be improved. One way this can be accomplished is to better understand the process of portfolio writing.

Because the current study has collected data that provide a clear linguistic demographic of students enrolled in first year writing, and as such will function as a foundation for future research in this area, I was particularly interested in how students approach their final portfolio. For instance, a themed portfolio that encourages students to construct and judge cultural and linguistic identity would be influential in designing a writing curriculum that connects with students. However, the data collected show that only a small number of students wrote about topics that related—in any capacity-to their cultural heritage. The fact that students are sitting in classes with such high levels of diversity but not writing about their linguistic and cultural experiences is not surprising; as Chapter Two explains, despite pockets of immense linguistic diversity (as seen amongst students at the University of Windsor) the federal government's multicultural polices do not readily influence the educational choices made by provinces. If policy makers and educators worked together, there are a plethora of ethno-linguistically 
thematic possibilities for Canadian writing curricula, which will be examined more closely in the closing chapter of this text.

The data collected and analyzed in this chapter indicates that the vast majority of students enrolled in first year writing at the University of Windsor retain strong connections to both immigrant heritage(s) and language(s). This information situates this institution as an ideal location to study student multilingualism in Canada, and specifically in the province of Ontario. However, as evidenced in the responses of the student participants, post-secondary education remains entrenched in monolinguistic assumptions that favour Standardized English as well as language segregation. Yet, students reported that the languages used outside classroom - in the home, in home communities, and with friends, etc-incorporate elements of both code-switching and code-meshing. As cited in the opening chapter, a variety of scholars (Canagarajah, Lu, Matsuda, Soliday, Mangelsdorf) have reported the same finding in other regions of North America. While language meshing is not isolated to this continent, the long history of immigration to the United States and Canada has created unique populations of citizens that maintain strong ties to immigrant culture and language, which is particularly evident in the sample of students surveyed herein, and as such are an ideal point of study. There is also a loss of linguistic knowledge, which results from language loss, which could be culturally, economically, and cognitively beneficial to students if maintained. There would also be a benefit to the country as a whole, wherein citizens who hold such knowledge would be positioned to excel in areas of global commerce, cultural exchange, and political dialogue. And, for students particularly, the mobilization of their 
multilingual literacies can work to enhance the quality of their intellectual inquiry, as well as the quality and quantity of meanings and ideas they produce.

Still, despite Canada's bilingual and multilingual pro-active initiatives, multilingual students who enrol in post-secondary institutions continue to practice codeswitching, or Makoni's "plural monolingualism," rather than incorporate elements of code-meshing into their academic writing. The data collected overwhelmingly situates Canadian students (in the region studied) as extremely ethno-linguistically diverse, but, as demonstrated, this diversity continues to be confined to home environments and communities. Inaccessibility to home languages in government institutions, such as postsecondary education, contributes to immigrant social alienation and fails to recognize the importance of home languages upon greater society (Makoni 139). Yet, there exists the possibility to change the current conditions of Canadian writing classrooms; the research indicates that participant diversity provides a valid reason to bring multicultural initiatives into the classroom, which will create learning environments that will foster the very ideologies of Canadian multiculturalism. Chapter Five, which further analyzes student diversity and needs, will build upon this chapter's data findings and position the study at hand to discuss ways in which Canadian writing curricula can be modified to create learning environments that consolidate issues of linguistic diversity by way of accessing pedagogies of code-meshing in conjunction with Canada's multicultural policies. 


\section{CHAPTER FIVE Interview Analysis}

If I were telling a story of my own cultural experiences, mixing languages and providing translations would make my work more real and culturally rich. It would be interesting to be in a learning environment where students from different backgrounds are encouraged to mix languages. As Canadians, we would learn more about other cultures and languages.

-Aruna, Focus Student

The data analyzed in the previous chapter provides a generalized account of a population of students enrolled in first-year writing at the University of Windsor. While the information provides insight into the ways in which multilingual students experience first-year writing in one post-secondary institution in Canada, Chapter Five offers a focused analysis of the linguistic practices of students drawn from interviews. Student interviews offer examples of linguistic diversity that are specific and personalized. This information builds upon the previous chapter's data findings concerning student multilingualism through examining specific challenges faced by students.

This chapter concentrates on interviews with the two focus students. To begin, I analyze the cultural and educational backgrounds of the focus students as well as provide a context for these multilingual students, in terms of the generalized data presented in the previous chapter. This contextualization primarily examines how the focus students have encountered language previously in their academic and non-academic lives, in the context 
of Canadian multiculturalism, and in the context of language mixing (code-meshing, language integration).

Of the questionnaire participants $(n=90)$, two students volunteered to participate in focus interviews. One of these students, Munny, was enrolled in his second year at the University of Windsor and the other student, Aruna, was in her first year ${ }^{25}$. I will present each student's academic and linguistic background separately. Following this introduction, I will discuss their perspectives on language inside and outside the academy, language and multiculturalism, and language mixing (code-meshing, language integration); during this discussion I alternate the interview responses of each focus student rather than addressing each student's point of view separately.

During the period that this research was conducted, Munny was a second-year student majoring in Biochemistry. Munny is a first generation Canadian who was born in Windsor. His parents immigrated to Canada from Vietnam in the nineteen-seventies, and they have lived in Canada for most of their lives. While Cambodian remains his parents' primary language, English was the first language Munny learned to speak, read, and write as a child; as such, he views himself as proficient in all aspects of English language comprehension and communication. Accordingly, Munny identifies primarily as a NES, but he also categorizes himself as (allophone) bilingual in Cambodian. At home, he uses English at least half of the time when communicating with parents, siblings, and other relatives; however, languages are also constantly meshed during communication. This meshing of English and Cambodian occurs with parents and other relatives more than

${ }^{25}$ All interview participants' names have been replaced with pseudonyms. 
half the time and with siblings less than half the time. Meshing occurs in both spoken and written communication.

Aruna, a first-year Biology student, was born in India and immigrated to Canada with her family at the age of eight. As a Generation 1.5 immigrant, it is not surprising that Aruna's first spoken language is not English, but Hindi; she learned English between the ages of two and three, English was also the first language she learned to read and write in. Unlike Munny, Aruna identifies as a NNES (although I would describe her speech and written communication at the level of a NES) as well as (allophone) bilingual in Hindi. While Munny feels confident in only English, Aruna describes herself as equally proficient in her comprehension and spoken ability of English and Hindi; however, she feels more confident reading and writing in English. She describes her parents as holding native-like abilities in all aspects of both languages (comprehension, speech, reading, and writing). At home, Aruna uses English when talking to her parents and siblings more than half the time, her grandparents less than half the time, and other relatives half the time. Like Munny, Aruna and her family regularly move between languages. She frequently meshes when talking to her parents, siblings, and other relatives; however, this meshing only occurs in spoken communication.

Questionnaire data confirmed that language meshing among multilingual students is a communicative strategy that is regularly employed outside the classroom - in common spaces across the university as well as in home and community environments. As discussed in Chapter Four, language meshing occurs seventy-five percent of the time during speech. The focus interviews were able to provide tangible examples of language 
meshing; Munny and Aruna's descriptions of this meshing indicate that they prefer to use allophone languages in out-of-school home communities. For instance, Munny explains,

Sometimes we have Cambodian get togethers - just a normal party of Cambodian people...there's Cambodian New Year in April and that's pretty much just, like, a normal get together and we also have some temple that we go to to pray sometimes... [if you speak English] They'll usually respond in Cambodian, they can understand English, but they will respond in Cambodian.

Similarly, in Aruna's non-academic life,

There's the Hindu Mandir, that's the temple, we go there, we don't really go every week or anything, but whenever there's a celebration, or something like that, there was just the Diwali on Saturday, so we went for that and that's about it...[when we go] we speak Hindi.

These two examples illustrate that the use of allophone languages are an intrinsic and expected cultural identity marker. The events described by Munny and Aruna are authenticated in these communities not simply through attendance, but through linguistic participation. And while there are most likely differing degrees of participation allowed - meshing would be more acceptable at a family gathering than during templethe descriptions offered suggest that to fully participate in the Cambodian New Year or Diwali, members must be able to engage in more than the traditional celebration or ceremony; they are expected to draw on the specific culture's language:

I don't think you can participate in cultures if you don't know the languages much...you need to know both to participate in culture...I'm not too much into the culture because I don't know the language that much (Munny).

Munny and Aruna's depiction of allophone language usage as necessary to participate in these events would suggest that in order to participate fully in cultural celebrations each student must also be able to communicate effectively in their heritage language. However, as Munny explains, this is not really the case,

Now that I'm in university I don't use [Cambodian] much because I'm not home that much, so maybe like ten minutes a day I use it... [in high school] I was home more so I 
talked to my parents more about cooking, how my day was, yeah...[and] they primarily speak Cambodian.

Aruna does not share the same experiences in terms of language loss; perhaps her status as Generation 1.5 immigrant offers one explanation why her oral and comprehension. skills in her allophone language have been maintained, but another reason could be that she still lives at home with her family, who regularly use Hindi in spoken communication, (but they do not use Hindi to the same degree in reading and writing). Whatever the case, while both students do have spoken skills, neither has developed equivalent abilities in the reading and writing of their allophone languages. These experiences point to Li (135) and Laponce's (82) research, which suggests that beyond the first generation of immigration home languages are often lost.

Munny and Aruna's responses on these issues match the data collected via questionnaire, which indicate that with succeeding immigrant generations comes loss of heritage language. Specifically, of the immigrant students, ranging from first to fourth generation, only $12 \%$ acquired their home language as children. A primary reason for so comparatively few respondents acquiring their parents' language seems to be lack of use, which is illustrated in both Munny and Aruna's narratives (e.g. since moving to Canada, Aruna only uses Hindi in speech). In each of these examples it would appear that in order for students to retain home languages they must maintain some level of oral and written linguistic usage; a loss of either of these skills leads to weakened abilities in all aspects of the students' allophone language. Nevertheless, despite this loss, Munny noted,

I'll try to keep my culture with [future children]. It's good to have more than just English, to be bilingual. I think I would try to teach them Cambodian.

This comment occurred as an aside during the interview, a digression during an openended question. However, despite it being an aside, Munny's point is quite telling: there 
is an intrinsic value to home languages and bilingualism as well as a link between language and culture, pointing to the interconnectivity of language and culture. It is almost as if Munny is implying that in order to maintain one's culture one must retain one's language. This reasoning falls in line with the discussion of cultural membership in Chapter Two: in minority language communities language functions not just as a communicative tool, but as a component and characteristic of cultural membership and, consequently, inclusion. Thus, the loss of one's language seems to be followed by the loss of one's culture. This potential loss is implied in Munny's repeated use of "try." $\mathrm{He}$ reiterates that he will "try" to keep his culture and will "try" to teach his language to his children; the echoing of "try" as well as his earlier disclosure, "Now that I'm in university I don't use [Cambodian]," points to a future wherein this student's language and culture may be lost. While there remains the possibility that Munny will reacquaint himself with his immigrant heritage, as $\mathrm{Li}$ and Laponce have shown, there is a greater possibility that Munny's cultural identity will be lost as a result of disuse. Furthermore, in this example, it would appear that Munny's motivation to preserve his culture is at odds with his commitment to preserve his home language.

It is this impending cultural and linguistic loss that is central to my project, particularly in terms of how we can create relationships within the classroom between Canadian multiculturalism and student writing that can help to mitigate this loss. While Canadian multiculturalism policies support citizen—specifically immigrantmaintenance of cultural and linguistic pluralism at least in words, the lack of funding to back up these words suggests that Canadians expect that the maintenance is something that must somehow occur on one's own time, such as during ethnic celebrations (e.g., 
Cambodian New Year or Diwali). However, both focus students have explained that participation in these celebrations is not enough to ensure the survival of allophone languages, suggesting that programs are needed to counteract the loss of immigrant languages and to celebrate the nuances of allophone diversity. One step that could be taken at the post-secondary level is the development of writing curricula that utilize themes of Canadian multiculturalism and multilingualism to teach effective communication and critical thinking. Because so many students at the University of Windsor (as well as several other post-secondary institutions across Canada) have plurilingual capabilities, instructors could quite easily address ideologies of language integration in respect to culture in the classroom through designing assignments that encourage students to use their plurilingualism as a writing resource. My project focuses on the first-year writing classroom because of the flexibility of potential writing prompts, research projects, and final portfolios. Additionally, the diversity of allophone languages and cultures, as well as potential movement into diversalité, provides a rich infrastructure for students to engage in critical thinking activities that are both familiar and strange; in such a classroom students would be encouraged to consider what is similar between cultures and what is different.

In this consideration both culture and language would be central to the writing projects; as Munny expressed, culture and language are mutually dependent. At moments throughout this text I have emphasized the need to bring together aspects of culture and language in the writing classroom, but for the most part I have been speaking from my own experiences. Shortly, I will provide examples of how the two focus students imagine culture and language coming together in the composition of essays for first-year writing. 
Of the two students, Aruna is closer to her home language and as a result appeared more eager to bring Hindi into the writing she undertakes at the university; Munny's relationship with Cambodian has become somewhat removed, and while he explains ways in which his home language could function in university-level writing, his responses are not as engaged as those of Aruna. Consequently, while both students have offered examples, those of Aruna are more generous. For instance, when asked if a home language would be useful in the writing classroom Munny responded fairly succinctly,

I think if it related to the topic, like if you're talking about culture in a paper and you can compare... between English and a different language then yeah I think it's fine.

And while Aruna's initial comment was also brief,

You can really transport your reader to that cultural experience and explore the diversity of your culture with more detail and example.

She elaborated:

It would definitely be useful to use some Hindi words here and there. For example, if I were describing the Indian celebration Holi, the Festival of Colours, it would be fun to describe the Indian dishes with their Hindi names or the prayers associated with Holi in Hindi, with an English translation.

And,

I would include [the Hindi] word maybe in the context of a sentence. For example chai walla would translate to person who delivers tea but I would explain it by saying he or she was the person who approached people individually or else had a little stand to sell his homemade tea on the streets and sometimes in the offices of urban India.

While Munny offers a similar response - in terms of when he would inject his allophone language into an English-language essay - he does not provide the same level of detail.

I'd use a Cambodian word and describe [the word's meaning] in English, what it means...it would show more significance to the culture, I guess, and where it's coming from.

While I have made an attempt to better understand why one of the focus students appeared more enthusiastic about bringing elements of home language into her university 
writing, no real conclusions can be drawn with such a small sample size. I have chosen to attribute Aruna's keenness to the time of her immigration, but her detailed responses could simply be a personal trait that carries over into all aspects of her life. Nevertheless, the information provided by both students demonstrates tangible ways in which allophone languages could be incorporated into writing assignments. The key features of this integration of languages addressed by each student would be writing about culture, which we have seen to be intimately linked to home language, as well as potential cultural topics - food, celebrations, and traditions associated with each of these. This data would suggest that allophone languages can be introduced into the writing classroom through not only assignments that explore the various functions of traditional cultural activities, but, on a larger scale, the development of a multicultural curriculum would also serve to bring allophone languages into other aspects of student writing. For example, attention to the ways different languages can be used to explain concepts and ideas would serve to teach students the benefits of developing arguments within their writing, even those that have no tangible association to their allophone languages. Such a curriculum would base assignments, readings, invention exercises, and so on within a multicultural theme. However, critics have argued that when aspects of multiculturalism have been brought into the educational system, the result is simply the provision of platforms which showcase cultural activities such as food, music, and dance rather than the preservation of the whole culture, thereby excluding language education. Thus, historically, a problem in bringing ideologies of multiculturalism into the classroom is that they are taught using a "foods and festivals" approach, which doesn't concern itself with abstraction, such as 
social justice and power systems. This issue was not addressed during the interview process; however, it will be discussed in the closing chapter.

Students were also asked to consider ways in which meshing languages would be an advantage or drawback in the writing classroom. While both students acknowledged the diversity of languages outside the classroom as well as the meshing that occurs as a result of this diversity, it was only Aruna who offered substantial ways in which language interaction could occur within the first-year writing classroom. However, before I move to Aruna's response I would like to briefly examine the two students' descriptions of language interaction and segregation within both the classroom and the greater university. Munny explained that,

In [the] classroom it's all English, right, and outside the university, like campus, it's pretty much the same as off campus, there's a lot of people that speak different languages.

He went on to add,

I think it's a good thing [using English in the classroom] because it's a universal language and we can all learn it and it's better for outside [the university]...I guess, I don't know... outside I like it better, it's more different cultures, because I like the diversity outside of the classroom, not just all English.

These responses, while somewhat disjointed, are noteworthy because they demonstrate a valuation of both anglophone and allophone languages. Munny's argument that a single language is needed within the classroom reiterates the expectations of the academy as understood by a variety of scholars (Crawford; Horner and Trimbur; Hunt; Matsuda; Trimbur), and as such Munny is unwittingly supporting aspects of language segregation. However, he is also expressing his appreciation and respect for other languages. And, while I concede that some level of language standardization is necessary within the classroom to facilitate learning, I would also suggest that if languages outside this 
standard were brought into the mesh and used by students to enrich their writing the classroom would become a more dynamic, diverse, and rewarding space. For instance, in relation to the promotional framework of the Canadian Multiculturalism Act, students would become more astute and aware of the many cultures and languages at play within society, particularly in terms of discrete language communities and community dynamics. Additionally, the introduction of multiple languages would benefit students in their negotiation of the various shifts in meaning that occur between languages - particularly in translation. These two examples illustrate the rewards available to students enrolled in writing classrooms that support the introduction of allophone languages as resources used to enrich English-medium texts. In a writing classroom based within a multicultural theme, student texts that incorporate allophone languages and perspectives can be used to complement the texts of published authors; this approach could actualize the validity of teaching within this theme, particularly if the texts explored issues at play within policies such as the Canadian Multiculturalism Act. Aruna's response articulates the potential of such a linguistically enriched writing classroom:

[In the classroom] everyone's speaking English...but I think it would be really interesting [to bring in other languages] especially because there is so much multiculturalism in Canada now. But I think it would require a lot more work from a lot of people...but I think it would be really cool if they did...I think it would...help us learn in general, I think it would be really useful, like, in life.

In their comments both students have highlighted the diversity and multiculturalism that are a fundamental marker of Canadian society; moreover, ideologies of multiculturalism were never suggested in questions posed during the interview. What this tells me is that the students themselves view multiculturalism as a potential resource that, in the words of Aruna, would "help us learn" and "be really useful." These student observations suggest that a writing classroom that draws upon students' multicultural heritage has the potential 
to succeed in developing the federal government's multicultural agendas within one facet of post-secondary education, as the students interviewed have indicated they are interested and motivated to consider these issues. In addition, the integration of language meshing - bringing allophone languages into predominately English essays-would work to unite students in terms of general diversity as well as linguistic diversalité. Aruna explains,

I think being allowed to mix languages would encourage me to improve my Hindi, especially in the written word and if I were to write about my heritage, such as an experience I had when I was in India, being able to use cultural words would be enjoyable...you can really transport your reader to that cultural experience and explore the diversity of your culture with more detail and example.

And later in the interview she elucidates,

I sometimes think in mixed languages because there are thoughts that are so attached to Hindi that they are difficult to communicate in English.

Aruna advances three important points in her comments concerning the meshing of home languages and English in the writing classroom: an improvement of home languages, a level of enjoyment when introducing home languages into English-based writing, and a necessity for this introduction to explain specific concepts. All three points suggest the benefits of language meshing. The idea of improving home languages responds directly to policies of the Canadian Multiculturalism Act that support the retention of immigrant minority languages. Thus, bringing home languages into the classroom in this way would extend Canada's current model of pluralism through offering a practical educational initiative that would potentially preserve multiculturalism through its valuation of immigrant languages. Before I address the capacity for enjoyment attached to language meshing, I would like to discuss the necessity of home language inclusion in a curricula based within multiculturalism and linguistic diversity. 
As a number of students noted in the questionnaires, there are words and ideas which exist in certain cultural and language communities that are not easily translatable to other languages - English included. Moreover, when languages are translated there is often a moment of loss, as ideas and concepts are often unique to a specific language. Thus, there is a level of usefulness to translation, in that students would be required to labour more arduously over their words as they seek out the most appropriate English translation. In this way, meshing languages leads to the development of richer thoughts and meanings. Pennycook’s "English as a Language Always in Translation" (34) argues this point, suggesting that a central problem in the way we view language is the perception that it is a monolingual enterprise. He further posits, language competence should be measured not as capacity to perform in one language in a specific domain, but rather as 'the ability to translate, transpose and critically reflect on social, cultural and historical meanings'.

(Pennycook 34)

Ideologies of translation, particularly critical reflection upon the cultural, would be intrinsic to a writing classroom open to negotiations between home languages and English. However, I would also argue that with translation may also come a sacrifice to meaning — as hard as students may try, words do not always translate functionally. However, in addressing ideologies of translation with multilingual students, it must be emphasized that capturing the original meaning is not always the purpose of translation. Instead, one goal of translation is critical reflection upon the historical, particularly the social specificities tied to linguistic meaning. Thus, a writing classroom that embraces notions of language meshing, or movement between languages, must offer translation as an option, but also make students aware of the potential meaning that may be lost (or gained) in translation. Ultimately, students would have to choose, and explain, which 
language negotiation tactics would work in their writing in the creation of a rhetorically sound text.

Here I will return to Aruna's acknowledgement of the enjoyment attached to language meshing. It is a commonly held belief among educators that students who enjoy the subject matter and work will be more engaged in both the classroom and assigned work. Moreover, student satisfaction also leads to instructor satisfaction. Students who are invested in their work produce writing that is motivated and dynamic, a consequence of this is also pride. Ultimately, this pride would carry over to the subject matter, creating new connections to their home languages and cultures-connections which would, ideally, extend beyond the classroom, thereby uniting aspects of their home languages that are currently excluded in writing classrooms that function within English only paradigms. An additional benefit to language negotiation would be its consideration of the many shifting meanings within languages, which could contribute to knowledge generally. Hence, the academy could benefit from students bringing their many allophone languages into the classroom if these languages came to be viewed as resources, particularly in terms of how these languages come to offer multiple representations of single subjects.

The data presented in this and the previous chapter illustrates that very high levels of immigrant diversity exist among students enrolled in first-year writing at the University of Windsor. Moreover, during the interview process students recognized ways in which drawing upon the linguistic diversity already present in the classroom could benefit and enrich student writing inside and outside the university. These findings suggest that the creation of writing classrooms framed to acknowledge and discuss the 
linguistic diversity of Canadians, in terms of both academic and non-academic writing, would be relevant to the students enrolled. Additionally, such classrooms would create spaces where students could critically explore Canadian multiculturalist policy with respect to their own lives, those of their classmates, and the greater society. The development of such programs would respond practically to the lack of current programs that address citizen multiculturalism and multilingualism within the educational system, and as such transition the Canadian Multiculturalism Act into a living document that has a direct impact on the lives of all Canadians. 


\section{CHAPTER SIX \\ Conclusion}

Multiculturalism is no longer about celebrating cultural diversity... multiculturalism is about institutional accommodation and removal of discriminatory barriers.

- Augie Fleras and Jean Leonard Elliot, Multiculturalism in Canada

\section{$\underline{\text { Review of Research }}$}

This project began with a survey of multilingual U.S. composition research so as to emphasize the gap in current scholarship pertaining to multilingualism and writing studies in Canada. In the United States a growing number of compositionists are focusing their research upon shifts in student demographics, particularly the resources associated with students' diverse linguistic backgrounds. Debates between supporters of eradicationism, language segregation, and language interaction remain heated. However, in Canada the same attention has not been paid to multilingual literacies. For this reason it was necessary to begin this project with a review of the current U.S. scholarship, which provided a theoretical basis for the current study. Through exploring Canadian-based relationships between language, identity, citizenship, and academic writing this study has worked to provide insight into how future writing curricula can effectively recognize and respond to the diverse linguistic cultures of Canada's allophone students of immigrant descent. 
Ultimately, this project sought to provide a working description of who Canadian allophone students are and how they are classified in the academy. National and regional student population demographics were described in terms of language and language practices, particularly those at play in the first-year writing classroom. Examining the notions of multilingualism in Canadian language policy and post-secondary curriculum in terms of the current scholarship surrounding the teaching of Standardized Englishparticularly, eradicationism, language segregation, and language interaction-has pointed to a version of the U.S.'s multilingual composition scholarship that plays out in Canadian writing classrooms. In the classrooms studied, English monolingualism not multilingualism was found to be favoured by students. These views position Canadian post-secondary education as aligned with eradicationist ideologies, which privilege English and read difference in terms of error.

In order to arrive at this conclusion a series of steps were taken including the distribution of student questionnaires and student interviews. As previously explained, the primary drawback that occurred during data collection was the limited participationand, thus, sample size — of student interviewees. While the participants did offer rich examples and descriptions, a larger sample size would have offered stronger conclusions and a more thorough evaluation of the experiences encountered by allophone multilingual students. Any future research in this area should consider ways to increase student participation during the interview process.

While all data collected was valuable — to a point—-the student interviews proved most rewarding as they offered specific and detailed examples to questions posed. Nevertheless, questionnaire data was instrumental in creating a demographic description 
of allophone multilingual students, particularly in reference to academic, immigrant, and linguistic background. Future research in this area would require some form of questionnaire or survey, similar to the initial questionnaire distributed in this project (see appendix); however, additional data collection should take into consideration the benefits of instructor-driven action research as well as analysis of student writing. Due to ethics board approval neither of these options was available for this project, yet future projects should strive for these privileges. An action research approach, where the instructor functions as teacher/researcher, would have been extremely beneficial to the data collection process in its potential fostering of relationships between students and teacher as well as creating a true ethnographic environment where the researcher would have numerous points of data collection and analysis including observation of environment/relationships, written student work, questionnaires, interviews, classrocm discussion, and so on. Unfortunately, in the current study, data were really only collected via two sources: questionnaire and interview, which did not offer the same measure of validity as compared to studies that draw from multiple data sources. Despite these limitations, a large amount of data was collected and analyzed. As the findings and conclusions were drawn from two sources-student questionnaires and interviews-the results of this research were also, to a degree, separated during analysis; however, all data come together in the recommendations offered below.

The research can be viewed as successful in its offering of a working description of Canadian allophone students; however, the data and conclusions only pertain to a selection of students at one university and as such are hardly universal. Nevertheless, the findings point to a prevalence of allophone multilingualism amongst the students 
surveyed and, consequently, suggests that the University of Windsor would be a suitable location for future research in this area. Moreover, because the city of Windsor is not particularly unique in terms of cultural and linguistic pluralism, the findings suggest the need to extend the focus of future research to other regions in order to further corroborate the data herein, especially given the limited geographic focus of this project. The study's findings, which offer a Canadian contextualization of allophone multilingualism and writing scholarship, point to a classroom environment that prefers eradicationism and language segregation over language interaction and language negotiation. This conclusion is drawn from student's avoidance of languages other than English in the classroom and during the writing process. However, this is not to say that ideologies of language interaction and language negotiation will never have a place in the Canadian writing classroom; in order to fully assess the value of a writing curriculum that favours these practices further research must be conducted. As emphasized throughout, the Canadian Multiculturalism Act has been central in the development of this thesis; however, it would appear that the Act's tenets of Canadian citizen's "acquisition, retention and use of all languages that contribute to the multicultural heritage of Canada" (Canadian Multiculturalism Act) are not at play in the writing classroom. This separation of policy and practice can be attributed to the Act's implicit endorsement of a version of multilingualism that is based within linguistic separation.

This research suggests that while English-medium instruction is the lingua franca of the academy, there is room to respond to the diverse linguistic needs and realities of allophone multilingual students, which would serve to support the preservation and interaction of our students' and Canadian society's collective and diverse heritages. The 
predominance of cultural diversity in institutions, such as the University of Windsor, acknowledges this position.

In regard to this project's analysis of allophone multilingualism and first-year writing in current Canadian post-secondary educational practice, the data collected shows Canadian understandings of multilingualism to be comparable to mainstream practices in the rest of North America as well as abroad. Simply, Canadian classrooms expect and favour practices of English monolingualism, conforming to ideologies of eradicationism and language segregation. This finding is not startling as it is the academic norm in English-medium post-secondary education worldwide; however, when one considers the high levels of multilingualism and cultural diversity present within Canadian society as well as the many steps the Canadian government has taken to support its multicultural heritage it is somewhat surprising that multilingualism has not, as yet, been considered a resource to students enrolled in first-year writing. This is particularly of note when one considers the increasing levels of international writing research concerned with multilingualism (Blommaert et al; Canagarajah; Harris, et al; Makoni; Matsuda; Matsuda and Silva; Smoke; Lo Bianco; Lu; Rampton; Rassool etc.) that is occurring in countries other than Canada — countries that do not boast the same level of cultural and linguistic acceptance as suggested by policies such as the Canadian Multiculturalism Act. Thus, if we consider Canada as a leader in multilingual acceptance it seems only fitting that future writing research move further into discussions of language interaction and language negotiation.

Moreover, if we consider the work being accomplished to promote plurilingualism in European Union countries, specifically the Common European 
Framework of Reference (CEFR) for language education, the ability for Canadian postsecondary education to offer a complimentary program of multilingual support slips into a position of attainability. The recent decision of the CEFR encourages a kind of quadrilingualism, providing:

a basis for the mutual recognition of language qualifications, thus facilitating educational and occupational mobility... used in the reform of national curricula and by international consortia for the comparison of language certificates.

(Council)

Ultimately, the CEFR is validating of diverse language competences among students. Specifically,

Its purpose is to provide a response to the need to formulate language policies to promote plurilingualism and diversification in a planned manner so that decisions are coherently linked. Accordingly, the Guide does not promote any particular language education policy but attempts to identify the challenges and possible responses in the light of common principles.

(Council)

The European Union's promotion of plurilingual acceptance, which is based within interaction and negotiation, may be criticized by those who continue to promote English monolingualism as an intrinsic measurement of national identity. For example, Horner and Trimbur explain that in the U.S. English Only ideologies function as xenophobic-in their response to immigration-wherein immigrants are seen as a threat to the nation's cultural identity and linguistic purity. And while the pitfalls of English Only would appear obvious to readers of this project (homogenization, exclusion, elitism, etc), supporters feel that a singular national language/culture is necessary to uphold a true nation-state, that the status of English is fixed and not dependent upon geographical space/place, and that immigrants only need to know English to function in U.S. society ("English Only"). However, there is also growing support for initiatives like the CEFR. 
Leung, Harris, and Rampton's research in the U.K. acknowledges the complex relationship between language learning and language use within monolingual classrooms that teach primarily multilingual students. The authors position that in order to create effective writing pedagogies, which are currently based within English Only and nationstate rhetoric, teachers and policies makers must view immigrants as permanent and an intrinsic part of nation state, rather than foreign alien. This is exactly what the CEFR is attempting. Additionally, Lo Bianco's "Multiliteracies and Multilingualism" describes the English language as moving away from its current lingua franca categorization and, instead, assuming the role of lingual mundi. In this repositioning of English, Lo Bianco explains that intra- and inter-language tensions are working to destroy the false, or mythical, conceptualizations of countries holding a single and distinct national identity through language. In the past, nation-states have worked to create unitary language expectations to create unique expectations of nationhood, which has resulted in the marginalization of multilingualism. However, as we are met with shifting national and global realities of multiliteracies we see the ways in which language is moving towards an inherently multilingual existence, free of monolingual nation-state boundaries and assumptions.

Globally, research that embraces and encourages multilingual interaction within education, particularly post-secondary education, is flourishing; yet much of the research on multilingualism and education in Canada focuses on primary and secondary education, or Québécois francophone culture versus national French-English bilingualism (Hayday; Heller; Taylor). Canadian research must shift to concern itself with the relationships between multilingual allophone populations and post-secondary education-areas of 
language research underrepresented in current scholarship (Bleasdale; Bumsted; Gentil;

Hayday; Heller; MacMillian; Li; Lotherington et al; Taylor). Future research must assess how post-secondary institutions can utilize the Canadian Multiculturalism Act as a resource to encourage cultural and linguistic diversity. By testing and analysing approaches to multilingualism, particularly those related to language interaction and writing studies, research can provide example and insight into how educators and policy makers can approach and realize the conflicts and struggles that Canadian allophone students face. Ultimately, such scholarship will respond to gaps in international, North American, and Canadian multilingual scholarship.

\section{$\underline{\text { Research Recommendations }}$}

The findings of this study are far from conclusive; however, they do offer needed insight into the ways in which multilingualism exists and is treated at one Canadian postsecondary institution. What is most usable, at this point, are the questionnaire findings as these offer descriptive as well as demographic details concerning multiculturalism and multilingualism amongst a substantial sample size of students enrolled in first-year writing. The interview data obtained from students serves to provide an awareness of the ways in which allophone multilingualism operates inside and outside the academy that has not been documented in previous research. However, the interview data presented, while intriguing, can only impart a preliminary understanding of allophone multilingualism in terms of the Canadian writing classroom. Consequently, I am applying for a post-doctoral fellowship, from the Social Sciences and Research Council of Canada (SSHRC), so that these initial findings can be better contextualized in terms of student relationships to heritage languages and the writing they produce in the classroom. In 
other words, I feel that the information obtained thus far is compelling, yet requires further inquiry in order to offer a convincing argument; this project provides reasons why multilingualism within the writing classroom should be studied, but fails to provide the needed substantiation. Specifically, the data collected offers detailed information concerning the discrete languages and linguistic communities students are part of, as well as how they use language in their daily lives. However, the study does not offer any analysis of the ways in which multilingual initiatives, via coursework, can be integrated into the writing classroom; it is essential that future research consider the ways in which such initiatives can improve student learning. This research points to two areas of underrepresented research in Canadian writing research concerned with multilingualism; namely, (a) the temptation to acknowledge and thereby universalize the Canadian experience, which is predominantly anglophone (Statistics Canada), ultimately projecting English as the language of choice upon all students, as well as (b) the suggestion the Canadian government's policies of multiculturalism are equally applicable to all citizens. However, there is no curricular unpacking of these problems, particularly in terms of how the competing approaches to language differences-eradicationism, language segregation, and language interaction —are negotiated in Canadian post-secondary institutions.

In order to substantiate the current project, U.S. research should be used to develop a Canadian context for the employment of allophone multilingualism as a pedagogical resource (Canagarajah; Lu; Matsuda; Matsuda and Silva; Smoke; Soliday). This research would work to develop Canadian-specific pedagogies, which would offer a descriptive analysis of Canadian writing contexts as well as the diverse linguistic student 
populations in Canada. The work of international scholars must be adapted to consider the ways allophone multilingualism functions as a phenomenon of globalization within a Canadian context (Appadurai; Harris et al; Kachru; Rampton; Street). To achieve these ends, future research should be set within an action research framework. As a methodology action research has been in use since the mid-twentieth century, being developed within a variety of fields (including writing studies and education). It is defined as comparative research based within social action, leading to recommendations for change (McLaren; Lewin). Action research differs from participant observation, ethnography, and simple textual analysis in its emphasis upon social action. It does more than collect and analyze data; it calls for the researcher to critically reflect upon research conditions, pedagogical practices, as well as data collection, creating a research driven atmosphere based within reflective practice. Implicit in this methodology is identification of a problem; collection, organization, and interpretation of data; and action/recommendation based on data analysis. Using action research, a writing course based within a multicultural-multilingual context could be developed, wherein all readings, assignments, activities, and classroom discussions extend from this theme. This course will differ from current writing courses in that student work will always be functioning within a multicultural-multilingual agenda. Readings would include excerpts from the CMA, the work of Canadian multicultural scholars, literature featured in a Canadian multicultural anthology (e.g. Kamboureli's Making a Difference: Canadian Multicultural Literature), as well as current-event pieces from Canadian magazines and newspapers; students would be asked to write essays in response to these readings as well 
as texts produced by their classmates. In this way, the course would promote social action.

Moreover, the methodology of action research would be central to data collection (including student writing, interview, observation, questionnaire, student evaluations) due to its focus on real world contexts; its attempt to understand events from participant perspectives; data collection from multiple sources; as well as analysis of data in terms of the meaning and function of participant actions (Lillis). These research activities would provide a pedagogical analysis of students' reactions to coursework, assessing what strategies are successful in terms of student engagement with the coursework and subject matter. Analysis of data would address the proposed research question in its examination into how the Canadian Multiculturalism Act's policies can effectively integrate into postsecondary education.

Thus, future research should work to develop writing courses that examine multiculturalism as a living and functioning element of Canadian society. As noted in the analysis of the student interviews, the potential of a writing course that draws upon multiculturalism appealed to allophone students. The two students interviewed, Munny and Aruna, expressed that issues of multiculturalism are intimately linked to home languages. This finding suggests that allophone languages could be a resource to a writing classroom that is thematically based in multiculturalism; in such a classroom the assignment of essays that explore traditional cultural activities would function as a platform for discussions of language interaction and negotiation. Furthermore, this field of inquiry could be expanded beyond the writing classroom, and consider the ways in 
which learning could be facilitated in the greater academy as well as within local and national communities.

A writing course based within multiculturalism needs to be relevant to both the students being taught and the larger community. In order for students to truly invest in such a class they will need to be engaged. Encouraging students to explore sameness and difference in the multicultural traditions of their peers readies them to work from the position of expert and novice when composing written texts, which is an ideal situation when developing the skill of critical inquiry. A writing course that considers how cultural and linguistic diversity can be used as a resource to students during the process of making meaning has enormous potential, in terms of prompts, discussion, research, etc. Because these traditions have the ability to cross over into disciplines of anthropology, history, literature and so on they offer dynamic approaches to the teaching of multiculturalism. When students are encouraged to consider issues of cultural and linguistic plurality in their writing they are given the opportunity to look at their peers in new ways, and analyze how the writing of their classmates' experiences is both unique and ordinary. Thus, topics of multiculturalism can allow teachers to create a space where students and teachers alike can be unified and divided in terms of individual agency and community. Moreover, emphasizing the similarity and difference between cultures encourages selfexploration and requires students to question how their individual experiences fit into Canada's mosaic.

Writing about Canadian multiculturalism would create a space for students to author texts that are meaningful to them as well as their classmates and the larger community that exists outside the university. In terms of our students, curricula based 
within multiculturalism offer a variety of benefits - classrooms that cultivate diversity are not simply places to learn, but provide an environment that fosters relationships between a community of peers, which encourages students to be critically reflective and grow intellectually. Multicultural writing prompts provide practical approaches to promote pluralist ideologies within our pedagogies, affording students a platform to explore how the many cultures of Canada collide and manifest within a single classroom. Moreover, as this research has shown, intercultural community building is not always cultivated in society, despite initiatives like the Canadian Multiculturalism Act. Therefore there is a need for universities and colleges to create support systems. While most research to date has explored the failure of multicultural advancement, cultivation, and functionality within Canadian society, this study suggests ways in which post-secondary education can take a proactive stance and create specific courses that foster and encourage multicultural learning.

\section{Final Summary}

The data presented herein indicates that the vast majority of student participants enrolled in first-year writing at the University of Windsor retain strong connections to immigrant language(s). However, Canadian post-secondary education remains entrenched in monolinguistic assumptions that favour Standardized English. Despite Canada's bilingual and multilingual pro-active initiatives, multilingual students who enrol in postsecondary institutions continue to practice Makoni's "plural monolingualism," rather than bring elements of language meshing to academic writing. The data collected overwhelmingly situates Canadian students (in the region studied) as extremely ethno- 
linguistically diverse, but, as demonstrated, this diversity continues to be confined to home environments and communities. Inaccessibility to home languages in government institutions, such as post-secondary education, contributes to immigrant social alienation and fails to recognize the importance of home languages upon greater society (Makoni). However, there exists the possibility to change the current conditions of Canadian writing classrooms. The research indicates that participant diversity provides a valid reason to bring multicultural initiatives into the classroom, which will create learning environments to foster the very ideologies of the Canadian government's cultural mosaic.

The notion of bringing immigrant home languages into the classroom responds directly to policies of the Canadian Multiculturalism Act that support the retention of immigrant minority languages. Thus, the introduction of allophone languages into the English-medium classroom would function to uphold the Canadian government's current model of pluralism through offering a practical educational initiative that would potentially preserve the nation's cultural heritage through its valuation of immigrant languages.

The lingua franca of both the education system and greater Canadian society is English. However, while there are also many communicative situations where English is the language of choice in Canada there are also instances when language negotiation is more effective, particularly in areas saturated with immigration. Consequently, writing teachers should be trained to offer options beyond English only. In his research, Guillaume Gentil suggests that social forces are central to our commitment to the empowerment of students who possess allophone languages; I believe one of these forces is the recognition of government multiculturalist policies in the classroom. Gentil 
considers the establishment of social conditions that embrace multilingual sustainability as central to writing instruction. Bringing ideologies of the Canadian Multiculturalism Act into the writing classroom would serve to empower allophone students through engendering student awareness and encouraging multilingual dialogue.

Because a large population of students across Canada have allophone capabilities, ideologies of language negotiation in respect to culture could quite easily be addressed in the classroom. This project focuses on the first-year writing classroom because of the flexibility of potential writing prompts, research projects, and final portfolios. Additionally, the diversity of allophone languages and cultures provides a rich infrastructure for students to engage in critical thinking activities that are both familiar and strange; in such a classroom students would be encouraged to consider what is similar between cultures and what is different.

The existence of a policy such as the Canadian Multiculturalism Act would suggest that language variety and moving between languages are constants in all areas of Canadian society. However, students who attend postsecondary institutions in Canada are confined to English. This monolingual expectation works to every students' detrimentmonolingual and mutltilngual alike. In it its failure to recognize that knowledge extends beyond English, recognizing only one language limits student knowledge to one experience, ignoring the many knowledges and knowledge practices at play. Such an approach restricts access to cultural and linguistic knowledge. This project argues that we need to view difference as resource, where students' home languages and cultures become an asset to their linguistic development. Writing classrooms need to be redesigned as spaces where students can draw upon sameness and difference without 
inhibition. Moreover, because the Canadian government's commitment to intercultural community building positions universities and colleges as integral in the creation of linguistic support systems, it is necessary to provide educational spaces where students can draw upon their plurilingual abilities. This project illustrates that the multicultural and multilingual ecology of our Canadian classrooms situates them as ideal sites for engendering student awareness and encouraging multilingual dialogue. However, it is not enough to realize the linguistic potentiality of Canadian society and its education systems; future research must work to implement the government's multilingual policies in post-secondary classrooms. 


\section{REFERENCES}

Appadurai, Arjun. Modernity at Large: Cultural Dimensions of Globalization. Minneapolis, MN.: U of Minnesota P, 1996.

Armour, Leslie. "Language, Culture and Values in Canada at the Dawn of the $21^{\text {st }}$ Century: A retrospective." Language, Culture and Values in Canada at the Dawn of the $21^{\text {st }}$ Century. Eds. André Lapierre, Patricia Smart, and Pierre Savard. Ottawa: Carleton UP, 1996. 15-30.

Ashworth, Mary. "More Than One Language." Multiculturalism, Bilingualism and Canadian Institutions. Ed. Keith A McLeod. Toronto: Faculty of Education, University of Toronto, 1979. 80-88.

Bakhtin, M.M. The Dialogic Imagination. Austin: U of Texas P, 1981.

Ball, Arnetha, and Ted Lardner. "Dispositions toward Language: Teacher Constructs of Knowledge and the Ann Arbor Black English Case." College Composition and Communication 48.4 (1997): 469-85.

Bean, Janet, Cucchiara, M., et al. "Should We Invite Students to Write in Home Languages? Complicating the Yes/No Debate." Composition Studies 31.1 (2003): $25-42$.

Bernabé, Jean, Patrick Chamoiseau, and Raphaël Confiant. Éloge de la Créolité. Paris: Gallimard, 1993.

Bhabha, Homi. "Cultures in Between." Questions of Cultural Identity. Ed. Stuart Hall. London: Sage, 1996. 53-60.

---. The Location of Culture. London: Routledge, 1994.

Blakeslee, Ann M. "Activity, Context, Interaction, and Authority: Learning to Write Scientific Papers in Situ." Journal of Business and Technical Communication. 11 (1997): 125-168.

Bleasdale, Tom. "Labour's Stand on the Language Issue in Canada." Multiculturalism, Bilingualism and Canadian Institutions. Ed. Keith A. McLeod. Toronto: Faculty 
of Education, University of Toronto, 1979. 32-36.

Blommaert, J., Muyllaert, N, et al. "Peripheral Normativity: Literacy and the Production of Locality in a South African Township School." Linguistics and Education: An International Research Journal, 16.4 (2005): 378-403.

Bridgeman, B, and S. Carlson. "Survey of Academic Writing Tasks." Written Communication 1 (1984): 247-80.

Bruch, Patrick, and Richard Marback. The Hope and the Legacy: The Past, Present, and Future of "Students' Right to Their Own Language". Cresskill, NJ: Hampton, 2004.

Bumsted, J. M. The Peoples of Canada: A Post-Confederation History, $3^{\text {rd }}$ ed. Oxford: Oxford UP, 2008.

Canagarajah, A. Suresh. Resisting Linguistic Imperialism in English Teaching. Oxford: Oxford UP, 1999.

---. Critical Academic Writing and Multilingual Students. Ann Arbor: U of Michigan P, 2002.

---. A Geopolitics of Academic Writing. Pittsburgh: U of Pittsburgh P, 2002.

---. "Multilingual Writers and the Academic Community: Towards a Critical Relationship." Journal of English for Academic Purposes 1.1 (2002): 29-44.

---. "Toward a Writing Pedagogy of Shuttling between Languages: Learning from Multilingual Writers." College English 68 (2006): 589-604.

---."The Place of World Englishes in Composition: Pluralization Continued." College Composition and Communication 57 (2006): 586-619.

--.. "Lingua Franca English, Multilingual Communities, and Language Acquisition." Modern Language Journal 91 (2007): 921-937.

Chiang, Yuet-Sim D. and Mary Schmida. "Language Identity and Language Ownership: Linguistic Conflicts of First-Year University Students." Generation 1.5 Meets College Composition: Issues in the Teaching of Writing to U.S.-Educated Learners of ESL. Ed. Linda Harklau, Kay M. Losey, and Meryl Siegal. Mahwah, NJ: Erlbaum, 1999. 81-96.

Clary-Lemon, Jennifer. "Shifting Tradition: Writing Research in Canada." American Review of Canadian Studies 39.2 (2009): 94-111.

Comeau, Paul. "Multiculturalism and Bilingualism at the Community Level." 
Multiculturalism, Bilingualism and Canadian Institutions. Ed. Keith A McLeod. Toronto: Faculty of Education, University of Toronto, 1979. 37-41.

Confiant, Raphaël. "Rejeter nos Langues nationales est un suicide." Repeating Islands. 11 Aug. 2009. Web. 9 May 2010.

Council of Europe. "Common European Framework of Reference for Languages: Learning, Teaching, Assessment (CEFR)." n.d. Web. 12 September 2010. http://www.coe.int/t/dg4/linguistic/CADRE_EN.asp

Coupland, Nikolas. "Sociolinguistic Prevarication about 'Standard English.' Journal of Sociolinguistics 4.4 (2000): 622-634.

Crawford, James. Hold Your Tongue: Bilingualism and the Politics of "English Only" Reading: Reading, Mass: Addison-Wesley, 1992.

Cullen, J. S.G. "Immigration and Canada." Multiculturalism, Bilingualism and Canadian Institutions. Ed. Keith A McLeod. Toronto: Faculty of Education, University of Toronto, 1979. 23-26.

Cushman, Ellen. "The Rhetorician as an Agent of Social Change." College Composition and Communication 47 (1996): 7-28.

Denis, Wilfrid. "Language in Saskatchewan: Anglo-hegemony Maintained." Language in Canada. Ed. John Edwards. Cambridge: Cambridge UP, 1998. 425-42.

Delpit, Lisa. "The Silenced Dialogue: Power and Pedagogy in Educating Other People's Children." Cross Talk in Composition Theory. Ed. Victor Villanueva. Urbana, IL: 1997. 565-88.

Elbow, Peter. 'Inviting the Mother Tongue and Beyond 'Mistakes,' 'Bad English,' and 'Wrong Language."' JAC 19 (1999): 359-88.

Fleras and Elliot. Multiculturalism in Canada. Scarborough: Nelson Canada, 1992.

Friedrich, Patricia, and Aya Matsuda. "When Five Words Are Not Enough: A Conceptual and Terminological Discussion of English as a Lingua Franca." International Multilingual Research Journal 4.1 (2010): 20-30.

Genesee, Fred. "Schools, Bilingualism, and Multiculturalism." Multiculturalism, Bilingualism and Canadian Institutions. Ed. Keith A McLeod. Toronto: Faculty of Education, University of Toronto, 1979. 89-101.

Gentil, Guillaume. "Commitments to Academic Biliteracy: Case Studies of Francophone University Writers." Written Communication 22 (2005): 421-71. 
Graves, Roger. Writing Instruction in Canadian Universities. Winnipeg: Inkshed Publications, 1994.

Grenier, Line and Guilbault, Jocelyne. "Créolité and Francophonie in Music: SocioMusical Repositioning Where it Matters.” Cultural Studies 11.2 (1997): 207-34.

Harris, R., Constant Leung, and Ben Rampton. "Globalization, Diaspora and Language Education in England." Globalization and Language Teaching. Eds. David Block and Deborah Cameron. London: Routledge, 2002. 29-46.

Harrison, Brian R. "Intergenerational Language Learning." Immigrant Canada: Demographic, Economic, and Social Challenges. Eds. Shiva S. Halli and Leo Driedger. Toronto: U of Toronto P, 1999. 307-19.

Hayday, Matthew. Bilingual Today, United Tomorrow: Official Language in Education and Canadian Federalism. Montreal and Kingston: McGill-Queen's UP, 2005.

Heller, M. Bilingualism: A Social Approach. New York: Palgrave Macmillan, 2007.

---. "Globalization, the New Economy, and the Commodification of Language and Identity." Journal of Sociolinguistics 7 (2003): 473-92.

---. "Globalization and the Commodification of Bilingualism in Canada." Globalization and Language Teaching. Eds. David Block and Deborah Cameron. London: Routledge, 2002. 47-63.

Horner, Bruce. "Cross-Language Relations in Composition." College English 68.6 (2006): 569-74.

--. " 'Student's Right,' English Only, and Re-imagining the Politics of Language." College English 63.6 (2001): 741-58.

Horner, Bruce, and Min-Zhan Lu. "Resisting Monolingualism in 'English': Reading and Writing the Politics of Language." Rethinking English in Schools: A New and Constructive Stage. Eds. Viv Ellis, Carol Fox, and Brian Street. London: Continuum, 2007. 141-57.

Horner, Bruce, and John Trimbur. "English Only and U.S. College Composition." College Composition and Communication 53.4 (2002): 594-630.

Hubert, Henry A. Harmonious Perfection: The Development of English Studies in Nineteenth-Century Anglo-Canadian Colleges. East Lansing: Michigan State UP, 1994.

Hunt, Theodore W. "The Place of English in the College Curriculum." PMLA 1 (1885): 118-132. 
Johns, A. and M. Kelley Sipp. Diversity in College Classrooms: Practices for Today's Campuses. Ann Arbor: U of Michigan P, 2004.

Juzwik, M., S. Curcic, et al. "Writing Into the 21st Century: An Overview of Research on Writing, 1999 to 2004." Written Communication 23 (2006): 451-76.

Kachru, Braj. The Alchemy of English: The Spread, Functions, and Models of Nonnative Englishes. Urbana: U of Illinois P, 1990.

Kamboureli, Smaro. Making a Difference: Canadian Multicultural Literature, $2^{\text {nd }}$ ed. Toronto: Oxford UP, 2007.

King, Ruth. "Language in Ontario." Language in Canada. Ed. John Edwards. Cambridge: Cambridge UP, 1998. 400-414.

Larsen-Freeman, Diane, and D. Freeman. "Language Moves: The Place of "Foreign" Languages in Classroom Teaching and Learning. Review of Research in Education. 32.1 (2008): 147-86.

Laponce, Jean A. "Minority Languages in Canada: Their Fate \& Survival Strategies." Language, Culture and Values in Canada at the Dawn of the $21^{\text {st }}$ Century. Ed. André Lapierre, Patricia Smart, and Pierre Savard. Ottawa: Carleton UP, 1996. $75-88$.

Leavitt, Robert M. "Language in New Brunswick." Language in Canada. Ed. John Edwards. Cambridge: Cambridge UP, 1998. 373- 384.

Lerner, L. "Laboratory Lessons for Writing and Science." Written Communication 24 (2007): 191-222.

Leung, Constant, R. Harris, and Ben Rampton. "The Idealized Native Speaker, Reified Ethnicities, and Classroom Realities." TESOL Quarterly 31 (1997): 543-75.

Lewin, K. "Action Research and Minority Problems." Journal of Social Issues 2 (1946): 34-46.

Li, Peter S. Destination Canada: Immigration Debates \& Issues. Oxford UP, 2003.

Lillis, Theresa. "Ethnography as Method, Methodology, and Deep Theorizing." Written Communication 25.3 (2008): 353-88.

Lo Bianco, J. "Multiliteracies and Multilingualism." Multiliteracies: Literacy Learning and the Design of Social Futures. Eds. B. Cope and Mary Kalantzis. London: Routledge, 2000. 92-105. 
Lotherington, H., M. Holland, et al. "Project-Based Community Language Learning: Three Narratives of Multilingual Story-Telling in Early Childhood Education." Canadian Modern Language Review 65.1 (2008): 125-45.

Lovejoy, Kim Brian, "Practical Pedagogy for Composition." Language Diversity in the Classroom: From Intention to Practice. Eds. Geneva Smitherman and Victor Villanueva. Carbondale: Southern Illinois UP, 2003. 89-108.

Lu, Min-Zhan. "Living-English Work." College English 68.6 (2006): 605-19.

-.-. "An Essay on the Work of Composition: Composing English Against the Order of Fast Capitalism." College Composition and Communication 56 (2004): 16-50.

---. "Professing Multiculturalism: The Politics of Style in the Contact Zone." College Composition and Communication 45.4 (1994): 442-58.

Lutz, Jean, and Mary Fuller. "Exploring Authority: A Case Study of a Composition and a Professional Writing Classroom." Technical Communication Quarterly 16.2 (2007): 201-33.

Lyons, Scott. "The Fine Art of Fencing: Nationalism, Hybridity, and the Search for a Native American Writing Pedagogy.” JAC 29.1-2 (2009): 77-105.

MacMillian, C. Michael. The Practice of Language Rights in Canada. Toronto: U of Toronto P, 1998.

Mangelsdorf, Kate. "Spanglish as Alternative Discourse: Working against Language Demarcation." Cross-Language Relations in Composition. Ed. Bruce Horner, Min-Zhan Lu, and Paul Kei Matsuda. Carbondale: Southern Illinois UP, 2010. $161-81$.

Makkai, Valerie Becker. Phonological Theory: Evolution and Current Practice. New York: Holt, 1972.

Makoni, Sinfree. "From Misinvention to Disinvention of Language: Multilingualism and the South African Constitution." Black Linguistics: Language, Society, and Politics in Africa and the Americas. Eds. Sinfree Makoni, Geneva Smitherman, Arnetha F. Ball, and Arthur R. Spears. London: Routledge, 2003. 132-51.

Martel, Angéline. Official Language Minority Education Rights in Canada: From Instruction to Management. Office of the Commissioner of Official Language, Government of Canada, 1991.

Matsuda, Paul Kei. "The Myth of Linguistic Homogeneity in U.S. College Composition." College English 68.6 (2006): 637-51. 
Matsuda, Paul Kei, and Tony Silva. "Cross-Cultural Composition: Mediated Integration of U.S. and International Students." Composition Studies 27 (1999): 15-30.

McLaren, Peter. Life in Schools: An Introduction to Critical Pedagogy in the Foundations of Education, 5th ed. Boston, MA: Pearson, 2007.

Minister of Public Works and Government Services. New Perspectives: The Canadian Heritage Approach to Official Language Support (1970-2003). Canadian Government, 2006.

Munro, John. "Multiculturalism-the Policy." Multiculturalism, Bilingualism and Canadian Institutions. Ed. Keith A McLeod. Toronto: Faculty of Education, University of Toronto, 1979. 12-15.

Newkirk, Thomas. "Seduction and Betrayal in Qualitative Research." Ethics and Representation in Qualitative Studies of Literacy. Ed. Peter Mortensen and Gesa Kirsch. Urbana, IL: NCTE, 1996. 3-16.

Pennycook, Alastair. "English as a Language Always in Translation." European Journal of English Studies 12.1 (2008): 33-47.

Pratt, Mary Louise. "Art of the Contact Zone." Ways of Reading, 5th edition. New York: St. Martin's, 1999. 581-96.

-.-. "Linguistic Utopias." The Linguistics of Writing: Arguments between Languages and Literature. Ed. Nigel Fabb, Derek Attridge, Alan Durant, and Colin MacCabe. New York: Methuen, 1987. 48-66.

---. "Fieldwork in Common Places." Writing Culture: The Poetics and Politics of Ethnography. Ed. James Clifford and George E. Marcus. Berkeley, CA: U of California P, 1986. 27-50.

Rampton, Ben. Crossing, $2^{\text {nd }}$ ed. Manchester: St.Jerome, 2005.

Rassool, N. "Sustaining Linguistic Diversity Within the Global Cultural Economy: Issues of Language Rights and Linguistic Possibilities." Comparative Education 40.2 (2004): 199-214.

Schaub, Danielle, and Verduyn, Christl. Identity, Community, Nation: Essays on Canadian Writing. Jerusalem: The Hebrew University Magnes P, 2002.

Smitherman, Geneva. "CCCC's Role in the Struggle for Language Rights." College Composition and Communication 50.3 (1999): 349-76.

---. Talkin that Talk: Language, Culture, and Education in African America. 
NewYork: Routledge, 2000.

Smitherman, Geneva, and Victor Villanueva, eds. Language Diversity in the Classroom: From Intention to Practice. Carbondale: Southern Illinois UP, 2003.

Smoke, Trudy. "Mainstreaming Writing: What Does This Mean for ESL Students?" Mainstreaming Basic Writers: Politics and Pedagogies of Access. Ed. Gerry McNenny. Mahwah, NJ: Erlbaum, 2001. 193-214

Soliday, Mary. "Towards a Consciousness of Language: A Pedagogy for Multicultural Classrooms." The Journal of Basic Writing 16.2 (Fall 1997): 62-75.

---. "Translating Self and Difference through Literacy Narratives." College English 56 (1994): 511-26.

---. "The Politics of Difference: Toward a Pedagogy of Reciprocity." Writing in Multicultural Settings. Ed. Carol Severino, C., Juan Guerra, and Johnnella Butler. New York: MLA, 1997.

Spack, Ruth. “Teaching across Cultures.” College English 58.5 (1996): 592-598.

Statistics Canada. "2006 Census release topics." n.d. Web. 10 September 2009. http://www.census2006.com/census-recensement/2006/rt-td/index-eng.cfm

Street, Brian. Social Literacies. London: Longman, 1995.

---. Cross-cultural Approaches to Literacy. Cambridge: Cambridge UP, 1993.

Szwed, J. "Solibo Magnificent." Artforum International Magazine. March, 1998.

Taylor, L. K. "Of Mother Tongues and Other Tongues: The Stakes of Linguistically Inclusive Pedagogy in Minority Contexts." Canadian Modern Language Review 65.1 (2008): 89-123.

University of Windsor. About the University. n.d. Web. 23 July 2010. http://www.uwindsor.ca/about-the-university

Valdès, G. "Bilingual Minorities and Language Issues in Writing." Written Communication 9 (1992): 85-136.

Widdowson, H.G. "The Ownership of English." TESOL Quarterly 28 (1994): 377-89.

Williams, Colin H. "Citizenship and Minority Cultures: Virile Participants or Dependant Supplicants?" Language, Culture and Values in Canada at the Dawn of the $21^{\text {st }}$ Century. Ed. André Lapierre, Patricia Smart, and Pierre Savard. Ottawa: Carleton UP, 1996. 155-182. 
Young, Vershawn Ashanti. "Your Average Nigga." College Composition and Communication 55.4 (2004): 693-715. 


\section{APPENDIX}

\section{1}

\section{LANGUAGE USE SURVEY \#1}

Please generate a unique, anonymous code. Include, the first two letters of your middle name, the last two digits of your student number, and the first two letters of your mother's maiden name. For instance my code would be: EI43LO. My middle name is EILEEN, my student number is $98151 \underline{43}$, and my mother's maiden name is LOCKYER.

\section{YOUR CODE:}

As you complete the following survey, please be aware that there are no "right" or "wrong" answers to any of the following questions.

\section{MY BACKGROUND}

1. I am: female male

2. I am a: First Year Second Year Third Year Fourth Year

3. I was born in Canada. Yes ___ No

If yes, please indicate what province you were born in:

4. I was not born in Canada. I was born in:

$$
\text { what country }
$$

5. I was not born in the Canada, but I came here when I was: under 5 years old 6-12 years old 13-17 years old 18 years or older

6. English was the first language I learned to speak. Yes __ No 
a) If not English, I first learned to speak:

$$
\text { what language }
$$

b) If English is your second language, how old were you when you learned to speak it:

7. English was the first language I learned to write.

Yes

No

a) If not English, I first learned to write:

$$
\text { what language }
$$

b) If English is your second language, how old were you when you learned to write it:

8. English was the first language I learned to $\underline{\mathrm{read}}$.

Yes No

a) If not English, I first learned to read:

$$
\text { what language }
$$

b) If English is your second language, how old were you when you learned to read it:

9. I am a native speaker of English.

Yes

No

10. I am a native speaker of French.

Yes

No

11. I am bilingual, in French and English. Yes

No

12. I am a non-native speaker of English.

Yes

No

13. I speak English as a second language. Yes

No

14. I speak English as a foreign language.

Yes

No

15. I am an ESL student.

Yes

No

16. I am bilingual.

Yes

No

17. I am neither an ESL student, nor bilingual. I am:

(what best describes your language background)

\section{HOW I USE LANGUAGE}


18. Please list in the chart what languages you know. (Don't include languages you studied only as a school subject.) Tell how well you understand, speak, read, and write these languages by circling the appropriate number that corresponds to the following.

$$
1=\text { well } \quad 2=\text { some } \quad 3=\text { not much }
$$

\begin{tabular}{|c|c|c|c|c|c|c|c|c|c|}
\hline Language & UnderstaI & & Speak & & Read & & Wr & & \\
\hline 1. English & 12 & 3 & 12 & 3 & 1 & 3 & 1 & 2 & 3 \\
\hline 2. & 12 & 3 & 1 & 3 & 1 & 3 & 1 & 2 & 3 \\
\hline 3. & 12 & 3 & 12 & 3 & 1 & 3 & 1 & 2 & 3 \\
\hline 4. & 12 & 3 & 12 & 3 & 1 & 3 & 1 & 2 & 3 \\
\hline
\end{tabular}

19. Please list in the chart what languages your parents know. (Don't include languages they studied only as a school subject.) If possible, explain how well you think your parents understand, speak, read, and write using these languages by circling the appropriate number that corresponds to the following.

$$
1=\text { well } \quad 2=\text { some } \quad 3=\text { not much }
$$

\begin{tabular}{|c|c|c|c|c|c|c|c|c|c|c|}
\hline Language & Understan & & Speak & & Read & & & Wri & & \\
\hline 1. English & 12 & 3 & 1 & 3 & 1 & 2 & 3 & 1 & 2 & 3 \\
\hline 2. & 12 & 3 & 1 & 3 & 1 & 2 & 3 & 1 & 2 & 3 \\
\hline 3. & 12 & 3 & 1 & 3 & 1 & 2 & 3 & 1 & 2 & 3 \\
\hline 4. & 12 & 3 & 1 & 3 & 1 & 2 & 3 & 1 & 2 & 3 \\
\hline
\end{tabular}

20. Please list in the chart what languages your grandparents know. (Don't include languages they studied only as a school subject.) If possible, explain how well you think your grandparents understand, speak, read, and write using these languages by circling the appropriate number that corresponds to the following.

\begin{tabular}{|c|c|c|c|c|}
\hline Language & Understand & Speak & Read & Write \\
\hline 1. English & 123 & $\begin{array}{lll}1 & 2 & 3\end{array}$ & $\begin{array}{lll}1 & 2 & 3\end{array}$ & $\begin{array}{lll}1 & 2 & 3 \\
\end{array}$ \\
\hline 2. & 123 & 123 & 123 & 123 \\
\hline 3. & 123 & 123 & $1 \quad 2 \quad 3$ & 123 \\
\hline 4. & $\begin{array}{lll}1 \quad 2 & 3 \\
\end{array}$ & $\begin{array}{lll}1 \quad 2 & 3 \\
\end{array}$ & $\begin{array}{lll}1 \quad 2 & 3 \\
\end{array}$ & 123 \\
\hline
\end{tabular}

$$
1=\text { well } \quad 2=\text { some } \quad 3=\text { not much }
$$


21. Please indicate how much you use English in the following situation by circling the appropriate number that corresponds to the following:

$1=$ never $\quad 2=$ less than half the time $3=$ half the time $\quad 4=$ more than half the time $\quad 5=$ always

a) talking to my parents

b) parents talking to me

c) talking to my grandparents

d) grandparents talking to me

e) talking to my brothers/sisters

f) brothers/sisters talking to me

g) talking to other relatives

h) other relatives talking to me

i) talking with my friends

j) reading/writing at home

k) reading/writing at school

l) writing to my friends (i.e. email, text)

$\mathrm{m})$ reading for pleasure

n) dreaming

$\begin{array}{ccccc}\text { never } & & & & \text { always } \\ 1 & 2 & 3 & 4 & 5 \\ 1 & 2 & 3 & 4 & 5 \\ 1 & 2 & 3 & 4 & 5 \\ 1 & 2 & 3 & 4 & 5 \\ 1 & 2 & 3 & 4 & 5 \\ 1 & 2 & 3 & 4 & 5 \\ 1 & 2 & 3 & 4 & 5 \\ \text { never } & & & & \text { always } \\ 1 & 2 & 3 & 4 & 5 \\ 1 & 2 & 3 & 4 & 5 \\ 1 & 2 & 3 & 4 & 5 \\ 1 & 2 & 3 & 4 & 5 \\ 1 & 2 & 3 & 4 & 5 \\ 1 & 2 & 3 & 4 & 5 \\ 1 & 2 & 3 & 4 & 5\end{array}$

22. When I take into consideration all the situations where I use language (at home, at school, with friends, etc) I would say that, overall, my best language is:

what language

23. When I take into consideration all the situations where I use language (at home, at school, with friends, etc) I would say that, overall, my most comfortable:

speaking

what language

reading

what language

writing 
24. The researcher would like to meet with students to further discuss the answers they gave on this survey. Would you be willing to take part in an interview?

$$
\text { Yes ___ No }
$$

If you answered yes, please complete the attached contact form.

1.2

\section{LANGUAGE USE SURVEY \#2}

Please generate a unique, anonymous code (it should be the same as the one you created in the first survey). Include, the first two letters of your middle name, the last two digits of your student number, and the first two letters of your mother's maiden name. For instance my code would be: EI43LO. My middle name is EILEEN, my student number is $98151 \underline{43}$, and my mother's maiden name is LOCKYER.

YOUR CODE:

As you complete the following survey, please be aware that there are no "right" or "wrong" answers to any of the following questions.

\section{BACKGROUND INFORMATION}

1. I was born in Canada. Yes

No

2. If you answered yes, please indicate which of your family was also born in Canada.

Parents: $\quad$ Yes __ No

Grandparents: $\quad$ Yes ___ No

Great grandparents: Yes ___ No

Great great grandparents: Yes ___ No 
2. If you answered no, please indicate if you are an international student.

Yes

No

3.In the previous survey did you indicate that you speak, read, or write in a language other than English?

Yes__ No

\section{How I USE Language In My DaILY Life}

**If you speak, read, or write in only English please go to question 19.**

4. Do you ever use more than one language (mix languages) when you communicate?

$$
\text { Yes }
$$

No

5. If yes, please indicate if you mix languages in the following situations by circling the appropriate number that corresponds to the examples. (Mixing means using more than one language in a conversation.)

$1=$ never $\quad 2=$ less than half the time $\quad 3=$ half the time

$4=$ more than half the time

$$
5 \text { = always }
$$

a) talking to my parents

c) talking to my grandparents

e) talking to my brothers/sisters

g) talking to other relatives

never

i) talking with my friends

n) dreaming

$\begin{array}{ccccc}\text { never } & & & & \text { always } \\ 1 & 2 & 3 & 4 & 5 \\ 1 & 2 & 3 & 4 & 5 \\ 1 & 2 & 3 & 4 & 5 \\ 1 & 2 & 3 & 4 & 5 \\ 1 & 2 & 3 & 4 & 5 \\ 1 & 2 & 3 & 4 & 5\end{array}$

6. Do you ever use more than one language in a spoken sentence?

Yes

No

7. Do you ever use more than one language in a written sentence?

Yes

No

8. If yes, please indicate in what types of writing you mix languages by circling the appropriate number that corresponds to the examples.

$1=$ never $\quad 2=$ less than half the time $\quad 3=$ half the time $\quad 4=$ more than half the time $\quad 5=$ always 
a) writing a list

(i.e. a things to do list)

c) writing a quick note to my parents

(i.e. I'll be back in five minutes)

b) writing a note to my grandparents

(i.e. I'll be back in five minutes)

e) writing a letter to relatives

g) writing a letter to a friend

h) writing an email to relatives

i) writing an email to a friend

j) texting never

$\begin{array}{lllll}1 & 2 & 3 & 4 & 5\end{array}$

$\begin{array}{lllll}1 & 2 & 3 & 4 & 5\end{array}$

$\begin{array}{lllll}1 & 2 & 3 & 4 & 5\end{array}$

$\begin{array}{lllll}1 & 2 & 3 & 4 & 5\end{array}$

$\begin{array}{lllll}1 & 2 & 3 & 4 & 5\end{array}$

$\begin{array}{lllll}1 & 2 & 3 & 4 & 5\end{array}$

$\begin{array}{lllll}1 & 2 & 3 & 4 & 5\end{array}$

$\begin{array}{lllll}1 & 2 & 3 & 4 & 5\end{array}$

\section{How I USE LANGUAGE AT UNIVERSITY}

9. Please indicate if you mix languages in any of the following situations by circling the appropriate number that corresponds to the examples.

$1=$ never $\quad 2=$ less than half the time $\quad 3=$ half the time

$4=$ more than half the time

never
$5=$ always

always
a) taking notes in class
b) drafting a paper for school
c) brainstorming a paper for school
$\begin{array}{lllll}1 & 2 & 3 & 4 & 5 \\ 1 & 2 & 3 & 4 & 5\end{array}$
d) writing a paper for school
12

12
e) writing an email to my professor

12

3
$4-5$

$\begin{array}{lll}3 & 4 & 5\end{array}$

$\begin{array}{lll}3 & 4 & 5\end{array}$

10. Consider the following situations. Tell how you use language in these situations by putting an " $\mathrm{X}$ " in the appropriate box.

\begin{tabular}{|l|l|l|l|}
\hline Situation & I only use English & I mix languages & $\begin{array}{l}\text { I only use a language } \\
\text { other than English }\end{array}$ \\
\hline $\begin{array}{l}\text { Thinking about a difficult } \\
\text { concept. }\end{array}$ & & & \\
\hline $\begin{array}{l}\text { Thinking about an essay } \\
\text { topic. }\end{array}$ & & & \\
\hline $\begin{array}{l}\text { Trying to remember the } \\
\text { right/appropriate word. }\end{array}$ & & & \\
\hline Before you speak in class. & & & \\
\hline
\end{tabular}




\begin{tabular}{|l|l|l|l|}
\hline $\begin{array}{l}\text { Before you speak to your } \\
\text { teacher during office hours or } \\
\text { after class. }\end{array}$ & & & \\
\hline $\begin{array}{l}\text { When participating in } \\
\text { group work. }\end{array}$ & & & \\
\hline
\end{tabular}

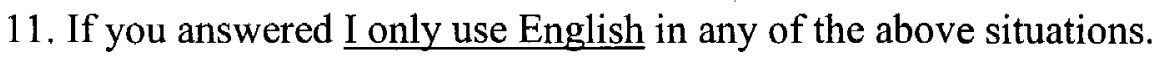

a) Do you ever wish that you could mix languages in these situations?

Yes No

b) Do you ever wish that you could use a language other than English in these situations?

Yes __ No

c) In a few words, please explain why.

12. Do you think that you are expected to use only English in your university classes?

Yes _ No

13. Do you ever think that you would do better in school if you could mix languages with English?

Yes _ No

14. Do you ever think that you would do better in school if you could use a language other than English?

Yes ___ No

15. Have you ever tried to mix languages in school?

Yes _ No

16. If yes, please explain how you did this.

17. Are there words that you would like to use that do not translate to English?

Yes No 
18. Do you think that mixing languages with English would allow you to better explain your ideas?

Yes ___ No

19. Do you think that students should be allowed to mix languages in academic writing?

Yes No

1.3

\section{LANGUAGE USE SURVEY \#3}

Please generate a unique, anonymous code (it should be the same as the one you created in the first survey). Include, the first two letters of your middle name, the last two digits of your student number, and the first two letters of your mother's maiden name. For instance my code would be: EI43LO. My middle name is EILEEN, my student number is 9815143 , and my mother's maiden name is LOCKYER.

YOUR CODE:

As you complete the following survey, please be aware that there are no "right" or "wrong" answers to any of the following questions.

\section{Why I Chose This Class}

1.My major is:

2.Please explain why you chose to register for this class.

(e.g. Were you advised to take it? If so, by whom?) 
3. What do you think this course should do for you as a student?

4. Is the class fulfilling your expectations (i.e. your answer to \#3)?

Yes

No

5. If no, why not?

6. What grade do you think you are going to get in this class?

\section{How I use Language IN THIS Class}

7. In this class you have been asked to plan out your essays before you write. Specifically, you may have been asked to think about audience or organization. Planning is primarily a mental process. When you plan your essays do you:

a) use only English

b) mix more than one language (if you chose $\underline{b}$, name languages:

8a. In this class you have been assigned a variety of "invention" exercises, such as "freewriting." If you were expected to show your work to your teacher, would your writing:

a) use only English

b) mix more than one language

(if you chose $\underline{b}$, name languages: 
8b. In this class you have been assigned a variety of "invention" exercises, such as "freewriting." If you were not expected to show your work to your teacher, would your writing:

a) use only English

b) mix more than one language

(if you chose $\underline{b}$, name languages:

9. Do you think it is easier to complete "invention" exercises when you:

a) use only English

b) mix more than one language

10a. A main goal of this course is to practice writing through "drafting." Where you usually have a rough draft, a second draft, a final draft, etc. Do your rough/first drafts:

a) use only English

b) mix more than one language

10b. If you use only English, is this because (check all that apply):
a) English is the only language you know
b) writing using only English is easier
c) you think the teacher's first language is English
d) you have never used another language when drafting
e) you are expected to use English
f) you never considered using a language other than English

11a. Does your second draft:
a) use only English
b) mix more than one language

11b. If you use only English, is this because (check all that apply):
a) English is the only language you know
b) writing using only English is easier
c) you think the teacher's first language is English
d) you have never used another language when drafting
e) you are expected to use English
f) you never considered using a language other than English

12a. Does your final draft:
a) use only English
b) mix more than one language

12b. If you use only English, is this because (check all that apply): 

a) English is the only language you know
b) writing using only English is easier
c) you think the teacher's first language is English
d) you have never used another language when drafting
e) you are expected to use English
f) you never considered using a language other than English

13. If you were encouraged to use more than one language when drafting your essays, would you be able to explain your ideas better?
Yes
No
N/A (I only speak English)

14. If you answered yes, please explain why.

15. In this class you often peer review the work of your classmates. This is most often an oral exercise where you talk about each others work. When you are in groups peer reviewing, do you:
a) use only English
b) sometimes use a language other than English
b) sometimes use a word from another language
c) wish you could sometimes use a word from another language

16. In this class you are often asked to revise your writing. Think about an essay you have written using English. Sometimes there are words that just don't work. Do you ever wish you could use a word from another language when an English word doesn't work?
a) never
b) sometimes
c) N/A (I only speak English)

\section{How I use Language in my Final Portfolio}

17. What is the topic of your final portfolio:

18. Do you think your topic, or aspects of your topic, relate to your cultural identity:

$$
\text { Yes _ No }
$$

19. If yes, does your cultural identity relate best to: 

a) English
b) another language (please name language(s)

If you answered another language, please answer questions $20-24$.

20. As you have written your portfolio essays, are there any times when you have not been able to fully develop your ideas in English?

$$
\text { Yes _ No }
$$

21. If you could draft in another language, or mix languages, would you be able to better develop your ideas?

$$
\text { Yes ___ No }
$$

22. Is there ever a word from your home (or first) language that you think would work better than an English word or idea?

$$
\text { Yes _.... No }
$$

23. If yes, do you think you should be allowed to use this word in your essay?

$$
\text { Yes__ No }
$$

24. If you answered yes, please explain why: 


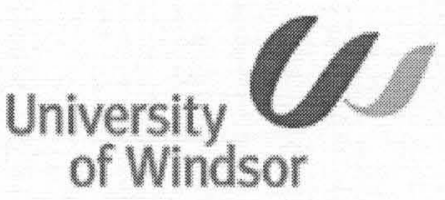

\title{
LETTER OF INFORMATION FOR CONSENT TO PARTICIPATE IN RESEARCH
}

\author{
Title of Study: An Observation into How Canadian Students Utilize Language in the First- \\ Year Writing Classroom
}

You are asked to participate in a research study conducted by Julia Kiernan (PhD Candidate at the University of Louisville) and Dr. Bruce Horner from University of Louisville, as well as Dr. Dale Jacobs from the University of Windsor. The information gathered will be used toward the completion of the PhD dissertation of Julia Kiernan.

If you have any questions or concerns about the research, please feel to contact Bruce Horner (Faculty Supervisor) at 502- 852-2185 or Dale Jacobs (Faculty contact) at 519-253-3000 x 2309.

\section{PURPOSE OF THE STUDY}

The purpose of this study is to observe how students use language in the first-year writing classroom. I plan to study what I see as a strong tendency in Canadian post-secondary educational programs to reduce language differences/dialects brought to the classroom by multilingual students. How students consider language is an important site of inquiry because students who attend university are more often than not expected to produce writing in only one language variety - the Standard Written English of the academyhowever, they often come to the university with a diverse language background. I believe an exploration into how the many languages and cultures of Canada collide and manifest in students' writing and students' perceptions of their writing abilities will offer Canadian institutions of higher learning new ways to serve its ever diversifying student populations.

\section{PROCEDURES}

If you volunteer to participate in this study, you will be asked to:

- Complete three questionnaires, which will be distributed at the beginning, middle, and end of the semester.

- $\quad$ The questionnaires will take no longer then ten minutes to complete.

- The questionnaires will be distributed at the end of a class period, in the absence of the course instructor. Only the researcher and the students will be present.

- You will not be pressured to complete questionnaires, participation is optional.

- You will not attach your name to a completed questionnaire. Instead you will be asked to create a unique and anonymous code.

- A separate contact sheet will also be handed out with each questionnaire.

- The last question on the questionnaire will ask whether or not you wish to participate in a follow up interview, where the researcher will gather qualitative data, or elaboration, upon your questionnaire responses.

- If you agree to participate further in the study, you will complete the contact sheet as well. The contact sheet will ask for the same self-generated code as the questionnaire. 
- This project will take place over one semester. All questionnaires will take place in your classroom.

\section{POTENTIAL RISKS AND DISCOMFORTS}

There are no foreseeable risks in participating in this research. Questions asked are concerned with how you use language, and are not personal in nature.

\section{POTENTIAL BENEFITS TO SUBJECTS AND/OR TO SOCIETY}

The possible benefits of this study include a better understanding of how you use language in the university classroom, which could offer you insight into how your language choices may impede or facilitate your larger academic career. However, the information collected may not benefit you directly. The information learned in this study may be helpful to others.

\section{PAYMENT FOR PARTICIPATION}

There is no compensation for participation in this study.

\section{CONFIDENTIALITYI ANONYMITY}

Consent to participate in this study is implied in the completion of your questionnaire.

Your answers to the distributed questionnaires will remain anonymous unless you have agreed to participate in a follow-up interview.

In order to ensure that the data collected is kept private all questionnaires will be kept in a locked file cabinet at the home office of the researcher.

Completed questionnaires will be destroyed at the end of the Fall 2009 semester.

\section{PARTICIPATION AND WITHDRAWAL}

You can choose whether to be in this study or not. If you volunteer to be in this study, you may withdraw up to one month upon course completion (January 4, 2010), after this date all questionnaire data will be incorporated into the researcher's dissertation. You may also refuse to answer any questions and still remain in the study. The investigator may withdraw you from this research if circumstances arise which warrant doing so.

\section{FEEDBACK OF THE RESULTS OF THIS STUDY TO THE SUBJECTS}

Results for this study will be available by 1 , September 2010 . The information will be posted to the REB website in the form of a summary report.

Web address: http://www.uwindsor.ca/reb

Date when results are available: 1 , September 2010

\section{SUBSEQUENT USE OF DATA}

This data may be used in subsequent studies.

\section{RIGHTS OF RESEARCH SUBJECTS}


You may withdraw your consent at any time and discontinue participation without penalty. If you have questions regarding your rights as a research subject, contact: Research Ethics Coordinator, University of Windsor, Windsor, Ontario, N9B 3P4; Telephone: 519-253-3000, ext. 3948; e-mail: ethics@uwindsor.ca

\section{SIGNATURE OF RESEARCH SUBJECT/LEGAL REPRESENTATIVE}

I understand the information provided for the study An Observation into How Canadian Students Utilize Language in the First-Year Writing Classroom as described herein. My questions have been answered to my satisfaction, and I agree to participate in this study. I have been given a copy of this form.

\section{SIGNATURE OF INVESTIGATOR}

These are the terms under which I will conduct research. 


\section{univesis of Windsor}

\section{CONSENT TO PARTICIPATE IN RESEARCH}

\section{Title of Study: An Observation into How Canadian Immigrant Students Utilize Language in the First-Year Writing Classroom}

You are asked to participate in a research study conducted by Julia Kiernan (PhD Candidate at the University of Louisville) and Dr. Bruce Horner from University of Louisville, as well as Dr. Dale Jacobs from the University of Windsor at the University of Windsor. This information gathered will be used in the PhD dissertation of Julia Kiernan.

If you have any questions or concerns about the research, please feel to contact Bruce Horner (Faculty Supervisor) at 502- 852-2185 or Dale Jacobs (Faculty contact) at 519-253-3000 x 2309.

\section{PURPOSE OF THE STUDY}

The purpose of this study is to observe how students use language in the first-year writing classroom. I plan to study what I see as a strong tendency in Canadian post-secondary educational programs to reduce language differences/dialects brought to the classroom by multilingual and immigrant students. How students consider language is an important site of inquiry because students who attend university are more often than not expected to produce writing in only one language variety - the Standard Written English of the academy - however, they often come to the university with a diverse language background. I believe an exploration into how the many languages and cultures of Canada collide and manifest in students' writing and students' perceptions of their writing ability will offer Canadian institutions of higher learning new ways to serve its ever diversifying student populations.

\section{PROCEDURES}

If you volunteer to participate in this study, you will be asked to:

- Participate in three open-ended interviews.

- Interview questions will be based upon anonymous questionnaires.

- $\quad$ Participants will be linked to their questionnaire responses via a unique, anonymous, selfgenerated code.

- Interviews will be approximately thirty minutes in length.

- With participant permission, interviews will be video-taped.

This project will take place over one semester. All questionnaires will take place in your classroom, interview locations are yet to be determined.

Finally, you are not required to answer every (or any) question(s) on the questionnaire or during the interview; any question(s) that you find uncomfortable may be omitted.

\section{POTENTIAL RISKS AND DISCOMFORTS}

There are no foreseeable risks other than possible discomfort in answering personal questions. 
However, because interviews will be video-taped and viewed by a small audience this data cannot be kept confidential; however, participants names will be changed upon viewing. Also, during the interview, the participants will be given the option of not answering questions. Participants will have the option of turning off the camera at any point during the interview. Participants will also be given the opportunity to view their recorded interviews before they are included in my dissertation.

\section{POTENTIAL BENEFITS TO SUBJECTS AND/OR TO SOCIETY}

The possible benefits of this study include a better understanding of how you use language in the university classroom, which could offer you insight into how your language choices may impede or facilitate your larger academic career. However, the information collected may not benefit you directly. The information learned in this study may be helpful to others.

\section{PAYMENT FOR PARTICIPATION}

There is no compensation for this study.

\section{CONFIDENTIALITY}

Because your interviews will be video-taped, you will be able to visually identified and therefore information that is obtained from you for this this study will not remain confidential. However, your name will not be used in this study, the researcher will use a pseudonym when identifying and referring to your responses.

In the hard copy of the researcher's dissertation only a transcription (no video) of your responses will be included. Thus, in this instance your confidentiality will be ensured.

In order to ensure that the data collected is kept private all questionnaires will be kept in a locked file cabinet at the home office of the researcher.

Videotaped interviews will be made available to you for review before inclusion in the researcher's dissertation. You will have the opportunity to review these videotapes to verify the data within. With your permission, these interviews may be used for future educational purposes and research endeavors.

Videotapes will be destroyed at the end of the September 1, 2010.

\section{PARTICIPATION AND WITHDRAWAL}

You can choose whether to be in this study or not. If you volunteer to be in this study, you may withdraw at up to one month upon course completion (January 4, 2010), after this date will be incorporated into the researchers dissertation. You may also refuse to answer any questions you don't want to answer and still remain in the study. The investigator may withdraw you from this research if circumstances arise which warrant doing so.

\section{FEEDBACK OF THE RESULTS OF THIS STUDY TO THE SUBJECTS}

Results for this study will be available by 1 , September 2010 . The information will be posted to the REB website in the form of a summary report.

Web address: http://www.uwindsor.ca/reb

Date when results are available: 1 , September 2010

\section{SUBSEQUENT USE OF DATA}

This data may be used in subsequent studies.

\section{RIGHTS OF RESEARCH SUBJECTS}


You may withdraw your consent at any time and discontinue participation without penalty. If you have questions regarding your rights as a research subject, contact: Research Ethics Coordinator, University of Windsor, Windsor, Ontario, N9B 3P4; Telephone: 519-253-3000, ext. 3948; e-mail: ethics@uwindsor.ca

\section{SIGNATURE OF RESEARCH SUBJECT/LEGAL REPRESENTATIVE}

I understand the information provided for the study An Observation into How Canadian Immigrant Students Utilize Language in the First-Year Writing Classroom as described herein. My questions have been answered to my satisfaction, and I agree to participate in this study. I have been given a copy of this form.

Name of Subject

Signature of Subject

Date

\section{SIGNATURE OF INVESTIGATOR}

These are the terms under which I will conduct research.

Date 


\section{English 26-100 \\ Composition \\ Sections 04-10, 30 \\ Fall 2009}

\section{Introduction}

This course is designed to help each of you gain greater fluency, confidence, and control as writers through an exploration of your own lives, communities, and cultural experiences. You will use writing as a way to learn and to critically examine the world around you, but also as a way to communicate what you have learned to others. You will use language to discover connections between yourselves and the broader world, and between your ideas and those of others. To this end, each of you will be asked to write in multiple genres, including exposition, editorial, proposal, public service message, and research article. Through your work in these genres, you will learn how to engage in all aspects of the writing and revision process, how to read and think critically, and how to engage in a variety of kinds of research. The course will provide each of you with many opportunities to interact with each other and to explore issues and ideas that are important to you through the act of writing; these opportunities are designed to help you acquire the necessary habits of mind to communicate in meaningful ways within today's society.

\section{Texts/Equipment}

Blau, Susan and Kathryn Burak. Writing in the Works. $2^{\text {nd }}$ ed. New York: Houghton Mifflin, 2007.

Set aside $\$ 20.00$ for photocopying your own work.

\section{Recommended Reference Text}

Lunsford, Andrea A. The Everyday Writer. $4^{\text {th }}$ ed. Boston: Bedford/St. Martin's, 2009.

\section{Requirements}

Writing and Research Notebook - Each of you will keep a notebook in which you can explore topics for writing and develop and pursue research questions. You will be expected to use this notebook every week; periodically you will be given prompts to help you think and write in this notebook. The writing in this notebook will give you the space to try out ideas, ask questions, and think critically about your research and writing. This writing is informal, but will be taken in periodically and will form part of your class participation grade.

Weekly Writing/Research - You will be expected to write or research at least four (4) hours per week. You will get substantial feedback on your writing and research from the other members of the class and from your instructor throughout the semester. Remember that as you write, you are working towards the creation of a final portfolio of material.

Final Portfolio - Your final portfolio will consist of polished versions of four types of writing; exposition, editorial, proposal, and public service message. The final portfolio must be organized coherently and must also include a learning letter in which you discuss your progress as a writer 
over the course of the semester, provide detailed descriptions of the revision choices you made, and analyze how each piece of writing addresses issues of context, purpose, and audience. More information on the final portfolio will be provided in the next few weeks. The final portfolio is due December 14, 2009.

Research Packet - At about mid-term, you will be asked to develop a research packet around a trend you have identified. In this packet, you will write about how you chose this topic, consider the potential of the topic as a subject to research, develop research strategies, and demonstrate that you have engaged in finding and evaluating information for your topic. In other words, you will think about whether your topic is appropriate, think about the appropriate research strategies to use, and demonstrate that you have both found material and thought about its relevance to your topic. The due date for this assignment will be handed out during the first full week of classes and more information on this project will follow shortly after.

Research Article - After mid-term, you will be asked to hand in a research article in which you explain a trend. In this article, you will be expected to prove the trend exists, analyze its causes and/or effects, and contextualize it for your audience. Along with the research article, you must include a research narrative that details the connections between your research process and the research article you produced. The due date for this assignment will be handed out during the first full week of classes and more information on this project will follow shortly after.

Class Attendance and Preparedness - You are expected to attend all classes and to be prepared to participate in all class activities, including peer workshops, writing activities, and class discussions. As well, you will be expected to attend and be prepared for all writing conferences. Each member of the class is vital to everyone's learning experience and regular attendance is crucial. Therefore, more than three (3) absences for MWF classes, two (2) absences for TR or MW classes, or one (1) absence for a night class may seriously affect your grade for class participation.

Late assignments will be penalized by $1 / 3$ letter grade per day.

\section{Grade Distribution}

$\begin{array}{ll}\text { Research Packet } & 20 \% \\ \text { Research Article } & 20 \% \\ \text { Class Participation } & 20 \% \\ \text { Final Portfolio } & 40 \%\end{array}$

The Student Evaluation of Teaching will be administered within the final two weeks of the term. 


\section{1}

Table X: Course Expectations

\begin{tabular}{ll}
\hline Expectation & Students \\
\hline Develop critical thinking & 2 \\
Grammar & 1 \\
Improve English & 3 \\
Improve writing & 43 \\
Prepare for later education & 8 \\
Prepare for professional programs & 3 \\
Prepare for research & 2 \\
Teach academic writing & 7 \\
Unsure & 2 \\
\hline
\end{tabular}

\section{2}

$\underline{\text { Table Y: Reasons for Registration }}$

\begin{tabular}{ll}
\hline Reason & Students \\
\hline Advised (academic) & 11 \\
Advised (family/friend) & 10 \\
Elective & 6 \\
Enjoy writing & 2 \\
Improve English & 2 \\
No reason & 6 \\
Required & 18 \\
Thought it would be easy & 3 \\
To improve writing & 10 \\
\hline
\end{tabular}




\section{CURRICULUM VITAE}

Julia E. Kiernan

\section{EDUCATION}

Doctor of Philosophy, Composition \& Rhetoric, 2010

University of Louisville, Louisville, KY

Dissertation: "Cultivating our Mosaic: Understanding the Language Choices of Canadian Immigrant Students," Director: Dr. Bruce Horner

Master of Arts, English Literature, 2005

University of Windsor, Windsor, $\mathrm{ON}$

Bachelor of Science, Biology, 2003

Memorial University of Newfoundland, St. John's, NL

Bachelor of Arts, English, 2002

Memorial University of Newfoundland, St. John's, NL

\section{PEER-REVIEWEd Publications}

2010. "The Canadian Context: Monolingual Education in an "Officially" Multilingual Country." The Reading Matrix. Special Edition: Second Language Acquisition and Multilingual Communities. Forthcoming. 
2010. Julia Kiernan, Scott Rogers, and Ryan Trauman. "Designing for Discussion: Using Multimodal Student Texts in the First-Year Writing Classroom." Teaching with Student Texts. Eds. Joseph Harris, John Miles, and Chuck Paine. NCTE. Forthcoming.

2008. "The Liberatory Positioning of British Female Rhetoric: Bathsua Makin's An Essay to Revive the Antient Education of Gentlewomen, Mary Wollstonecraft's The Education of Daughters, \& Lucy Wilson's The Education of Women." Dominant Culture and the Education of Women. Ed. Julia C. Paulk. Cambridge Scholars Publishing.

2008. Andrea Ascuena and Julia Kiernan. "The Problem of Email: Working to Decentralize Consultant Authority in Online Writing Centers." Praxis: A Writing Center Journal. 5.2 (Spring 2008).

\section{PAPERS PRESENTED}

2011. "L2 Literacy Landscapes." Conference on College Composition \& Communication, Atlanta, Georgia, US.

2010. "Writing in Canada: Monolingual Work in a Multilingual Country." Thomas R. Watson Conference, University of Louisville, US.

2010. "Multilingual Student Writing Beyond Borders (but Between Coasts)." Conference on College Composition \& Communication, Louisville, Kentucky, US.

2009. "Cultivation of a Mosaic: A Canadian Approach to Multilingualism." Symposium on Second Language Writing. Arizona State University, US.

2009. "Enabling Collaboration: An Open Discussion into the Headaches, Hedges, and Headbutts of Group Publication." Feminism(s) \& Rhetoric(s), Michigan State University, US.

2009. "Multiculturalism \& The Literacy Narrative." Conference on College Composition \& Communication, San Francisco, California, US.

2008. "Online Writing Centers 2.0: (Re)envisioning our Work." Thomas R. Watson Conference, University of Louisville, US.

2008. "Designing an Aesthetic: Multimodal Texts and First Year Composition." Mediating the Aesthetic, Memorial University, Canada. (Accepted.) 
2008. "Multilingual Immigrant Narrative." Narrative Matters 2008, University of Toronto, Canada.

2008. "The Containment of Multilingual Immigrant Realities."

Conference on College Composition \& Communication, New Orleans, US.

2007. "The Early Modern Quaker Woman Writer \& Print Culture: The Non-Conformity of Margaret Fell." Feminism(s) \& Rhetoric(s), University of Arkansas, US.

2006. "The Unconscious Construction of The Female in George MacDonald's The Princess and the Goblin." The Art of the Fairy Tale from Grimm to Disney, Kent State University, US.

2006. "Culture, Subculture, \& Gaze: Who Is the Female Nude?" The Fourth Annual Meeting of the Cultural Studies Association, George Mason University, US.

2005. "Reproductive Science: The Chronological Impacts of Gendered Cyclicity." Survivals: The Past in the Present, Cardiff University, Wales.

2005. "The Implications of Vladimir Nabokov's Pale Fire in the Poststructuralist Debate between Author and Reader Identity." Encounters with the History of Books, University of Windsor, Canada.

\section{WORKSHOP PRESENTATIONS}

2011. Allophone Canadians: Negotiating Multiculturalist Policy within Pedagogical Development. Conference on College Composition \& Communication, Atlanta, Georgia, US.

\section{RESEARCH INTERESTS}

* Early Modern Rhetoric

* Early Modern Women Writers

* Digital Media

* Multimodality

* Technical Writing

- Generation 1.5

*nline Writing Centres

- Composition 


\section{HONOURS \& AWARDS}

Canada Study Grant for Females Pursuing Doctoral Studies

Years: 2007, 2008, 2009

Graduate Teaching Assistantship, University of Louisville

August 2006 to present

Graduate Teaching Assistantship, University of Windsor

September 2003 - December 2004

\section{GRADUATE TEACHING EXPERIENCE}

Department of Engineering, University of Windsor, 2008

English for Professional Purposes (Fall 2008)

\section{UNDER-GRADUATE TEACHING EXPERIENCE}

Department of English, University of Louisville, 2006 - 2008

English 303: Scientific and Technical Writing (Summer 2008)

English 101: Introduction to College Writing (Fall 2006, 2007, Winter 2008)

English 102: Intermediate College Writing (Winter 2007, 2008)

Department of English, University of Windsor, 2004 - 2005

Composition 100: Composition (Fall 2004)

\section{PROFESSIONAL EXPERIENCE}

Research Assistant (to Dr. Bruce Horner), Department of English,

University of Louisville. Louisville, KY. August 2006 - May 2007

Writing Tutor, Writing Centre, Memorial University of Newfoundland. St. John's, NL. May 2004 - August 2004, September 2002 - December 2002

\section{ADMINISTRATIVE EXPERIENCE}

Assistant Director of the Writing Centre, University of Louisville.

Louisville, KY. August 2006 - May 2007

Assistant to the Graduate Affairs Committee, Dept. Anthropology and Sociology, University of Windsor. Windsor, ON. April 2005 - July 2006 


\title{
SERVICE TO THE UNIVERSITY
}

Student Chair, PhD Mentoring Program, University of Louisville.

Louisville, KY. April 2007 - present

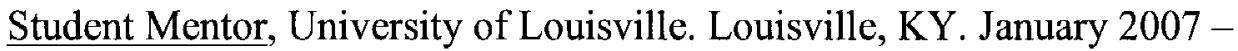
present

Executive Member, English Graduate Organization, University of Louisville. Louisville, KY. April 2007 - May 2008

\section{$\underline{\text { SELECTED GRAduATE COURSES }}$}

\author{
Pedagogy \\ Composition Pedagogy: Theory and Practice, Dale Jacobs, University of Windsor \\ Teaching College Composition, Bronywn Williams, University of Louisville \\ Composition Theory and Practice, Karen Kopleson
}

\section{Technology}

The Rhetoric of Professional and Technical Discourse: Geoffrey Cross, University of Louisville

Digital Media and Composition, Debra Journet, University of Louisville

\section{Rhetoric}

Seminar in Rhetorical Studies: Basic Writing, Bruce Horner, University of Louisville History of Rhetoric II, Carol Mattingly, University of Louisville

\section{Language}

Research in the Composing Process, Debra Journet, University of Louisville English Language and Linguistics, Linda Bebout, University of Windsor $20^{\text {th }}$ Century Theories of Language, Karen Hadley

\section{MEMBERSHIP IN PROFESSIONAL ORGANIZATIONS}

CASLL The Canadian Association for the Study of Language and Learning

NCTE National Council of Teachers of English

CCCC Conference on College Composition and Communication

\section{ADDITIONAL EMPLOYMENT}

Technical Writing Internship, Kentucky Youth Advocates, Louisville, KY. January 2008 - April 2008

Science Technician II, Faculty of Medicine, Memorial University of Newfoundland. St. John's, NL. October 2001 - January 2002 
Laboratory Assistant, Faculty of Medicine, Memorial University of

Newfoundland. St. John's, NL. May 1999 - August 2001

\section{REFERENCES}

Available upon request. 